\title{
An overview of snow photochemistry: evidence, mechanisms and impacts
}

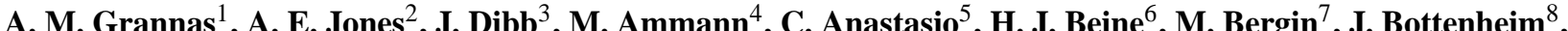

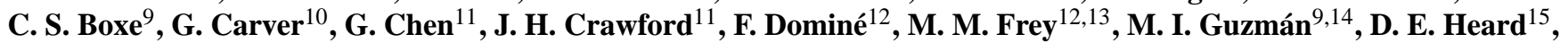
D. Helmig ${ }^{16}$, M. R. Hoffmann ${ }^{9}$, R. E. Honrath ${ }^{17}$, L. G. Huey ${ }^{18}$, M. Hutterli ${ }^{2}$, H. W. Jacobi ${ }^{19}$, P. Klán ${ }^{20}$, B. Lefer $^{29}$, J. McConnell ${ }^{21}$, J. Plane ${ }^{15}$, R. Sander ${ }^{22}$, J. Savarino ${ }^{12}$, P. B. Shepson ${ }^{23}$, W. R. Simpson ${ }^{24}$, J. R. Sodeau ${ }^{25}$, R. von Glasow $^{26,27}$, R. Weller ${ }^{19}$, E. W. Wolff ${ }^{2}$, and T. Zhu ${ }^{28}$

${ }^{1}$ Department of Chemistry, Villanova University, Villanova, PA 19085, USA

${ }^{2}$ British Antarctic Survey, Natural Environment Research Council, Cambridge, CB3 0ET, UK

${ }^{3}$ Institute for the Study of Earth, Oceans and Space, University of New Hampshire, Durham, NH 03824, USA

${ }^{4}$ Laboratory for Radio- and Environmental Chemistry, Paul Scherrer Institute, 5232 Villigen, Switzerland

${ }^{5}$ Department of Land, Air \& Water Resources, University of California at Davis, Davis, CA 95616, USA

${ }^{6}$ Consiglio Nazionale delle Ricerche - Istituto Inquinamento Atmosferico (C.N.R. - I.I.A); Via Salaria Km 29,3; 00016

Monterotondo Scalo, Roma, Italy

${ }^{7}$ School of Civil and Environmental Engineering and School of Earth and Atmospheric Sciences, Georgia Institute of

Technology, Atlanta, GA 30332, USA

${ }^{8}$ Air Quality Research Branch, Environment Canada, Downsview, Ontario, Canada

${ }^{9}$ W. M. Keck Laboratories, California Institute of Technology, Pasadena, CA 91125, USA

${ }^{10}$ Center for Atmospheric Sciences, Department of Chemistry, Cambridge University, Lensfield Road, Cambridge, UK

${ }^{11}$ NASA Langley Research Center, Hampton, VA 23681, USA

${ }^{12}$ Laboratoire de Glaciologie et Géophysique de l'Environnement,CNRS/Université Joseph Fourier-Grenoble, St Martin d'Hères Cedex, France

${ }^{13}$ School of Engineering, University of California-Merced, Merced, CA 95343, USA

${ }^{14}$ Currently at School of Engineering and Applied Sciences, Harvard University, Cambridge, Massachusetts, USA

${ }^{15}$ School of Chemistry, University of Leeds, Leeds, LS2 9JT, UK

${ }^{16}$ Institute of Arctic and Alpine Research, University of Colorado, Boulder, CO 80309, USA

${ }^{17}$ Department of Civil and Environmental Engineering, Michigan Technological University, Houghton, MI 49931, USA

${ }^{18}$ School of Earth and Atmospheric Sciences, Georgia Institute of Technology, Atlanta, GA 30033, USA

${ }^{19}$ Alfred Wegener Institute for Polar and Marine Research, Bremerhaven, Germany

${ }^{20}$ Masaryk University, Department of Chemistry, Brno, Czech Republic

${ }^{21}$ Department of Earth and Space Science and Engineering, York University, Toronto, Ontario, Canada

${ }^{22}$ Air Chemistry Department, Max-Planck Institute of Chemistry, P.O. Box 3060, 55020 Mainz, Germany

${ }^{23}$ Dept. of Chemistry and Department of Earth and Atmospheric Sciences, Purdue Univ., West Lafayette, IN 47907, USA

${ }^{24}$ Department of Chemistry and Geophysical Institute, University of Alaska Fairbanks, Fairbanks, AK 99775-6160, USA

${ }^{25}$ Department of Chemistry, University College Cork, Cork, Ireland

${ }^{26}$ Institute of Environmental Physics, University of Heidelberg, Heidelberg, Germany

${ }^{27}$ School of Environmental Sciences, University of East Anglia, Norwich, UK

${ }^{28}$ College of Environmental Sciences, Peking University, Beijing 100871, China

${ }^{29}$ Department of Geosciences, University of Houston, TX 77204, USA

Received: 21 February 2007 - Published in Atmos. Chem. Phys. Discuss.: 29 March 2007

Revised: 17 July 2007 - Accepted: 13 August 2007 - Published: 22 August 2007

Published by Copernicus Publications on behalf of the European Geosciences Union. 
Abstract. It has been shown that sunlit snow and ice plays an important role in processing atmospheric species. Photochemical production of a variety of chemicals has recently been reported to occur in snow/ice and the release of these photochemically generated species may significantly impact the chemistry of the overlying atmosphere. Nitrogen oxide and oxidant precursor fluxes have been measured in a number of snow covered environments, where in some cases the emissions significantly impact the overlying boundary layer. For example, photochemical ozone production (such as that occurring in polluted mid-latitudes) of 3-4 ppbv/day has been observed at South Pole, due to high $\mathrm{OH}$ and NO levels present in a relatively shallow boundary layer. Field and laboratory experiments have determined that the origin of the observed $\mathrm{NO}_{\mathrm{x}}$ flux is the photochemistry of nitrate within the snowpack, however some details of the mechanism have not yet been elucidated. A variety of low molecular weight organic compounds have been shown to be emitted from sunlit snowpacks, the source of which has been proposed to be either direct or indirect photo-oxidation of natural organic materials present in the snow. Although myriad studies have observed active processing of species within irradiated snowpacks, the fundamental chemistry occurring remains poorly understood. Here we consider the nature of snow at a fundamental, physical level; photochemical processes within snow and the caveats needed for comparison to atmospheric photochemistry; our current understanding of nitrogen, oxidant, halogen and organic photochemistry within snow; the current limitations faced by the field and implications for the future.

\section{Introduction}

It is now widely recognized that the Earth System is tightly interconnected. Changes in one component can strongly affect the state of another; feedbacks between them can have subtle influences that might either amplify or mitigate trends. A connection now receiving growing attention is that between the atmosphere and the cryosphere. The cryosphere forms a large proportion of the Earth's surface: a seasonal maximum of $40 \%$ of land is covered by snow or ice, while several percent of the world's oceans are covered by sea ice. Traditionally, the cryosphere has been viewed as a "cap", inhibiting emissions from land and ocean surfaces below and acting itself as a permanent sink of atmospheric species. The snow itself has not been considered beyond its effect on radiative transfer through albedo.

Recent evidence, however, has shown that the polar cryosphere can have a major influence on the overlying atmosphere. Rather than being inert, or simply a sink for impurities, snow is highly photochemically active, with snowpack impurities photolyzed to release reactive trace gases into the

Correspondence to: A. M. Grannas

(amanda.grannas@villanova.edu) boundary layer. Since the initial discoveries of $\mathrm{CH}_{2} \mathrm{O}$ and $\mathrm{NO}_{\mathrm{x}}$ production within polar snow (Fuhrer et al., 1996; Sumner and Shepson, 1999; Honrath et al., 1999) evidence for the photochemical production and release of a range of trace gases has been found. These processes appear to be ubiquitous, occurring wherever sunlight shines on snow. The significance of their influence varies according to background concentrations of radicals, and is less important in boundary layers that are anthropogenically perturbed. But in the remote high latitudes, emissions from the snow can dominate boundary layer chemistry. On the Antarctic plateau, for example, some oxidants are as abundant as in the tropical troposphere when viewed in terms of $24 \mathrm{~h}$ averages (Mauldin et al., 2004).

The cryosphere, however, is not static. Global snow/ice coverage fluctuates over both seasonal and climatic timescales. In our present interglacial period, snow and ice are not restricted to polar regions but are found at much lower latitudes according to the time of year. Previously, the great ice sheets of the glacial periods covered 25\% of the Earth's surface year-round (as opposed to the present-day 10\%) with additionally extensive seasonal snow and sea-ice coverage. Predictions for the future are for considerably less snow coverage than at present. The influence of the cryosphere on atmospheric composition certainly has varied through time and will change in the future.

The science of "snow photochemistry" is relatively young. It is an interdisciplinary subject, drawing on expertise in a wide range of areas. The aim of this paper is to draw this expertise together, and to disseminate information that is relevant for understanding emissions from snow and their influence on atmospheric chemistry. Here we review the detailed chemistry and microphysics of snow itself; explore photochemistry above and within snow; and review observational evidence of the impact snow photochemistry has on the boundary layer and the chemical and physical mechanisms that drive the emissions. Finally we assess current limitations that are impeding progress in understanding, and consider implications for future atmospheres.

\section{Unique physical and chemical aspects of snow}

\subsection{Understanding the location of impurities in snow}

Fundamental to the study of snow photochemistry is an appreciation of snow structure, and in particular, the location within snow crystals/grains where impurities reside. It is these impurities that may ultimately undergo reactive processes and generate trace gas products.

Most of the mass of precipitating snow crystals forms by the condensation of water vapor onto an ice-forming nucleus (IFN) or by the freezing of supercooled droplets onto growing ice crystals, a process called riming (Pruppacher and Klett, 1978). IFNs are therefore a source of impurities in 
snow crystals, as are the cloud condensation nuclei $(\mathrm{CCN})$ that nucleate supercooled water droplets. Various materials can act as IFN or CCN: plant debris, bacteria, minerals, and the ubiquitous sulfate aerosols (Pruppacher and Klett, 1978; Khvorostyanov and Curry, 2000; Sattler et al., 2001; Targino et al., 2006). Supercooled droplets can also scavenge gases and non-activated aerosols in the cloud. Rimed snow is usually more concentrated in impurities than snow formed solely from the condensation of water vapor (Mitchell and Lamb, 1989; Poulida et al., 1998). The location of species trapped in rime ice has been little studied. They could form supersaturated solid solutions (a solid-state solution of solutes within ice), or pockets and veins of brine, as observed during the freezing of sea water (Eicken, 1992).

The growth of ice crystals by vapor condensation often takes place in a discontinuous manner, with new layers of water molecules condensing at crystal edges (Nelson and Knight, 1998). Experiments at low temperatures $(<190 \mathrm{~K})$ have shown that molecules such as $\mathrm{HCl}$ or $\mathrm{HNO}_{3}$ ionize and become solvated on contact with ice surfaces (Horn et al., 1992; Banham et al., 1995). Experiments on the photolysis of the nitrate ion at temperatures relevant to snow conditions indicate that ionization also takes place at these higher temperatures (e.g. Chu and Anastasio, 2003; Boxe et al., 2005). The ions can soon become incorporated in the frozen lattice because of the rapid desorption/adsorption of water from/to the ice surface. Other molecules such as $\mathrm{H}_{2} \mathrm{O}_{2}$ and $\mathrm{CH}_{2} \mathrm{O}$ also can become buried in ice structures but little is known of the chemical form that they take (for example as $\mathrm{CH}_{2} \mathrm{O}$ or $\mathrm{H}_{2} \mathrm{C}(\mathrm{OH})_{2}$ ) or whether they attach to surface hydrogen bonds, dissolve in the quasi-liquid layer (see below) or reside in ice "micropockets". Larger molecules such as acetone, acetaldehyde and alcohols adsorb on ice by forming hydrogen bonds (Picaud et al., 2000, Sokolov and Abbatt, 2002; Dominé and Rey-Hanot, 2002; Winkler et al., 2002; Hudson et al., 2002; Bartels-Rausch et al., 2004). Semi-volatile organic molecules of low polarity adsorb onto ice through van der Waals interactions (Roth et al., 2004; Goss, 2005), and are considered not to dissolve. These large molecules include polycyclic aromatic hydrocarbons (PAHs) and persistent organic pollutants (POPs) (Jaffrezo et al., 1994; Blais et al., 1998; Daly and Wania, 2004).

The surface and grain-boundaries of ice are disordered (e.g. Petrenko and Withworth, 1999; Döppenschmidt and Butt, 2000; Wei et al., 2001; Girardet and Toubin, 2001; Sadtchenko and Ewing, 2002; Cho et al., 2002) to the extent that near the freezing point, the ice surface layer has been called the quasi-liquid layer (QLL). The lowest temperature where the QLL still exists is uncertain, as it depends on the method used to detect it and on the presence of adsorbed impurities that can lower its temperature range of existence. Wei et al. (2001) show evidence for the existence of the QLL down to $-70^{\circ} \mathrm{C}$. For ice with very high ionic concentrations, the ions are excluded from the bulk and form a brine layer at the surface or at grain boundaries, with large ionic strengths in that layer (Cho et al., 2002; Carignano et al., 2006). Adsorption of gases on ice surfaces at tropospheric temperatures has sometimes been described as dissolution in the QLL. Molecular dynamics studies confirm that actual solvation and solution of polar molecules within the QLL takes place (Compoint et al., 2002). Therefore, the more soluble and dissociating acids probably even affect the structure of the QLL. For the less soluble gases, most experimental results have been able to describe the adsorption of trace gases on ice by the formalism used for adsorption on solid surfaces (e.g. Sokolov and Abbatt, 2002; Winkler et al., 2002; Dominé and Rauzy, 2004; Ullerstam et al., 2005; Ullerstam and Abbatt, 2005).

During precipitation, falling crystals can scavenge atmospheric aerosols, and gases can adsorb onto the crystal's surfaces or even diffuse into its bulk. The composition of a snow crystal arriving at the Earth's surface is a complex function of the process of formation, the composition of the cloud where it was formed, and the composition of the air mass underlying the cloud (Schwikowski et al., 1998; Franz and Eisenreich, 1998; Lei and Wania, 2004). Following precipitation, the snow will be out of thermodynamic equilibrium with the atmosphere, due to differences in temperature and air composition from that of the originating cloud, thus, gases can be taken up or emitted by the snow (Conklin et al., 1993; McConnell et al., 1998; Hutterli et al., 2002, 2003). Chemical reactions can also take place on the crystal surface, in its volume, or on/in aerosol particles captured by the snow, or scavenged during descent. The availability of species to be emitted or to react will depend on how they were incorporated in the snow.

Adsorbed species react rapidly to changes in thermodynamic conditions and are readily available for reaction with atmospheric gases. Species present on scavenged aerosols located on the surface of snow crystals can be expected to have a reactivity similar to that in the aerosol phase. Species dissolved within ice crystals, or contained in IFN and CCN are completely trapped within ice crystals, and are thus not in contact with atmospheric gases. Their reactivity will be limited to solid phase processes that are extremely slow, and to photolysis, whose efficiency may be severely limited by cage effects. Species forming a solid solution with ice can diffuse within the ice crystalline lattice and reach the surface. The diffusion coefficients, $D$, measured for $\mathrm{HCl}$, $\mathrm{HNO}_{3}$ and $\mathrm{CH}_{2} \mathrm{O}$ in ice around $-15^{\circ} \mathrm{C}$ are in the range $10^{-11}$ to $10^{-12} \mathrm{~cm}^{2} \mathrm{~s}^{-1}$ (Thibert and Dominé, 1997, 1998; Perrier et al., 2003; see also a critical review of $D$ measurements in Huthwelker et al., 2006). The physical environment of species in rime ice is not clear. However, if they are contained in brine pockets or veins in contact with the atmosphere, their release time will be dictated by their diffusion rate in a liquid phase, with a $D$ value around $10^{-5} \mathrm{~cm}^{2} \mathrm{~s}^{-1}$, much faster than for species in solid solutions.

At present, understanding of the location of impurities in natural snow is limited, so that predicting snow chemical 
reactivity based solely on bulk chemical composition is not possible. It is therefore clear that one of the great needs to advance the state of the science is the ability to probe the chemical morphology of snow and ice, in the macro- and microscopic domains (as further discussed in Sect. 6).

\subsection{Physical and chemical transformations of snow crystals} after deposition

After deposition, snow crystals in the dry snowpack are subjected to temperature gradients that generate water vapor fluxes between crystals. These fluxes cause the sublimation of parts of crystals and condensation on other parts, resulting in changes in snow crystal sizes and shapes, and changes in the physical properties of the snowpack, such as density, porosity, heat conductivity, hardness, specific surface area and albedo. The processes that lead to snowpack metamorphism occur on individual grains, but result in bulk compositional changes to both physical and chemical properties of the snowpack. Snow physics as related to photochemical processes is reviewed by Dominé et al. (2007).

Major changes in snow composition occur after deposition. Examples include the decrease of nitrate in seasonal snowpacks and on ice caps (Mayewski and Legrand, 1990; Nakamura et al., 2000; Röthlisberger et al., 2000, 2002; Beine et al., 2002a), and the increase in sulfate, mineral dust, and sea salt compounds (Harder et al., 2000; Aoki et al., 2000; Dominé et al., 2004). However, relating those changes to a specific process is often difficult. Changes can be caused by physical processes such as dry deposition of gases and aerosols, the formation of surface hoar crystals or the freezing of supercooled droplets during fog events (Bergin et al., 1994, 1995, 1996). Photoreaction of snow species between themselves or with atmospheric gases (Sumner and Shepson, 1999; Spicer et al., 2002; Grannas et al., 2004) may also lead to changes in snow composition, as well as processes directly linked to snow metamorphism such as the release of adsorbed and dissolved species (Hutterli et al., 2004). Sublimation/condensation cycles during metamorphism have the potential to release or trap dissolved species and expose trapped aerosols, changing snow and atmospheric composition and making these species available for gas phase or surface reaction. Solid-state diffusion of species forming solid solutions with ice can also take place. Metamorphism almost always results in the decrease of the specific surface area of snow (Cabanes et al., 2002, 2003), which inevitably results in a decrease in the amount of adsorbed species.

Physical processes and photochemistry can both contribute to decreases in impurity concentrations in snow. For example, release by purely physical processes has been invoked to explain the huge post-depositional decrease in nitrate concentrations in central Antarctic snow (Nakamura et al., 2000; Röthlisberger et al., 2000; Blunier et al., 2005), but nitrate photolysis (Honrath et al., 1999; Ridley et al., 2000; Davis et al., 2001, Jones et al., 2001; Wolff et al., 2002) is also likely to contribute (see further discussion in Sect. 5.3). In addition, the presence of high levels of other impurities in snow affecting the $\mathrm{pH}$ influence the preservation of e.g. nitrate and chloride: Elevated levels of sulfate can mobilize nitrate whereas high levels of dust immobilizes chloride in the snow (Röthlisberger et al., 2002, 2003). Fewer processes can affect aerosol species that have long been considered to be irreversibly deposited (Dibb and Jaffrezo, 1997). However, species such as semi-volatile organics, which are partly aerosol bound, can be lost through both physical and photochemical processes. Most observations indicate an increase in aerosol species by dry deposition, a process accelerated by wind, as snow can effectively filter out particles entrained into its pores by wind-driven air motion (e.g., Waddington et al., 1996; Harder et al., 2000; Dominé et al., 2004). Snow metamorphism can also affect the nature and rate of photochemical reactions, largely through changes in snow grain size and specific surface area, hence snow albedo (Dominé et al., 2006) and light penetration depth (Simpson et al., 2002a).

Wet metamorphism can dramatically affect snow composition. Soluble species, including the well-studied acids $\mathrm{H}_{2} \mathrm{SO}_{4}, \mathrm{HNO}_{3}$ and $\mathrm{HCl}$, have a greater affinity for water than for ice. They partition preferentially to the liquid phase and are readily removed by the first stages of percolation (e.g., Tranter et al., 1986). However, even for inorganic ions there is evidence for significant fractionation driven by preferential elution of some ions (e.g. $\mathrm{SO}_{4}^{2-}, \mathrm{Ca}^{2+}, \mathrm{Mg}^{2+}, \mathrm{K}^{+}, \mathrm{Na}^{+}$) before others $\left(\mathrm{NO}_{3}^{-}, \mathrm{NH}_{4}^{+}, \mathrm{Cl}^{-}, \mathrm{F}^{-}\right)$(Eichler et al., 2001). Less soluble species such as non-polar organic molecules are also found in meltwaters, but are less easily removed by percolation (Meyer et al., 2006). Particulate material is also entrained by percolating water, but rarely in the early stages and may remain in the snow until the final stages of melting (Hodgkins et al., 1998; Lyons et al., 2003; Meyer et al., 2006).

\subsection{Interaction of organics with ice}

An understanding of the interfacial interactions between ice/snow and organic molecules comes from various studies, including those of physical and chemical properties of the ice surface (Engquist 1995a, 1995b; Bertilsson et al., 1997, 1999; Wania et al., 1998; Schaff and Roberts, 1999a, 1999b; Girardet and Toubin, 2001; Borodin et al., 2004; Gudipati, 2004; Roth et al., 2004; Guzmán et al., 2006a; Heger et al., 2005; Heger and Klán, 2007) and cryogenic chemical behavior of ice contaminants (Sumner and Shepson, 1999; Wania et al., 1999; Dubowski and Hoffmann, 2000; Klán and Holoubek, 2002; Coloussi and Hoffmann, 2003; Klán et al., 2003; Klánová et al., 2003a, 2003b; Grannas et al., 2004; Guzmán et al., 2006b; Heger et al., 2006). Adsorption of various organic molecules on ice surfaces can be described well with a multi-parameter linear free energy relationship, based on the van der Waals and the electron donor/acceptor interactions (such as H-bonding) (Roth et al., 2004). Studies 
at low to very low temperatures ( 80 to $190 \mathrm{~K}$ ) have found that ice surfaces interact with contaminants via three different important types of surface water molecules, including those with dangling hydrogen or oxygen atoms (Devlin, 1992; Devlin and Buch, 1995). Many organic halocarbon compounds have also been shown to adsorb on water-ices by interactions with the ice surface dangling bonds (Holmes and Sodeau, 1999). Studies of the adsorbed states of some organic molecules, such as acetonitrile, chloroform (Schaff and Roberts, 1999a, 1999b), acetone (Schaff and Roberts, 1998), or benzene derivatives (Borodin et al., 2004) have revealed the scope of hydrogen-bonding or dipolar interactions. It is not clear, however, how these low temperature data apply to snow surfaces that exist in the range 200-273 K, where the QLL is present. Most importantly, adsorption, desorption, interaction types, or diffusion of the molecules are known to be temperature and phase-dependent variables (Cho et al., 2002; Abbatt, 2003; Heger et al., 2005).

Some solutes are known to become spontaneously segregated at grain boundaries in the polycrystalline ice during the freezing process (Cohen et al., 1996; Finnegan and Pitter, 1997), however most studies have focused on inorganic ions, with relatively little known about the behavior of neutral organics. Such a solute concentration-enhancing effect (Dash et al., 1995; Takenaka et al., 1996; Cho et al., 2002) may cause solute organic molecules to self-organize (Heger et al., 2005). Many laboratory studies have provided evidence that the ice/snow impurities are located in the QLL on the surface of the single ice crystals (Conklin and Bales, 1993; Dash et al., 1995; Dubowski et al., 2001; Wei et al., 2001; Cho et al., 2002; Dubowski et al., 2002; Chu and Anastasio, 2003; Klánová et al., 2003a; Robinson et al., 2006). Most of these studies, however, used dopant concentrations much higher than natural ones, and this preferential segregation may not always occur in nature. Indeed, species such as $\mathrm{CH}_{2} \mathrm{O}$, and possibly others, have a small but non-zero solubility in ice (Burkhart et al., 2002; Perrier et al., 2003), and it is possible that this segregation takes place only once this solubility limit is exceeded, which happens in the laboratory but not in nature. The concentration-enhancing effect in partially frozen aqueous solutions also has been described in connection with the acceleration of some thermal reactions since the 1960s (Grant et al., 1961; Bruice and Butler, 1964; Butler and Bruice, 1964; Fennema, 1975; Takenaka et al., 1992; Takenaka et al., 1996). Recent work has illustrated that the freeze-concentration effect can also have significant impacts on the photochemistry of organics occurring in the QLL on the surface of ice (Bausch et al., 2006).

2.4 Impacts of freezing on snowpack impurities and reactions

Various studies have shown that the action of freezing can affect chemical impurities or reaction processes in snow (Takenaka et al., 1992, 1996; Betterton and Anderson, 2001;
O'Driscoll et al., 2006). In many heterogeneous reactions, rate acceleration and/or new product pathways are promoted by natural freeze-thaw cycles which can occur in snow and ice.

For example, it has been shown that both sulfur dioxide and sulfide ions incorporated into ice are oxidized to sulfate ions (Valdez et al., 1989; Finnegan et al., 1991, Betterton and Anderson, 2001). Similarly iodide and bromide ions become oxidized to higher valence species when frozen (Eyal et al., 1964). It was later discovered that the $\mathrm{N}(\mathrm{III})$ species, $\mathrm{NO}_{2}^{-}$ and $\mathrm{HONO}$, can be oxidized by molecular oxygen to nitrate ions upon freezing in aqueous solution at a rate about $10^{5}$ faster than that found at room temperature (Takenaka et al., 1992). The mechanism was ascribed to a combination of ionseparation and a "freeze-concentration" pathway in which hydrogen ions were rejected from the ice to solution pockets existing within the overall structure. The reaction was suggested to take place in unfrozen solution "micropockets" surrounded by walls of ice grains. The importance of acidity in driving the reaction was also shown in the experiments, which were performed at $\mathrm{pH}$ values between 3.0 and 5.6. To occur within natural snow, therefore, these micro-pockets must be considerably acidic, something that needs further investigation.

\section{Introduction to photochemistry in and above snow}

The ultraviolet (UV) spectral region is the most critical for photochemistry in the atmosphere and snowpack because those photons possess high enough energy to break chemical bonds, but low enough energy to penetrate the ozone layer and reach the troposphere. Radiation of wavelengths shorter than $290 \mathrm{~nm}$ (UV-C region) is completely absorbed by the ozone layer and is thus not important to tropospheric chemistry. Photons in the UV-B region, 290 to $320 \mathrm{~nm}$, pass at least partially through the ozone layer, and are responsible for tropospheric ozone photolysis and production of hydroxyl $(\mathrm{OH})$ radicals through the reaction of $\mathrm{O}\left({ }^{1} \mathrm{D}\right)+\mathrm{H}_{2} \mathrm{O}$, although other production mechanisms for $\mathrm{OH}$ are likely to be more important at high latitudes. The UV-B levels in the troposphere are highly dependent on the stratospheric ozone abundance and the solar zenith angle, which determines the path of light through the stratosphere. Ozone, bromoform $\left(\mathrm{CHBr}_{3}\right)$, and nitrate ions in aqueous solution $\left(\mathrm{NO}_{3}^{-}\right)$are UV-B absorbers. The UV-A region, 320 to $400 \mathrm{~nm}$, has low enough energy to pass through the ozone layer with little attenuation, and thus has a lower dependence than UV-B radiation on overhead ozone and solar zenith angle. Important atmospheric chemicals that are photolyzed in the UV-A are $\mathrm{NO}_{2}, \mathrm{HONO}, \mathrm{CH}_{2} \mathrm{O}$, and $\mathrm{BrO}$. The solar zenith angle, ground reflectivity (albedo), and the overhead ozone are critical parameters for considering photochemical rates (Meier et al., 1997). At high latitudes, the sun never gets as high in the sky as it does at lower latitudes. Generally, this effect 


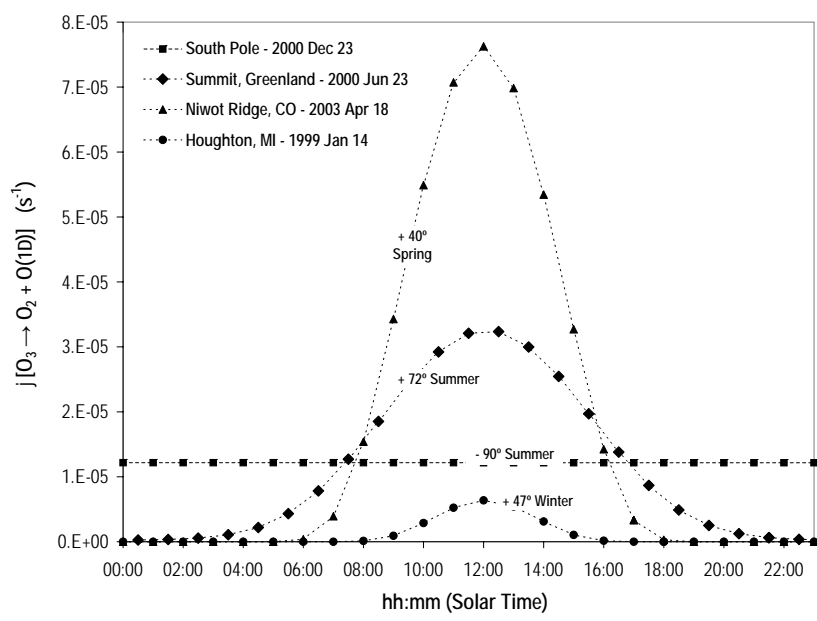

Fig. 1. Cloud-free $J\left[\mathrm{O}_{3}+\mathrm{h} v \rightarrow \mathrm{O}_{2}+\mathrm{O}\left({ }^{1} \mathrm{D}\right)\right]$ from TUV (Tropospheric Ultraviolet and Visible) radiation model for various latitudes and seasons at selected sites where snow photochemistry measurements have been made. Data shown for: South Pole $\left(90^{\circ} \mathrm{S}, 23\right.$ December, 2000); Niwot Ridge, Colorado, USA (40 N, 18 April, 2003); Houghton, Michigan, USA (47 ${ }^{\circ}$ N, 14 January, 1999); and Summit, Greenland ( $74^{\circ} \mathrm{N}, 23$ June, 2000).

significantly decreases the photolysis rates with increasing latitude. However, the presence of snow at high latitudes, which causes the ground to have a high albedo - often $>90 \%$ in the UV spectral region - acts to increase atmospheric photolysis rates, sometimes even overcoming the less favorable solar zenith angles. This albedo effect is very significant for UV-A absorbing species, and diurnally-averaged springtime photolysis rates at high latitudes often are comparable to mid-latitude values. Good examples of this effect are seen in the comparability of high and mid-latitude photolysis rates of $\mathrm{NO}_{2}, \mathrm{BrO}, \mathrm{HONO}$, and $\mathrm{CH}_{2} \mathrm{O}$. The same albedo enhancement effect is present in the UV-B spectral region, but the long slant paths of the light through the ozone layer greatly attenuate the UV-B intensity and cause the photolysis rates for UV-B absorbers to be up to an order of magnitude smaller in the high latitudes than at mid latitudes (Simpson et al., 2002b). This effect, which varies with season and latitude, is particularly seen in ozone photolysis resulting in $\mathrm{O}\left({ }^{1} \mathrm{D}\right)$ atoms (Fig. 1) (Lefer et al., 2001). In addition to the aforementioned albedo effect at very high latitudes, there can also be a substantial influence at these latitudes from having $24 \mathrm{~h}$ of continuous photolysis and thus continuous photochemistry in summer. Additionally, the loss of stratospheric ozone in both the Antarctic and Arctic will allow for greater penetration of shorter wavelength (and more photochemically reactive) UV radiation to the surface, albeit at a time of year when solar irradiance is reduced compared with the summer.

Photolysis frequencies are quantified by the first-order rate coefficient for a molecule, which is normally termed $J\left(\mathrm{~s}^{-1}\right)$, and is given by: (Madronich, 1987; Meier et al., 1997)

$J=\sigma(\lambda, T) \Phi(\lambda, T) F(\lambda) d \lambda$ where $\sigma$ is the absorption cross section and $\Phi$ the quantum yield for the production of the compounds in question. Both $\sigma$ and $\Phi$ are functions of wavelength, $\lambda$, and temperature, T. $F$ is the actinic flux (photons $\mathrm{cm}^{-2} \mathrm{~nm}^{-1} \mathrm{~s}^{-1}$ ), i.e. the omnidirectional flux of photons of wavelength impinging on the molecule.

In the atmosphere, light rays propagate long distances between scattering events, which allow the actinic flux to be measured directly by using a diffusing optic that collects light from all directions with equal sensitivity (Hofzumahaus et al., 1999). The actinic flux may also be modeled by radiation transfer models, such as the Tropospheric Ultraviolet and Visible model (TUV) (http://cprm.acd.ucar.edu/Models/ TUV) (Madronich and Weller, 1990). In the snowpack, it is difficult to place the diffusing optics of an actinic flux spectral radiometer because of their large size and the short scattering length within snow. Therefore, most investigators of photolysis rate coefficients in snow have used measurements of irradiance to constrain radiation transfer models and invert the measurements to actinic fluxes and then photolysis rate coefficients (Simpson et al., 2002a). A complementary method to measure photolysis rate coefficients in snow uses a molecular probe known as a chemical actinometer. The actinometer molecule undergoes a well characterized unimolecular chemical reaction at a rate proportional to the solar actinic flux, and thus the actinic flux in a spectral region can be determined (Qiu et al., 2002; Galbavy et al., 2007a, b). Comparisons of chemical actinometry and spectral radiation measurements have generally shown the methods to agree well (Phillips and Simpson, 2005; Galbavy et al., 2007a, b).

The snowpack is a highly scattering medium with little absorption in the visible and UV region, which makes it appear brilliant white (Wiscombe and Warren, 1980; Grenfell et al., 1981, Warren, 1982; Grenfell et al., 1994). The simplest snowpack radiation transfer models only take into account the scattering coefficient, $S$, which is the probability of a photon scattering per unit length, and the absorption coefficient, $K$, which is the probability of a photon being absorbed per unit length. The scattering coefficient, $S$, is a weak function of wavelength and is most directly related to the snow grain size, or equivalently the specific surface area (SSA), and the interested reader is referred to the companion snow physics review article (Dominé et al., 2007). The absorption coefficient is a strong function of wavelength, and also is very low for pure ice in the visible and near ultraviolet, which makes it very susceptible to large increases due to even trace impurities (Perovich and Govoni, 1991). Thus, in the UV and visible regions, the absorption coefficient of snow is critically dependent on impurity content and chemical nature.

When radiation enters the snowpack from above, the scattering alters its path, converting direct into diffuse radiation. This scattering ultimately redirects the light back upwards and out of the snow, leading to the high albedo of snow in the visible and UV regions. The scattering also enhances the pathlength of the photons in the snowpack and 
thus enhances the absorption probability and photochemical rates for trace absorbers in the snow. The scattering and absorption combine nonlinearly to control the depth to which photons, on average, penetrate into the snowpack. For diffuse radiation and deep and uniform snowpack, the attenuation of light follows the Bouger-Lambert law (Bohren and Barkstrom, 1974), which states that the attenuation of light varies exponentially with depth.

$I(d)=I\left(d^{\prime}\right) e^{-\alpha_{0}(\lambda)\left(d-d^{\prime}\right)}$

In this equation, $I(d)$ is the irradiance at depth $d$ and $a_{0}(\lambda)$ is the asymptotic flux extinction coefficient. The asymptotic flux extinction coefficient is the inverse of the e-folding depth, $\varepsilon(\lambda)$, which is the depth over which the intensity of radiation decreases by a factor of $e$,

$\varepsilon(\lambda)=1 / \alpha_{0}(\lambda)$

The e-folding depth of radiation in the UV-B to visible part of the spectrum in snow is typically in the range from 5$25 \mathrm{~cm}$ (Grenfell and Maykut, 1977; Grenfell et al., 1981; King and Simpson, 2001; Simpson et al., 2002a; Fisher et al., 2005; Warren et al., 2006; Galbavy et al. 2007a, b). The e-folding depth should be considered to be the characteristic depth of illumination of the snowpack, and the majority of photochemical reactions occur in this region (King and Simpson, 2001).

Penetration of light into snowpack, and thus the amount of photochemistry within the snowpack, is highly dependent on the solar zenith angle (Warren, 1982; Simpson et al., 2002a; Lee-Taylor and Madronich, 2002; Bourgeois et al., 2006). This effect is caused by the fact that snow grains typically act to forward-scatter light that interacts with them. Thus, for glancing incidence radiation that is characteristic of high solar zenith angles, a greater fraction of light is scattered back to space, the albedo is enhanced, and less light enters the snow to drive snowpack photochemistry. Light can impact snowpacks at low solar zenith angles near noon at mid- and low-latitude sites, for example at high altitude snowpacks on mountains. In this low solar zenith angle case, many forward scattering events are required to return a photon to space, and thus more of the illuminating light enters the snowpack and drives photochemistry. Therefore, snowpack photochemistry is highly dependent on the solar zenith angle and should be very rapid for noon-time conditions at low-latitude snowfields and glaciers.

\section{Current understanding of snow photochemistry}

\subsection{Nitrogen oxides}

\subsubsection{Introduction to nitrogen oxides in Polar regions}

Historically, measurements of trace gas chemistry at high latitudes targeted two distinct objectives. One was improved understanding of the chemistry of a clean background atmosphere; tropospheric concentrations of reactive trace gases such as $\mathrm{NO}_{\mathrm{x}}\left(\mathrm{NO}\right.$ and $\mathrm{NO}_{2}$ ) were expected to be very low (few parts per trillion by volume (pptv, pmol mol$\left.{ }^{-1}\right)$ ) as in the remote marine boundary layer (Logan, 1983). It was assumed that the dominant sources of total reactive nitrogen oxides $\left(\mathrm{NO}_{\mathrm{y}}\right)$ included downwelling from the stratosphere, or long-range transport of $\mathrm{N}$-species generated at lower latitudes by, e.g. tropical lightning, anthropogenic emissions or biomass burning. A second motivator was to increase our ability to interpret ice core data: nitrate $\left(\mathrm{NO}_{3}^{-}\right)$is an easy ion to measure from ice cores, so its interpretation in terms of changing atmospheric composition (of $\mathrm{NO}_{\mathrm{x}}$ or $\mathrm{NO}_{\mathrm{y}}$ ) would be a significant prize. The first polar NO measurements, supported the a priori position. Early measurements at Barrow, an Arctic coastal site, indicated very low NO mixing ratios during most periods analyzed; any enhanced mixing ratios were attributed to local or regional combustion emissions (Honrath and Jaffe, 1992). On the Antarctic Peninsula NO remained below the 5 pptv instrumental detection limit (Jefferson et al., 1998); in retrospect the site was atypical for Antarctica, being surrounded by rock and ocean.

The discovery of elevated $\mathrm{NO}_{\mathrm{x}}$ mixing ratios within the snowpack interstitial air at Summit, Greenland thus came as a surprise (Honrath et al., 1999). Within the surface snowpack, $\mathrm{NO}_{\mathrm{x}}$ was a factor of 3 to $>10$ times higher than in ambient air and was generally greater than ambient $\mathrm{NO}_{\mathrm{y}}$. Concentrations of $\mathrm{NO}_{\mathrm{y}}$ in interstitial air varied diurnally, indicating that a $\mathrm{N}$-containing reservoir within the snow, most likely nitrate $\left(\mathrm{NO}_{3}^{-}\right)$, was photolyzed to release $\mathrm{NO}_{\mathrm{x}}$ to snowpack interstitial air and potentially to the overlying boundary layer. A proximate source of $\mathrm{NO}_{\mathrm{x}}$ helped to explain anomalous $\mathrm{HNO}_{3}$ and $\mathrm{NO}_{\mathrm{y}}$ fluxes observed earlier at Summit (Dibb et al., 1998) and confirmed that standard tropospheric chemistry could not be directly applied in the boundary layer above sunlit snow.

\subsubsection{Field studies to identify/quantify processes}

A number of campaigns were subsequently conducted to look for snowpack $\mathrm{NO}_{\mathrm{x}}$ production at other locations and to test possible production processes (see Fig. 2 for location of measurement sites mentioned in the text). These studies used surface snow in a variety of ways - in the natural snowpack (Jacobi et al., 2004), as blocks (at Neumayer station, Antarctica, Jones et al., 2000), piles (at Alert, Nunavut, Canada, Beine et al., 2002a) and in flow-through chambers 

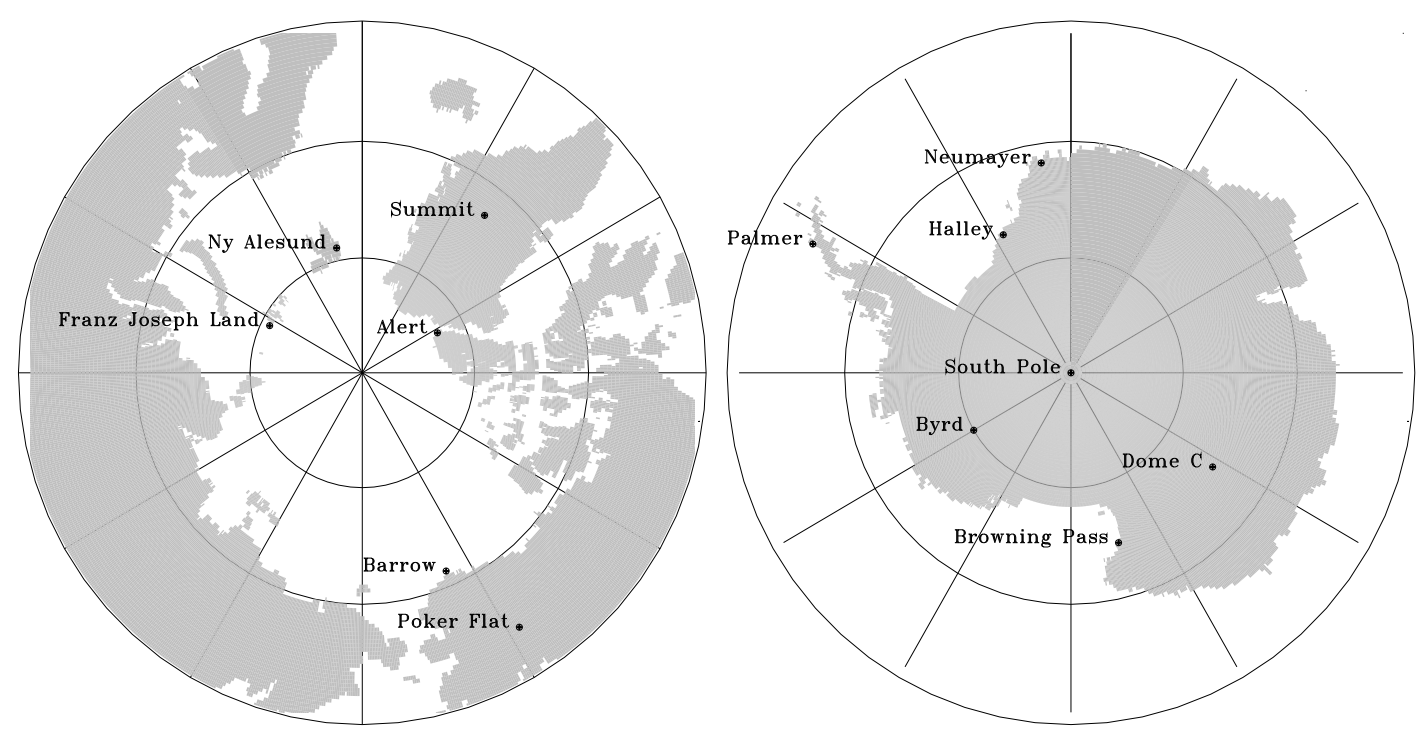

Fig. 2. Map of northern hemisphere (left) and southern hemisphere (right) study locations discussed herein.

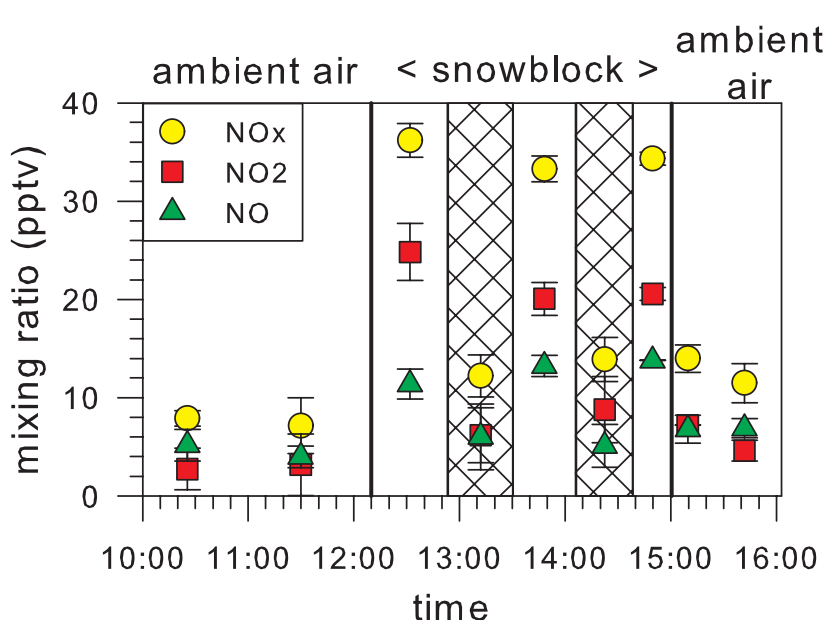

Fig. 3. Measurements of $\mathrm{NO}, \mathrm{NO}_{2}$ and $\mathrm{NO}_{\mathrm{x}}$ in a snowblock shading experiment at Neumayer Station, Antarctica (Jones et al., 2000). The first and final sections are measurements made in ambient air. Middle sections are measurements made within the snowblock, alternatively fully exposed to sunlight and fully shaded to eliminate any photochemical activity. Periods of shading are indicated by cross-hatching.

(at Summit, Greenland, Dibb et al., 2002); irradiated with either natural or artificial light. The experiments generally involved shading the surface snow in such a way as to minimize changes in temperature. They all came to the same fundamental conclusion that the action of light on natural snow caused the release of both $\mathrm{NO}$ and $\mathrm{NO}_{2}$, and that this production occurred rapidly (Fig. 3). Interestingly, one study in Michigan, U.S., demonstrated that mid-latitude snow also produced $\mathrm{NO}_{\mathrm{x}}$ (Honrath et al., 2000b). It seemed likely this process occurs in most, if not all, sunlit snowpacks across the globe.

The atmospheric significance of the snow photochemistry phenomenon depends on the potential to emit the photoproducts to the overlying boundary layer. A series of flux experiments was conducted at various sites in both polar regions, to detect and quantify $\mathrm{NO}_{\mathrm{x}}$ fluxes out of the snowpack (Jones et al., 2001; Honrath et al., 2002; Beine et al., 2002b; Oncley et al., 2004). In each case, the snowpack was found to be emitting $\mathrm{NO}_{\mathrm{x}}$ into the boundary layer. The flux varied throughout the day, depending on solar intensity, and also changes in turbulence.

Several of the early Arctic studies extended measurements to include HONO (see Fig. 4). Certain questions exist about HONO measurements made in locations where mixing ratios are low (Kleffmann et al., 2006), with the data being higher than can be reconciled with model $\mathrm{HO}_{\mathrm{x}}$ and $\mathrm{NO}_{\mathrm{x}}$ chemistry (e.g. Bloss et al., 2006, and see also Sect. 4.2). The high latitude measurements of HONO discussed here should be interpreted with these potential caveats in mind.

A photochemical source of HONO from snow was also indicated, with elevated mixing ratios in snowpack interstitial air that were reduced by shading (Beine et al., 2002a; Dibb et al., 2002). The ratio of photochemical production of HONO compared to $\mathrm{NO}_{2}$ at Summit ranged from 1:1 to 1:3. Flux studies showed that HONO could also be released into the overlying boundary layer (Zhou et al., 2001; Honrath et al., 2002) (Fig. 4), with an emission ratio of $\mathrm{NO}_{\mathrm{x}}$ (mainly as $\mathrm{NO}_{2}$ ) to $\mathrm{HONO}$ of roughly 1:1 measured at Alert (Beine et al., 2002a). Subsequent work at other sites (NyÅlesund (Beine et al., 2003; Amoroso et al., 2005) and a high altitude mid-latitude site (Beine et al., 2005)) found that in locations where snow was alkaline, no significant HONO 

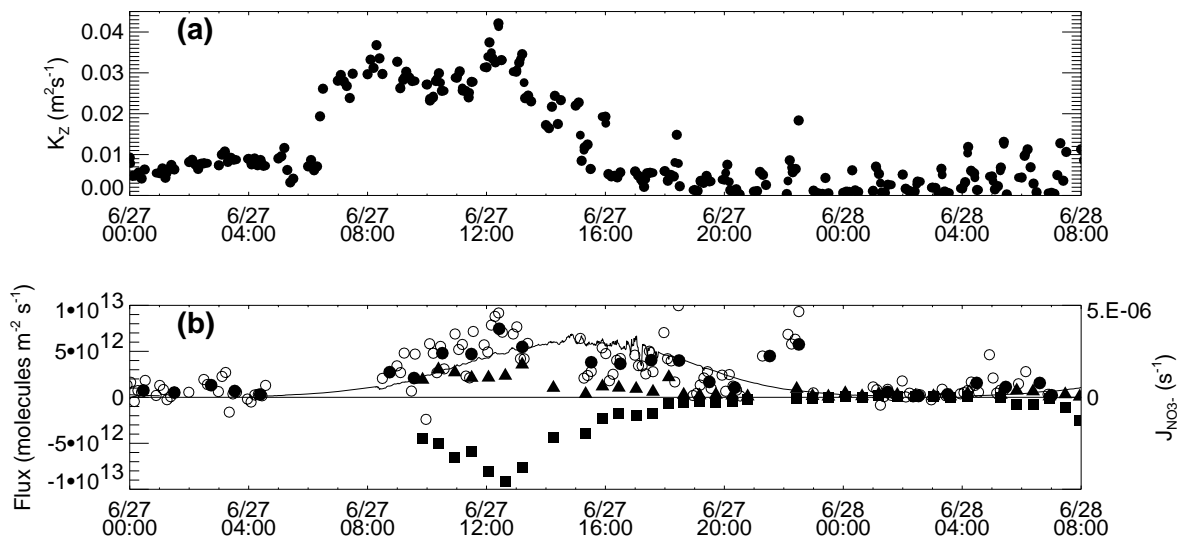

Fig. 4. (a) Eddy diffusivity measurements and (b) calculated fluxes (flux-gradient approach) during 27-28 June at Summit, Greenland. circles $=\mathrm{NO}_{\mathrm{x}}$, triangles $=\mathrm{HONO}$, squares $=\mathrm{HNO}_{3}$, solid line $=\mathrm{J}\left(\mathrm{NO}_{3}^{-}\right)$. Positive values indicate an upward flux. (Reprinted from Honrath et al., Vertical fluxes of $\mathrm{NO}_{\mathrm{x}}, \mathrm{HONO}$ and $\mathrm{HNO}_{3}$ above the snowpack at Summit, Greenland, Atmospheric Environment, 36, 2629-2640, 2002, with permission from Elsevier).

emissions were detected. Furthermore, at Browning Pass, Antarctica, where snow was acidic, surprisingly small emissions of HONO were measured (Beine et al., 2006). This demonstrates the sensitivity of $\mathrm{NO}_{\mathrm{y}}$ emissions to the chemical composition of the snow, not just to physical parameters, as is discussed in detail later (see Sect. 4.1.4).

\subsubsection{Field observations of ambient nitrogen oxides}

Seasonal variation of NO and $\mathrm{NO}_{\mathrm{x}}$ : Figs. 5 and 6 provide an overview of ambient measurements of $\mathrm{NO}$ and $\mathrm{NO}_{\mathrm{x}}$ that have been made at high latitudes since the discovery of snowpack nitrogen photochemistry. The data are presented according to latitude and as daily averages, and, except for South Pole, are plotted on the same scale. The original papers show details not apparent in Fig. 5. By considering both $\mathrm{NO}$ and $\mathrm{NO}_{\mathrm{x}}$, it is possible to see whether differences in $\mathrm{NO}$ are driven by emissions or by re-partitioning between $\mathrm{NO}$ and $\mathrm{NO}_{2}$.

Mixing ratios of $\mathrm{NO}_{\mathrm{x}}$ are similar at Summit and $\mathrm{Ny}$ Ålesund, but considerably lower than at Poker Flat. At Alert $\mathrm{NO}_{\mathrm{x}}$ is highly variable, ranging from $<5$ pptv to over $80 \mathrm{pptv}$, most likely driven by differing air mass origins, hence source regions. The $\mathrm{NO} / \mathrm{NO}_{2}$ partitioning also varies between sites. For example, $\mathrm{NO}_{\mathrm{x}}$ at Poker Flat is clearly dominated by $\mathrm{NO}_{2}$. The data from Ny-Ålesund reflect a more marine signature, with generally low mixing ratios of NO, but relatively high $\mathrm{NO}_{2}$. Mixing ratios of $\mathrm{NO}$ at Alert clearly follow the increasing intensity of solar radiation through polar sunrise, and achieve higher mixing ratios during April than measured at $\mathrm{Ny}$-Ålesund. At Summit, mixing ratios of both $\mathrm{NO}$ and $\mathrm{NO}_{\mathrm{x}}$ show little variability either within a year (spring to summer) or from year to year. Snowpack emissions are a significant source of $\mathrm{NO}_{\mathrm{x}}$ at this remote location on the Greenland plateau (Honrath et al., 2002). The remote coastal Antarc- tic sites (Neumayer and Halley) have the lowest $\mathrm{NO}_{\mathrm{x}}$ mixing ratios of all the snow-covered sites, reaching maxima on the order of only a few $10 \mathrm{~s}$ of pptv or less - nonetheless higher than originally anticipated, and higher than can be achieved in models that neglect snow photochemistry. Neumayer has very low NO throughout the entire year; as expected NO is < 5 pptv (typical instrument detection limits) during the polar night, with a signal appearing during October. The annual maximum appears (in this year) in early December coincident with that of UV-B radiation, rather than with UV-A, suggesting a source driven by photolysis of nitrate in snow rather than photolysis of $\mathrm{NO}_{2}$ (Weller et al., 2002, see also Sect. 3).

The real surprises regarding $\mathrm{N}$-oxides in polar regions have come from South Pole where summertime mixing ratios of several $100 \mathrm{~s}$ pptv of NO have been measured routinely during several campaigns (e.g. ISCAT 98 (Davis et al., 2001); ISCAT 2000 (Slusher et al., 2002; Davis et al., 2004; Huey et al., 2004); ANTCI 2003 (Oltmans et al., 2007)). In 2003 , mixing ratios of NO reached an extraordinary $1 \mathrm{ppbv}$ $\left(\mathrm{nmol} \mathrm{mol}{ }^{-1}\right.$ ). These exceedingly high $\mathrm{NO}_{\mathrm{x}}$ concentrations are highly correlated with atmospheric stability and are believed to result from snowpack emissions across the Antarctic plateau which are concentrated within a very shallow boundary layer (Davis et al., 2004). Mixing ratios of $\mathrm{NO}_{\mathrm{x}}$ at South Pole are high enough for local production of ozone (Crawford et al., 2001), a phenomenon normally associated with polluted atmospheres. Indeed, $\mathrm{O}_{3}$ enhancements of up to 25 ppbv have been observed (Helmig et al., 2007a). In addition to $\mathrm{NO}_{\mathrm{x}}$, very substantial concentrations (10's pptv) of gas phase $\mathrm{HNO}_{3}$ and $\mathrm{HO}_{2} \mathrm{NO}_{2}$ are measured at this site.

Diurnal variation in oxidized nitrogen compounds: Photochemistry occurring within snow and subsequent emissions from the snowpack also drive short timescale variation in boundary layer composition. For example, during the 


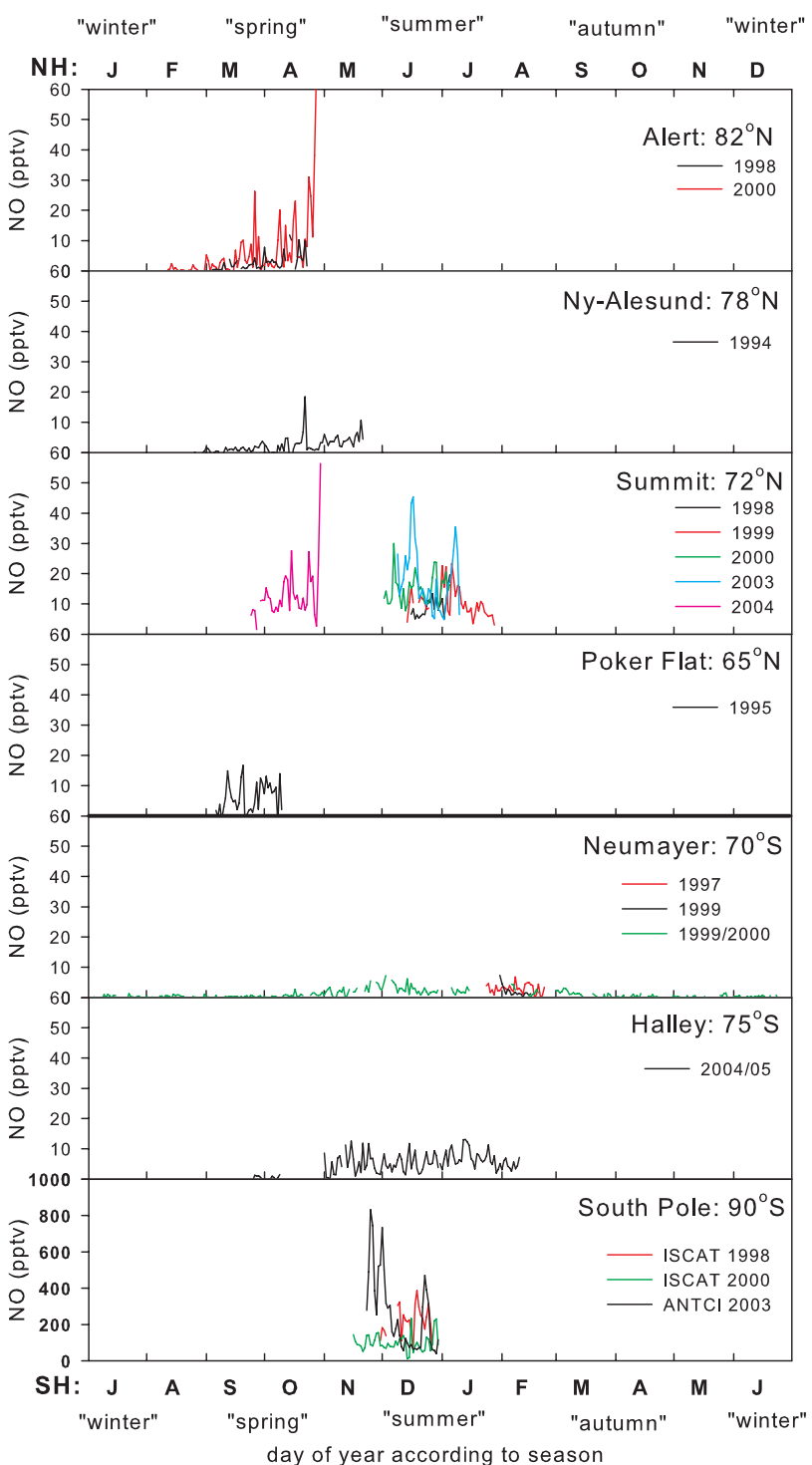

Fig. 5. Overview of recent NO measurements from high latitude sites. Refs: Alert 1998: Ridley et al., 2000; Alert 2000:Beine et al., 2002a, 2002b; Ny-Ålesund 1994: Beine et al., 1997; Summit "98: Ford et al., 2002; Summit "99: Ford et al., 2002, Yang et al., 2002; Summit 2000: Yang et al., 2002; Summit 2003: Sjostedt et al., 2006; Summit 2004: G. Huey, Pers. Comm; Poker Flat "95: Beine et al., 1997; Neumayer "97: Jones et al., 1999; Neumayer “99: Jacobi et al., 2000; Neumayer 99/2000: Weller et al., 2002; Halley 2004: S. Bauguitte pers. comm..; South Pole "98: Davis et al., 2001; South Pole 2000: Davis et al., 2004; South Pole 2003: G. Huey, personnel communication

Polar Sunrise 1998 experiment at Alert, $\mathrm{NO}_{\mathrm{x}}$ showed a clear diurnal variation whose amplitude increased as day length increased (Ridley et al., 2000). Daytime emissions of $\mathrm{NO}_{\mathrm{x}}$ from photolysis of snow $\mathrm{NO}_{3}^{-}$, with formation and fast redeposition of $\mathrm{HNO}_{3}$ explained this pattern. Surprisingly also, a diurnal variation in $\mathrm{NO}_{\mathrm{y}}$ was measured at Neumayer (Fig. 7)

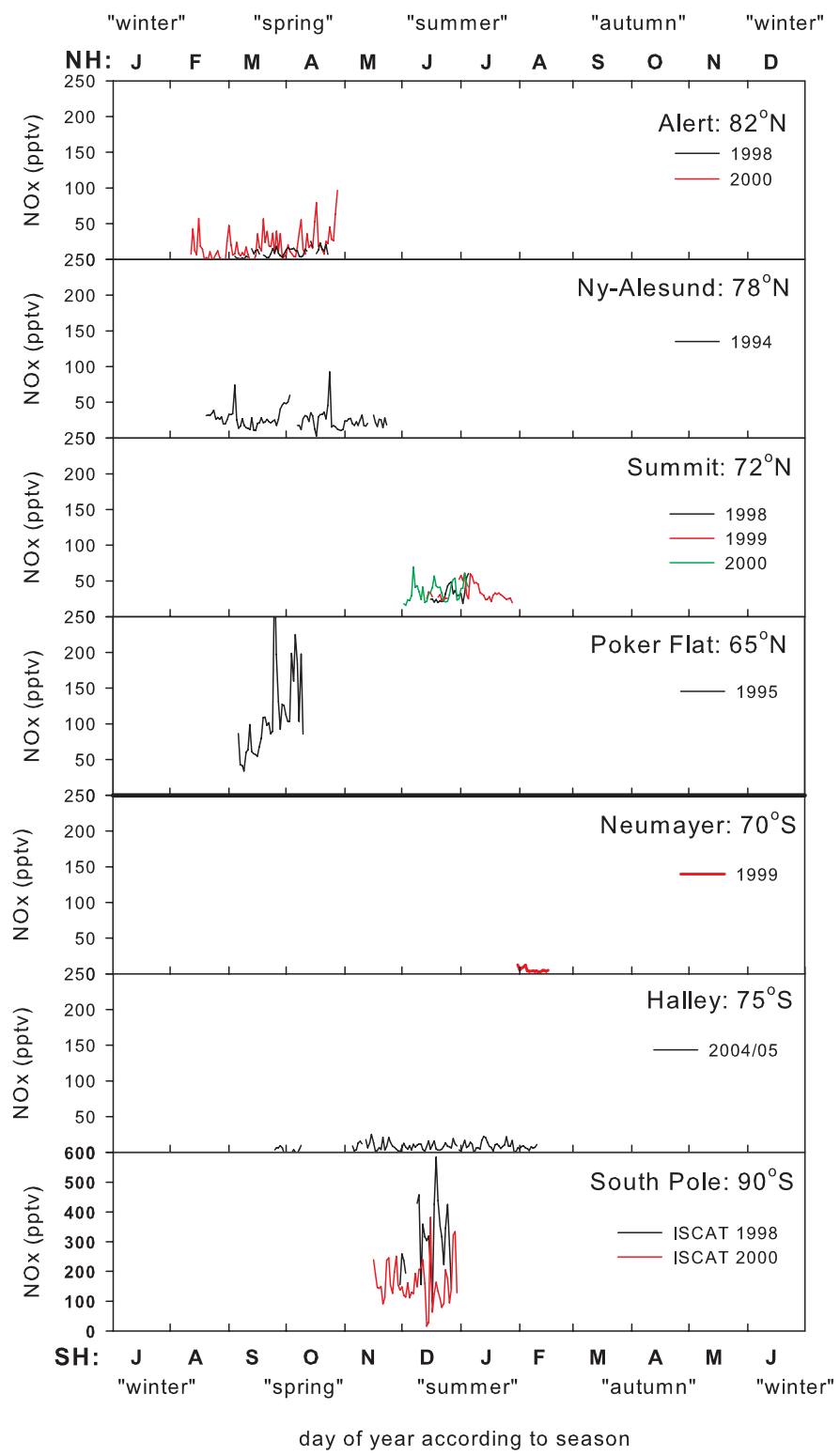

Fig. 6. Overview of recent $\mathrm{NO}_{\mathrm{x}}$ measurements from high latitude sites. References as for Fig. 5. South Pole $\mathrm{NO}_{\mathrm{x}}$ are based on calculated $\mathrm{NO}_{2}$ values and measured $\mathrm{NO}$ values.

(Weller et al., 1999). The variation was found to be linked both to exchanges at the snow surface and to changing stability of the boundary layer (Weller et al., 1999). When the boundary layer was shallow and highly stable, $\mathrm{NO}_{\mathrm{y}}$ mixing ratios were elevated, a relationship that has since also been observed at South Pole, where the highest NO levels were recorded under calm and shallow boundary layer conditions. Davis et al. $(2001,2004)$ suggested that the low boundary layer height was essential, but not sufficient, to explain the huge enhancements of NO at South Pole compared to other sites. 
The diurnal variation in $\mathrm{NO}_{\mathrm{y}}$ at Neumayer is a composite of diurnal variations in component species. Figure 7 shows that the cycle of $\mathrm{NO}$ is clearly well offset from the maximum in $\mathrm{NO}_{2}$ photolysis, evidence of a reduced role for this source at Neumayer. Some interesting new data from Summit show that the evolution of component species is not linear throughout the season from the early spring and into summer, as one might intuitively expect (J. Dibb, personal communication). Summit early spring has large amplitude diurnal variation in $\mathrm{NO}$; no equivalent signal for HONO is evident. By late spring, mixing ratios of $\mathrm{HONO}$ have increased and generally track NO and solar elevation. Summertime data collected during the previous year at Summit show NO and HONO varying in tandem. The data suggest that in the early spring, different mechanisms are determining the mixing ratios of $\mathrm{NO}$ and $\mathrm{HONO}$, but by the summer, the mixing ratios are being driven by the same (or strongly associated) processes. It is known that HONO evolution out of the snowpack is very different from that of NO, and HONO decomposition leads to NO generation, issues that are further explored below.

\subsubsection{Mechanisms for the production of $\mathrm{NO}, \mathrm{NO}_{2}$ and HONO}

The mechanisms driving the photochemical production of $\mathrm{NO}_{\mathrm{x}}$ and HONO in snow have been investigated in controlled studies, mainly in the laboratory but also in the field. For the laboratory studies, a critical point is whether the distribution of $\mathrm{NO}_{3}^{-}$in the artificially-generated snow/ice matches that of natural snow, where $\mathrm{NO}_{3}^{-}$is probably mostly very close to the ice crystal surface. Another factor to bear in mind is that reactant mixing ratios in some laboratory studies are so much higher than in nature that the relevance of proposed mechanisms in real snow may be questioned. One feature that all the studies reported thus far have in common, however, is to suggest that the reactions occur in the QLL or "micropockets" within the ice structure, as discussed in some detail in Sect. 2 of this paper.

The initial studies addressed whether $\mathrm{NO}_{3}^{-}$impurities in snow really could produce $\mathrm{NO}_{\mathrm{x}}$ when irradiated. Honrath et al. (2000a) made artificial snow by spraying a solution of deionized water doped with $\mathrm{NaNO}_{3}$ into liquid nitrogen. The rapidly frozen "snow" was irradiated and $\mathrm{NO}_{\mathrm{x}}$ was indeed detected. Submillimeter ice layers doped with $\mathrm{NO}_{3}^{-}$emitted $\mathrm{NO}_{2}$ when continuously irradiated at $\lambda \sim 300 \mathrm{~nm}$ (Dubowski et al., 2001). Laboratory experiments using blocks of Antarctic snow found that production of $\mathrm{NO}$ and $\mathrm{NO}_{2}$ ceased at $\lambda>345 \mathrm{~nm}$ (Cotter et al., 2003). The wavelength dependence of $\mathrm{NO}_{\mathrm{x}}$ production in these block studies is consistent with absorption by $\mathrm{NO}_{3}^{-}$in aqueous solution (maximum absorption around $300 \mathrm{~nm}$ and none above $345 \mathrm{~nm}$ ). A study to quantify the temperature-dependence of the $\mathrm{NO}_{3}^{-}$quantum yield found that the same temperature dependence described results both in solution and in ice, suggesting that photolysis

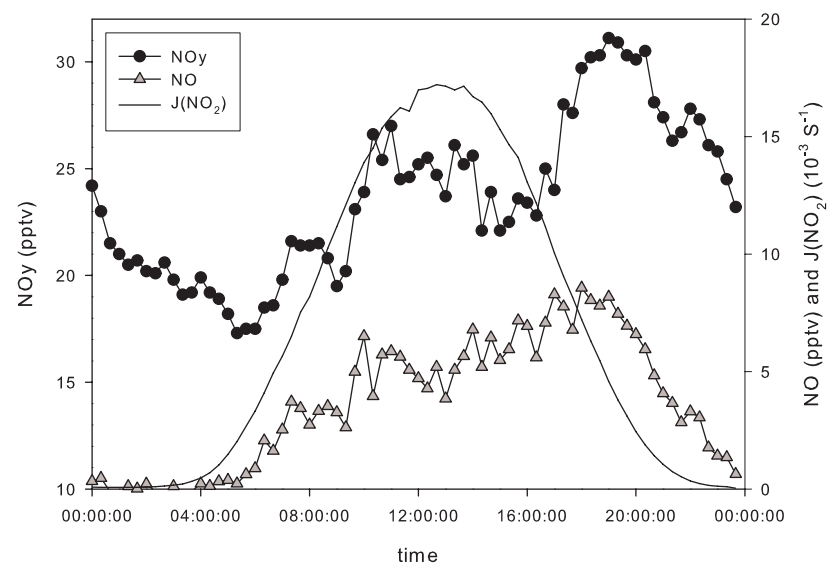

Fig. 7. Diurnal variation in $\mathrm{NO}_{\mathrm{y}}, \mathrm{NO}$ and $\mathrm{J}-\mathrm{NO}_{2}$ measured at Neumayer Station, Antarctica, 1997, (Weller et al., 1999).

of $\mathrm{NO}_{3}^{-}$on ice occurs in the QLL rather than in the bulk ice (Chu and Anastasio, 2003).

Nitrate photolysis in the aqueous phase at wavelengths above $290 \mathrm{~nm}$ is classically considered to proceed via two channels:

$\mathrm{NO}_{3}^{-}+\mathrm{h} v \rightarrow \mathrm{NO}_{2}+\mathrm{O}^{-}$

$\mathrm{NO}_{3}^{-}+\mathrm{h} v \rightarrow \mathrm{NO}_{2}^{-}+\mathrm{O}\left({ }^{3} \mathrm{P}\right)$

The overall quantum yields for these two channels is roughly 0.01 , i.e. only $1 \%$ of the photons absorbed lead to products. It appears from two laboratory studies, one studying the aqueous phase (Warneck and Wurzinger, 1988) and the other ice surfaces (Dubowski et al., 2001), that channel 4 exceeds channel 5 by roughly a factor of 8 to 9 . A further possible channel in this system results in production of the peroxynitrite ion, $\mathrm{OONO}^{-}$. Although the quantum yield at $254 \mathrm{~nm}$ is around 0.1, there is good evidence that the quantum yield decreases significantly with increasing wavelength, and it is unclear whether this channel exists for $\lambda>280 \mathrm{~nm}$ (see, e.g. Mack and Bolton, 1999). Even if it does exist, any peroxynitrite formed on snow may still not be significant; given that the pKa for HOONO is 6.5. Thus any $\mathrm{OONO}^{-}$formed will most likely be rapidly protonated to HOONO, whose major fate appears to be very rapid decay to $\mathrm{NO}_{3}^{-}(\tau \sim 1 \mathrm{~s})$, so that most OONO- probably returns back to $\mathrm{HNO}_{3}$.

Channel 5 can be followed by the photolysis of nitrite $\left(\mathrm{NO}_{2}^{-}\right)$via:

$\mathrm{NO}_{2}^{-}+\mathrm{h} \nu \rightarrow \mathrm{NO}+\mathrm{O}^{-}$

such that photolysis of $\mathrm{NO}_{3}^{-}$can generate $\mathrm{NO}$ as a secondary product. Alternatively, $\mathrm{NO}_{2}^{-}$can react with oxidants such as ozone or $\mathrm{OH}$ :

$\mathrm{NO}_{2}^{-}+\mathrm{OH} \rightarrow \mathrm{NO}_{2}+\mathrm{OH}^{-}$ 
which provides another route for the formation of $\mathrm{NO}_{2}$ (Jacobi and Hilker, 2007; Chu and Anastasio, 2007). Near midday in summer the calculated lifetime of $\mathrm{NO}_{2}^{-}$on polar surface snow is quite short (on the order of several hours), resulting in low estimated snow grain concentrations on the order of $10 \mathrm{nmol} \mathrm{kg}^{-1}$ or less (Chu and Anastasio, 2007).

The dominant product from $\mathrm{NO}_{3}^{-}$photolysis is therefore gaseous $\mathrm{NO}_{2}$, a result that is supported by many field observations which have found $\mathrm{NO}_{2}$ production to noticeably exceed that of NO (e.g. Jones et al., 2000; Dibb et al., 2002). The experiments of Dubowski et al. (2001) suggest, however, that not all of the $\mathrm{NO}_{2}$ is released from the snow, rather only $\mathrm{NO}_{2}$ produced near the ice crystal-air interface is released to the firn air, possibly then reaching the overlying boundary layer. The rest undergoes secondary chemistry (dark and photochemistry), a result supported by Boxe et al. (2005).

Various mechanisms have been proposed for HONO formation. The $\mathrm{pH}$ of melted present day fresh snow is acidic except in regions with strong inputs of dust or sea salt. If we assume that acid/base equilibria known for liquid water can be applied to snow (a hypothesis that is somewhat uncertain), it follows that $\mathrm{NO}_{2}^{-}$in snow can be protonated to produce $\mathrm{HONO}$ which will be released into the gas phase:

$\mathrm{NO}_{2}^{-}+\mathrm{H}^{+} \rightarrow \mathrm{HONO}$

Under sufficiently acidic conditions, the nitroacidium ion, $\mathrm{H}_{2} \mathrm{ONO}^{+}\left(p \mathrm{~K}_{a}=1.7\right)$ may also form (Hellebust et al., 2007), which could then react further to produce HONO.

In addition to Reaction (5), another proposed source of $\mathrm{NO}_{2}^{-}$involves the hydrolysis of photo-generated $\mathrm{NO}_{2}$ (Zhou et al., 2001; Boxe et al., 2005), via:

$2 \mathrm{NO}_{2}+\mathrm{H}_{2} \mathrm{O} \rightarrow \mathrm{NO}_{2}^{-}+\mathrm{NO}_{3}^{-}+2 \mathrm{H}^{+}$

These authors also suggest the heterogenous reaction $\mathrm{NO}+$ $\mathrm{NO}_{2}+\mathrm{H}_{2} \mathrm{O} \rightarrow 2 \mathrm{HONO}$ might be significant. McCabe et al. (2005) suggest extensive cage recombination of primary photofragments with the water solvent in the photolysis of $\mathrm{NO}_{3}^{-}$, consistent with the proposed mechanisms. However, the concentrations of reactants needed for these reactions are considerably higher than are found in nature so these processes are probably not very likely.

Other mechanisms have also been suggested to produce $\mathrm{HONO}$ within snow interstitial air. One example is the reaction of $\mathrm{NO}_{2}$ (produced from $\mathrm{NO}_{3}^{-}$photolysis) with specific photosensitized organics (George et al., 2005; Stemmler et al., 2006). It is not known whether such organic molecules are sufficiently widely found in surface snow to be influential. However, such reactions have been invoked to explain variations in HONO productions from snow in coastal Antarctica (Beine et al., 2006), where high concentrations of impurities were found in snow, and where the proximity of the Ross sea polynya could have supplied appreciable amounts of various organic molecules. Certainly humic substances and other plant degradation material are widely found in the Arctic snowpack, as discussed in Sect. 4.4.1. Of note also is that both Reactions (4) and (6) produce $\mathrm{O}^{-}$, which will be rapidly protonated to form $\mathrm{OH}$, which may then react with $\mathrm{NO}$ to produce HONO:

$\mathrm{O}^{-}+\mathrm{H}^{+} \rightarrow \mathrm{OH}$

$\mathrm{NO}+\mathrm{OH} \rightarrow \mathrm{HONO}$

However, this pathway is unlikely to be a significant source of HONO since snow grain concentrations of both NO and $\mathrm{OH}$ will be quite small. An extensive discussion of HONO formation mechanisms is presented by Cotter et al. (2003) and Jacobi and Hilker (2007). Of particular relevance for the overall discussion here, Jacobi and Hilker (2007) point out that, under natural conditions, the photolysis rates of $\mathrm{NO}_{3}^{-}$in snow are relatively small. As a result, the production rates of the short-lived compounds (such as NO) are also very small, which reduces the likelihood of the possible side and crossreactions that can be detected under laboratory conditions.

Temperature, $\mathrm{pH}$ and ionic content of natural snow will also affect many reactions, and additionally determine whether products are released. Jacobi and Hilker (2007) suggest that direct formation of HONO is highly dependent on the $\mathrm{pH}$ of the QLL, with effectively no production at $\mathrm{pH} \geq 5$ since the pKa of HONO is 2.8 in solution (Riordan et al., 1995). This is consistent with the field measurements of Beine et al. $(2003,2005)$ and Amoroso et al. (2005) who found no HONO production in alkaline snow.

\subsubsection{Establishing a modeling framework}

Irrespective of the mechanism, laboratory and field experiments indicate that $\mathrm{NO}_{\mathrm{x}}$ production in snow approximates that expected from aqueous photolysis of $\mathrm{NO}_{3}^{-}$, extrapolated to subfreezing temperatures (Wolff et al., 2002; Chu and Anastasio 2003; Jacobi and Hilker, 2006). The production rate should be proportional to the concentration of "available" $\mathrm{NO}_{3}^{-}$in snow and the photolysis frequency. The emission of products will be influenced by the microstructural location of $\mathrm{NO}_{3}^{-}$, which is influenced by its chemical form (acid or salt) (Beine et al., 2003, 2006). For snow $\mathrm{NO}_{3}^{-}$inventories dominated by $\mathrm{HNO}_{3}$, the $\mathrm{NO}_{3}^{-}$must rapidly reach the surface of the snow crystal, either through initial deposition to the surface or by relatively fast diffusion (Thibert and Dominé, 1998), since a very high proportion of it can be lost through physical processes such as volatilization (Röthlisberger et al., 2000). This might not be the case for $\mathrm{NO}_{3}^{-}$trapped as (e.g. $\mathrm{Na}^{+}$or $\mathrm{Ca}^{2+}$ ) salts. This issue is important for sites near the ocean or dust sources, and in other climate regimes such as those prevailing during the last glacial period.

The photolysis frequency can be calculated (Wolff et al., 2002) from the downwelling spectral irradiance at the snow surface, the properties of the snow that determine the actinic flux as a function of depth and wavelength, the absorption 
cross-section of aqueous nitrate (Mack and Bolton, 1999), and the quantum yield, which has recently been measured in ice (Chu and Anastasio, 2003) (see Sect. 3 for further details.) Snow temperature is required because the quantum yield is temperature dependent (Chu and Anastasio, 2003). As an indication of the importance of different factors in this calculation, the calculated $\mathrm{NO}_{\mathrm{x}}$ production (other factors being unchanged) will increase by around a factor of 6 between SZA of $80^{\circ}$ and $60^{\circ}$, emphasizing the potential importance of low latitude emissions. The production rate increases by around $1 \%$ per $100 \mathrm{~m}$ of altitude, and by around $25 \%$ at an ozone column of $200 \mathrm{DU}$ compared to $300 \mathrm{DU}$ (i.e. under stratospheric ozone depletion conditions). The quantum yield and production rate will about double at $273 \mathrm{~K} \mathrm{com-}$ pared to $253 \mathrm{~K}$. Of course, if the light penetration is doubled, then production rates will also double.

The largest uncertainty is caused by variability in the snow $\mathrm{NO}_{3}^{-}$concentration. The map (Fig. 8) shows our estimate of concentrations for important snow-covered regions; where we are aware of a strong seasonality in concentration we use summer values because that is when photolysis occurs.

\subsubsection{Sources of snowpack nitrate}

What do isotopic studies tell us of snowpack $\mathrm{NO}_{3}^{-}$ sources? The isotopic composition of snowpack $\mathrm{NO}_{3}^{-}$, should reveal whether photochemical loss is important in the overall budget of snowpack $\mathrm{NO}_{3}^{-}$. Freyer et al. (1996) showed that nitrogen isotope composition in Antarctic $\mathrm{NO}_{3}^{-}$ was closely related to snow accumulation rate, with lower ${ }^{15} \mathrm{~N}$ at higher accumulation sites. This result was later confirmed for Greenland ice (Hastings et al., 2005). For high accumulation sites, Hastings et al. (2004) concluded that ${ }^{15} \mathrm{~N}$ and ${ }^{18} \mathrm{O}$ of $\mathrm{NO}_{3}^{-}$are related to atmospheric sources/processes, in particular $\mathrm{NO}_{\mathrm{x}}$ oxidation chemistry, rather than post depositional effects, a result also suggested by other studies (Alexander et al., 2004; Heaton et al., 2004). For low accumulation sites such as Dome C, postdepositional processes profoundly modify the concentration and isotopic composition of snow $\mathrm{NO}_{3}^{-}$(Freyer et al., 1996; Blunier et al., 2005). Comparison with the fractionation constant obtained in laboratory photolysis experiments (Blunier et al., 2005) appears to rule out photolysis in the surface snow as the main process leading to changes in $\mathrm{NO}_{3}^{-}$isotopic composition, in agreement with calculations that found photolysis could account for up to just $40 \%$ (usually less) of observed losses of $\mathrm{NO}_{3}^{-}$from Antarctic snow (Wolff et al., 2002). It seems that photochemical production of $\mathrm{NO}_{\mathrm{x}}$ from snow $\mathrm{NO}_{3}^{-}$is more important for boundary layer chemistry than it is for the budget of $\mathrm{NO}_{3}^{-}$in polar snow and ice. Interestingly, in a recent field study combining the collection of year-round aerosols, surface snow, and snow pit samples at South Pole, McCabe et al. (2007) found strong isotopic evidence for a dominant stratospheric source of $\mathrm{NO}_{3}^{-}$in winter aerosol and surface snow, but a much stronger tropospheric signature in

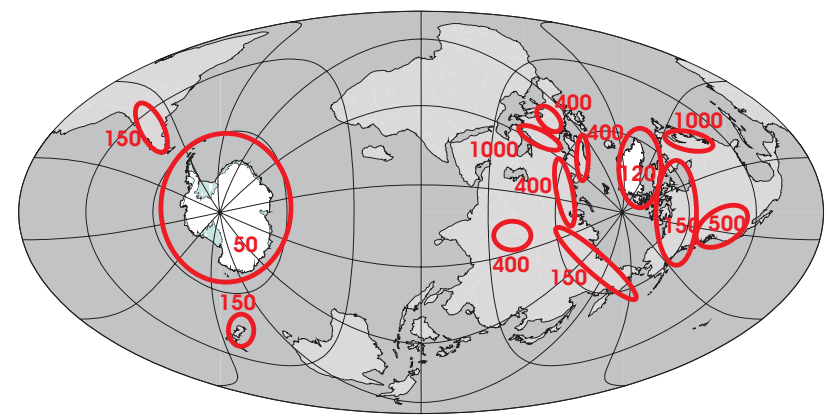

Fig. 8. Estimates of snow nitrate concentrations $\left(\mu \mathrm{g} \mathrm{kg}^{-1}\right)$ for different snow-covered regions. See original references for details. Antarctica and sea ice zone (Mulvaney and Wolff, 1994) (much higher values may be found in the very surface layer in central Antarctic (Röthlisberger et al., 2000) and in coastal regions, where sea salt and mineral aerosols efficiently scavenge nitric acid (Beine et al., 2006)); Greenland and adjacent Arctic islands (Röthlisberger et al., 2002; Koerner et al., 1999); North America: maps at National Atmospheric Deposition Program (NADP) (http: //nadp.sws.uiuc.edu/isopleths/annualmaps.asp); Alps (summer concentrations) (Preunkert et al., 2003); rest of Europe: EMEP (http: //www.nilu.no/projects/ccc/emepdata.html); Himalayas (Hou et al., 1999); other regions by analogy. The uncertainty on these values due to extrapolation from specific sites is at the very least a factor 2 , and this range has to be explored in sensitivity studies.

$\mathrm{NO}_{3}^{-}$in the snowpack. They hypothesized that photolysis of the stratospheric $\mathrm{NO}_{3}^{-}$produced $\mathrm{NO}_{\mathrm{x}}$ which reformed $\mathrm{HNO}_{3}$ (and we note would also likely produce $\mathrm{HO}_{2} \mathrm{NO}_{2}$, Slusher et al., 2002) with tropospheric ${ }^{17} \mathrm{O}$ signature and redeposited. The recycled (photochemical) $\mathrm{NO}_{3}^{-}$was suggested to dominate preserved $\mathrm{NO}_{3}^{-}$throughout the 10 -year record in the pit, with a larger fraction of recycled $\mathrm{NO}_{3}^{-}$seen in years with greater $\mathrm{O}_{3}$ depletion, hence enhanced UV flux in spring and early summer.

What do $\mathrm{NO}_{\mathrm{y}}$ budget studies tell us of snowpack $\mathrm{NO}_{3}^{-}$ sources?

Various studies have addressed the budget of $\mathrm{NO}_{\mathrm{y}}$ at high latitudes. Such studies by definition include numerous measurements, so have been conducted with varying degrees of coverage. Surface snow nitrate exhibits a summertime peak; so, if deposition occurs close to the ground (as opposed to being scavenged by snow aloft and then deposited), there should be a link to the $\mathrm{NO}_{\mathrm{y}}$ component species listed in Table 1. Uptake would be controlled both by the mixing ratio and the air/snow partitioning of the $\mathrm{NO}_{\mathrm{y}}$ constituent, as described in more detail below. There is no consistent story of any one $\mathrm{NO}_{\mathrm{y}}$ component dominating over the others across the polar regions where these measurements have been made.

Recent measurements from Halley during the CHABLIS campaign show an interesting contrast between summertime and wintertime $\mathrm{NO}_{\mathrm{y}}$ (Jones et al., 2007). During summer (December), the distribution of inorganic (68\%) vs organic 
(32\%) $\mathrm{NO}_{\mathrm{y}}$ components is quite different than during winter (July) (13\% inorganic vs $87 \%$ organic). The seasonal variation of $\mathrm{NO}_{3}^{-}$concentration in surface snow closely tracks the sum of $\left(\mathrm{HONO}+\mathrm{HNO}_{3}+\mathrm{p}-\mathrm{NO}_{3}^{-}\right)$in the air and bears no resemblance to the behavior of organic $\mathrm{NO}_{\mathrm{y}}$. Which drives what, however, is not yet fully resolved. Some light may be shed by recent observations of oxygen and nitrogen isotopic composition of inorganic aerosol nitrate $\left(\mathrm{p}-\mathrm{NO}_{3}^{-}\right.$plus a significant fraction of the inorganic acids) collected on filters (Savarino et al., 2006). Like the oxygen isotopes in $\mathrm{NO}_{3}^{-}$ at South Pole (McCabe et al., 2007) discussed earlier, these data suggest late winter deposition of $\mathrm{NO}_{3}^{-}$from polar stratospheric cloud (PSC) subsidence (in agreement with earlier work by Wagenbach et al., 1998), but a late spring concentration peak in recycled inorganic $\mathrm{NO}_{3}^{-}$species driven by snowpack emission of $\mathrm{NO}_{\mathrm{x}}$ inland (upwind).

\subsubsection{Air-ice partitioning of relevant $\mathrm{NO}_{\mathrm{y}}$ species}

Assuming photoproducts are created at the ice surface, or in the QLL at the surface, and not in a cage within the ice structure, their release to the firn air depends mainly on their affinity for the ice surface. Much of the published data refer to bulk aqueous solutions, with gas-liquid equilibria described by Henry's Law. Both $\mathrm{NO}$ and $\mathrm{NO}_{2}$ are only weakly soluble in water and interact weakly with ice (e.g. Cheung et al., 2000; Bartels-Rausch et al., 2002). It is likely that they will be lost to firn air before they undergo reaction on the ice surface or in the QLL, as discussed by Jacobi and Hilker (2007). The acidic gases, $\mathrm{HNO}_{3}$ and $\mathrm{HO}_{2} \mathrm{NO}_{2}$, and to a lesser extent HONO, have been shown to be much more strongly adsorbed on ice surfaces (Bartels-Rausch et al., 2002; Huthwelker et al., 2006), so that molecules formed in, or advected to, the firn layer can be adsorbed on ice. Partitioning of the acids between air, ice surface (and/or QLL), and ice matrix is a coupled process of adsorption and bulk diffusion, as described in more detail in the accompanying snow physics paper (Dominé et al., 2007). These processes depend strongly on the presence of other acids, since these affect whether the partitioning species is present as an acidic molecule or an ion (e.g., $\mathrm{HNO}_{3}$ or $\mathrm{NO}_{3}^{-}$). Finally we note that Henry's Law coefficients for PAN and methyl nitrate, which constitute an important part of the $\mathrm{NO}_{\mathrm{y}}$ family at some locations and times of the year, are only an order of magnitude smaller than for HONO. Some net uptake for these molecules by snow grains might therefore be expected (Ford et al., 2002; Dassau et al., 2004).

4.1.8 Fate of $\mathrm{NO}_{\mathrm{x}}$ released to snowpack interstitial air/boundary layer

The production of $\mathrm{NO}_{\mathrm{x}}$ within snowpack interstitial air has the potential to influence the chemistry of the overlying atmosphere and also concentrations of $\mathrm{NO}_{3}^{-}$(and other compounds) in surface snow and glacial ice. The extent to which this potential is realized depends on the fate of the snowpack $\mathrm{NO}_{\mathrm{x}}$. In order for $\mathrm{NO}_{\mathrm{x}}$ produced by photochemistry in snow to impact the wider troposphere, it must first escape the snowpack and then escape the near-snow boundary layer. This involves competition between vertical mixing, which is often quite weak over snow covered surfaces (e.g. Munger et al., 1999; Honrath et al., 2002; Oncley et al., 2004; Cohen et al., 2007), and reactions between $\mathrm{NO}_{\mathrm{x}}$ and $\mathrm{HO}_{\mathrm{x}}$ forming $\mathrm{HNO}_{3}$ and $\mathrm{HO}_{2} \mathrm{NO}_{2}$ which redeposit to the snow fairly rapidly. There is abundant evidence supporting significant production and rapid deposition of both acids at South Pole, with lifetimes against deposition on the order of a few hours (Chen et al., 2001; Slusher et al., 2002; Huey et al., 2004; Dibb et al., 2004). In the Arctic little is known about $\mathrm{HO}_{2} \mathrm{NO}_{2}$, but it is equally clear that a significant fraction of emitted $\mathrm{NO}_{\mathrm{x}}$ reforms $\mathrm{HNO}_{3}$ very close to the snow surface, and much of this is redeposited (Dibb et al., 1998; Munger et al., 1999; Ridley et al., 2000). Of course, any $\mathrm{HNO}_{3}$ and $\mathrm{HO}_{2} \mathrm{NO}_{2}$ deposited onto the surface can be photolyzed again, setting up a cycle. The key question is whether this cycle is closed, or leaks some of the $\mathrm{NO}_{\mathrm{x}}$ emitted by the snow to higher levels in the atmosphere (note that the $\mathrm{NO}_{\mathrm{x}}$ can be exported as $\mathrm{NO}_{\mathrm{x}}$ or any of the three acids; $\mathrm{HONO}, \mathrm{HO}_{2} \mathrm{NO}_{2}$, $\mathrm{HNO}_{3}$, with the first two being rapidly photolyzed in turn to release $\mathrm{NO}_{\mathrm{x}}$ again). It has been suggested that even if the $\mathrm{NO}_{\mathrm{x}}$ to acid to snow to $\mathrm{NO}_{\mathrm{x}}$ cycle is nearly closed, advective transport during the few hours before the acids redeposit could export $\mathrm{NO}_{\mathrm{x}}$ emitted from snow off the east Antarctic plateau in the drainage flow (Davis et al., 2006).

Honrath et al. (2002) found that upward fluxes of $\mathrm{NO}_{\mathrm{x}}$ plus $\mathrm{HONO}$ were larger than the downward fluxes of $\mathrm{HNO}_{3}$ at Summit during summer 2000, suggesting that there is net export of $\mathrm{NO}_{\mathrm{x}}$ emitted by snow to the free troposphere over Greenland. On the other hand, investigation of the $\mathrm{N}$ and $\mathrm{O}$ isotopes of $\mathrm{NO}_{3}^{-}$in snow at Summit found diurnal variations consistent with daytime losses due to photolysis, but redeposition of $\mathrm{NO}_{3}^{-}\left(\right.$as $\left.\mathrm{HNO}_{3}\right)$ at night restored the isotopic ratios (Hastings et al., 2004). Over seasonal and annual timescales the net impact of snow photochemistry on the isotopic composition of $\mathrm{NO}_{3}^{-}$at Summit was negligible, suggesting that the cycling described above has to be nearly closed. At South Pole it appears quite certain that $\mathrm{NO}_{\mathrm{x}}$ from the snow causes enhanced $\mathrm{O}_{3}$ production in the lower several hundred meters of the atmosphere (Crawford et al., 2001; Helmig et al., 2007a), suggesting that there has to be some loss of $\mathrm{NO}_{\mathrm{x}}$ upward out of the boundary layer. In contrast to the Greenland results, isotopic studies in the Antarctic show that post depositional effects strongly influence the isotopic signature of the remaining snow nitrate (Blunier et al., 2005; McCabe et al. 2007) as well as the isotopic composition of the filterable $\mathrm{NO}_{3}^{-}$collected at coastal sites (Wagenbach et al., 1998; Savarino et al., 2006). Observed $\mathrm{O}$ and $\mathrm{N}$ isotopic fractionations provide strong support for extensive recycling, and appear to be compatible with export of snowpack $\mathrm{NO}_{\mathrm{x}}$ from the central plateau to coastal sites. 
Table 1. Summary of boundary layer $\mathrm{NO}_{\mathrm{y}}$ component measurements made during various summertime campaigns (and spring at NyÅlesund).

\begin{tabular}{|c|c|c|c|c|c|c|c|}
\hline & $\begin{array}{l}\text { South Pole } \\
\text { (Field studies in 1998, } \\
\text { 2000, 2003) } \\
\text { Davis et al. 2001, 2004, } 2007 \\
\text { Huey et al. 2004 } \\
\text { Slusher et al. 2002 } \\
\text { Liao et al. 2006 } \\
\text { Arimoto et al. 2001, 2004, } 2007 \\
\text { Dibb et al. 2004, } \\
\text { Roberts et al., } \\
\text { (personal communication, 2007) } \\
\text { Swanson et al. 2004 }\end{array}$ & $\begin{array}{l}\text { Neumayer } 1997 \\
\text { (Jones et al., 1999) }\end{array}$ & $\begin{array}{l}\text { Neumayer } 1999 \\
\text { (Jacobi et al., 2000) }\end{array}$ & $\begin{array}{l}\text { Halley } \\
\text { Dec } 2005 \\
\text { (Jones et al., 2007) }\end{array}$ & $\begin{array}{l}\text { Summit } \\
1998 \\
\text { (Honrath et al., 1999;) } \\
\text { (Ford et al., 2002) } \\
\text { (Dibb, personal } \\
\text { communication) }\end{array}$ & $\begin{array}{l}\text { Summit } \\
1999 \\
\text { (Dibb et al., 2002;) } \\
\text { (Ford et al., 2002;) } \\
\text { (Yang et al., 2002) }\end{array}$ & $\begin{array}{l}\text { Ny-Ålesund } \\
1997 / 98 \\
\text { (Beine et al., 2001) }\end{array}$ \\
\hline $\mathrm{NO}$ & $143 \pm 128$ & $\begin{array}{l}3 \pm 5 \\
(2)\end{array}$ & $\begin{array}{l}1.2 \pm 2.2 \\
\text { (1) }\end{array}$ & $\begin{array}{l}5.3 \pm 0.5 \\
(5.0)\end{array}$ & & $\begin{array}{l}24.7 \\
{[8.3 \rightarrow 0.8]}\end{array}$ & $\sim 3.0$ \\
\hline $\mathrm{NO}_{2}$ & & $3.2 \pm 3.7$ & $2.9 \pm 0.4$ & (2.8) & $(3.0)$ & $\begin{array}{l}32.7 \\
{[7.9 \rightarrow 55.4]}\end{array}$ & 19.53 \\
\hline $\mathrm{NO}_{\mathrm{x}}$ & & & & $\begin{array}{l}8.3 \pm 0.8 \\
(8.2)\end{array}$ & $\begin{array}{l}36.2 \pm 13.6 \\
(31.6)\end{array}$ & $\begin{array}{l}38.5 \pm 16.8 \\
(33.3)\end{array}$ & \\
\hline HONO & $5.3 \pm 2.5^{\mathrm{a}}$ & $30 \pm 4^{\mathrm{b}}$ & & $5.3 \pm 0.1$ & $\begin{array}{l}42.7 \pm 16.7 \\
(42.1)\end{array}$ & $\begin{array}{l}7.0 \pm 13.1 \\
(4)\end{array}$ & 8.43 \\
\hline $\mathrm{HO}_{2} \mathrm{NO}_{2}$ & $39 \pm 1$ & & & & & & \\
\hline $\mathrm{HNO}_{3}$ & $\begin{array}{l}86 \pm 78^{c} \\
23 \pm 5^{b}\end{array}$ & $\begin{array}{l}5 \pm 2 \\
(5)\end{array}$ & $\begin{array}{l}4.0 \pm 2.0 \\
(3.6)\end{array}$ & $5.7 \pm 0.2$ & $\begin{array}{l}44.3 \pm 59.8 \\
(9.4)\end{array}$ & $\begin{array}{l}16.9 \pm 24.4 \\
(7.4)\end{array}$ & 8.74 \\
\hline $\mathrm{p}-\mathrm{NO}_{3}^{-}$ & $95 \pm 60 \mathrm{ng} / \mathrm{m}^{3}$ & $\begin{array}{l}4 \pm 3 \\
(4)\end{array}$ & $\begin{array}{l}4.2 \pm 2.4 \\
(3.8)\end{array}$ & $3.1 \pm 0.2$ & & & 15.56 \\
\hline PAN & $15.5 \pm 4.3^{\mathrm{d}}$ & & $\begin{array}{l}13.1 \pm 7.3 \\
(11.5)\end{array}$ & $7.2 \pm 0.3$ & $\begin{array}{l}52.9 \pm 18.2 \\
(51.9)\end{array}$ & $\begin{array}{l}73 \pm 25 \\
(70.9)\end{array}$ & $\begin{array}{l}53.35 \\
\text { (includes } \mathrm{RONO}_{2} \text { ) }\end{array}$ \\
\hline $\mathrm{MeONO}_{2}$ & $6 \pm 4^{e}$ & $10 \pm 2^{\mathrm{f}}$ & $9.5 \pm 1.4$ & $4.4 \pm 0.1$ & $6.1 \pm 2.0$ & & \\
\hline $\begin{array}{l}\mathrm{EtONO}_{2} \\
\text { 1-PrONO} \\
\text { 2-PrONO} \\
2\end{array}$ & $1.5 \pm 1$ & $3 \pm 1^{\mathrm{f}}$ & $\begin{array}{l}2.3 \pm 0.5 \\
1.1 \pm 0.8 \\
1.2 \pm 0.5\end{array}$ & $\begin{array}{l}1.0 \pm 0.1 \\
0.1 \pm 0.01 \\
0.4 \pm 0.06\end{array}$ & $\begin{array}{l}7.6 \pm 2.3 \\
1.7 \pm 0.7 \\
5.5 \pm 2.0\end{array}$ & & \\
\hline
\end{tabular}

Data are expressed as mean $\pm \mathrm{SD}$, (median) or [range] unless stated otherwise. All data are expressed in parts per trillion by volume (pptv). ${ }^{\mathrm{a}}$ Laser Induced Fluorescence

${ }^{b}$ Mist Chamber

${ }^{\mathrm{c} C h e m i c a l ~ I o n i z a t i o n ~ M a s s ~ S p e c t r o m e t r y ~}$

${ }^{\mathrm{d}} \mathrm{GC}$

${ }^{\mathrm{e}} \mathrm{Grab}$ samples/ GC analyses

${ }^{\mathrm{f}}$ These data are revised estimates of 1997 measurements following a re-calibration that showed the original data were overestimated by a factor 3 (Weller et al., 2002).

\subsection{Oxidants}

\subsubsection{Expectations in the absence of snow-atmosphere fluxes}

In the troposphere the most important oxidant is the hydroxyl radical $(\mathrm{OH})$. The main source of $\mathrm{OH}$ is the reaction of $\mathrm{O}\left({ }^{1} \mathrm{D}\right)$ $+\mathrm{H}_{2} \mathrm{O}$, with photolysis of $\mathrm{O}_{3}$ producing $\mathrm{O}\left({ }^{1} \mathrm{D}\right)$. As noted in Sect. 2, the global distribution of UV-B radiation results in greatly reduced rates of $\mathrm{O}_{3}$ photolysis at high latitudes compared to the tropics. Combining this with a similarly steep gradient in the abundance of water vapor between the tropics and polar regions leads to the expectation that the production and abundance of $\mathrm{OH}$ in the remote troposphere should be greatest in the tropics and least in the polar regions

This view was consistent with the first Antarctic OH observations conducted during late February 1994 on the coast at Palmer Station (on Anvers Island off the Antarctic Peninsula) as part of the Sulfur Chemistry in the Antarctic Troposphere Experiment (SCATE) (Berresheim and Eisele, 1998).
Using the selected ion chemical ionization mass spectrometry (SICIMS) technique, $24 \mathrm{~h}$ and daytime average values for $\mathrm{OH}$ were $1.1 \times 10^{5}$ and $3.0 \times 10^{5}$ molecule $\mathrm{cm}^{-3}$, respectively (Jefferson et al., 1998). These very low values were attributed to the high average solar zenith angle, extensive cloud cover, and low levels of NO (1-5 pptv). Comparison with models was hampered by uncertainty in the levels of $\mathrm{NO}$, which were below or similar to the instrumental detection limit of 5 pptv. However, by assuming NO levels near this detection limit, modeled and observed $\mathrm{OH}$ agreed to within $\sim 30 \%$, with $\mathrm{OH}$ production dominated by the reaction $\mathrm{O}\left({ }^{1} \mathrm{D}\right)+\mathrm{H}_{2} \mathrm{O}$, and loss dominated by reaction with $\mathrm{CO}$ and $\mathrm{CH}_{4}$. The results are those expected for an unperturbed remote pristine environment at high latitudes, and can be used as a base case in the absence of snowpack emissions.

\subsubsection{Recent findings at snow-covered sites: South Pole}

Surprisingly, average $\mathrm{OH}$ values of $2 \times 10^{6}$ molecule $\mathrm{cm}^{-3}$ were measured at South Pole (November-December 1998) 
Table 2. Mean values of selected parameters measured at South Pole during the 3 recent photochemistry campaigns.

\begin{tabular}{|c|c|c|c|c|c|c|}
\hline & ISCAT 98 & & ISCAT 00 & & ANTCI 03 & \\
\hline Parameter & NOV & DEC & NOV & DEC & NOV & DEC \\
\hline $2 \mathrm{~m} \mathrm{Temp}{ }^{\circ} \mathrm{C}$ & $-31.4 \pm 4.6$ & $-29.0 \pm 2.1$ & $-29.8 \pm 2.7$ & $-27.4 \pm 1.5$ & $-34.5 \pm 5.0$ & $-24.1 \pm 2.1$ \\
\hline Dewpoint ${ }^{\circ} \mathrm{C}$ & $-34.5 \pm 4.9$ & $-31.9 \pm 2.1$ & $-33.3 \pm 2.9$ & $-30.8 \pm 1.6$ & $-38.0 \pm 4.9$ & $-26.7 \pm 2.2$ \\
\hline $\mathrm{W}_{\text {Speed } \mathrm{m} \mathrm{s}^{-1}}$ & $6.3 \pm 2.4$ & $3.5 \pm 1.2$ & $6.1 \pm 1.8$ & $4.2 \pm 1.6$ & $4.9 \pm 1.3$ & $5.2 \pm 2.0$ \\
\hline Total $\mathrm{O}_{3} \mathrm{DU}$ & $174 \pm 24$ & $264 \pm 19$ & $282 \pm 23$ & $301 \pm 16$ & $230 \pm 25$ & $287 \pm 23$ \\
\hline $\mathrm{J}\left(\mathrm{O}^{1} \mathrm{D}\right) 10^{-6} \mathrm{~s}^{-1}$ & & $8.6 \pm 1.3$ & $5.8 \pm 1.8$ & $7.6 \pm 1.2$ & $12.2 \pm 2.2$ & $11.5 \pm 1.9$ \\
\hline $\mathrm{J}\left(\mathrm{NO}_{2}\right) 10^{-2} \mathrm{~s}^{-1}$ & & $0.95 \pm 0.01$ & $0.87 \pm 0.15$ & $1.03 \pm 0.12$ & $1.1 \pm 0.1$ & $1.2 \pm 0.1$ \\
\hline NO pptv & $171 \pm 27$ & $239 \pm 110$ & $99 \pm 39$ & $97 \pm 81$ & $441 \pm 225$ & $143 \pm 128$ \\
\hline $\mathrm{O}_{3} \mathrm{ppbv}$ & $35 \pm 5$ & $30 \pm 7$ & $32 \pm 3$ & $32 \pm 6$ & $33 \pm 3$ & $33 \pm 6$ \\
\hline CO ppbv & $45 \pm 3$ & $37 \pm 3$ & $40 \pm 2$ & $35 \pm 3$ & $47 \pm 1$ & $49 \pm 6$ \\
\hline $\mathrm{C}_{2} \mathrm{H}_{6}$ pptv & $485 \pm 116$ & $393 \pm 173$ & $213 \pm 10$ & $156 \pm 26$ & $200 \pm 11$ & $171 \pm 20$ \\
\hline $\mathrm{CH}_{2} \mathrm{O}$ pptv & & & & $103 \pm 33$ & & $71 \pm 24$ \\
\hline $\mathrm{H}_{2} \mathrm{O}_{2}$ pptv & & & & $268 \pm 111$ & & $278 \pm 67$ \\
\hline $\mathrm{OH} 10^{6}$ molecule $\mathrm{cm}^{-3}$ & & $1.8 \pm 0.9$ & $2.5 \pm 0.6$ & $2.4 \pm 1.0$ & $1.5 \pm 0.6$ & $1.7 \pm 0.9$ \\
\hline $\mathrm{HO}_{2}+\mathrm{RO}_{2} 10^{7}$ molecule $\mathrm{cm}^{-3}$ & & & & $8.3 \pm 2.4$ & & \\
\hline HONO (MC) pptv & & & & $27 \pm 3$ & $72 \pm 21$ & $30 \pm 4$ \\
\hline HONO (LIF) pptv & & & & $32 \pm 11$ & $7.4 \pm 4.2$ & $5.3 \pm 2.5$ \\
\hline $\mathrm{HNO}_{3}(\mathrm{MC}) \mathrm{pptv}$ & & & & $24 \pm 11$ & $42 \pm 15$ & $23 \pm 5$ \\
\hline $\mathrm{HNO}_{3}$ (CIMS) pptv & & & & $19 \pm 11$ & $107 \pm 53$ & $86 \pm 78$ \\
\hline $\mathrm{HO}_{2} \mathrm{NO}_{2} \mathrm{pptv}$ & & & & $23 \pm 11$ & $47 \pm 10$ & $39 \pm 1$ \\
\hline
\end{tabular}

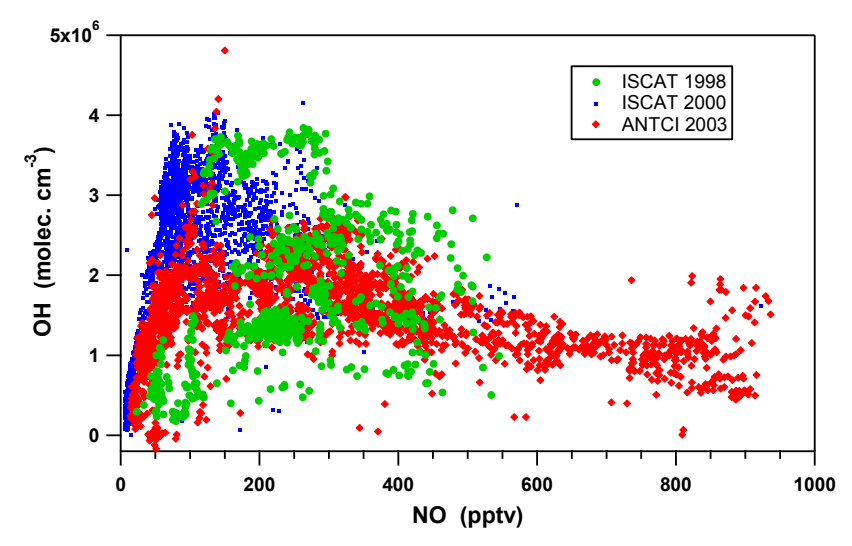

Fig. 9. $\mathrm{OH}$ versus $\mathrm{NO}$ at South Pole.

during the Investigation of Sulfur Chemistry in the Antarctic Troposphere (ISCAT) campaign (Mauldin et al., 2001). More than an order of magnitude greater than SCATE observations, and equivalent to tropical values, the high $\mathrm{OH}$ levels at South Pole mostly result from unexpectedly high NO levels, leading to an intensely oxidizing environment. Diurnal average values for key photolysis frequencies were comparable to equatorial values due to the high albedo $(\sim 0.8)$ and $24 \mathrm{~h}$ sunlight conditions (Lefer et al., 2001). In fact, $24 \mathrm{~h}$ average values for $\mathrm{J}\left(\mathrm{NO}_{2}\right)\left(1.1 \times 10^{-2} \mathrm{~s}^{-1}\right)$ were 3 times greater than for equatorial conditions while $\mathrm{J}\left(\mathrm{O}\left({ }^{1} \mathrm{D}\right)\right)$ $\left(9.0 \times 10^{-6} \mathrm{~s}^{-1}\right)$ was roughly equivalent. Given the dry conditions at South Pole, which reduce the conversion efficiency of $\mathrm{O}\left({ }^{1} \mathrm{D}\right)$ from $\mathrm{O}_{3}$ photolysis into $\mathrm{OH}$, primary production from $\mathrm{O}_{3}$ photolysis could not explain the observed $\mathrm{OH}$, but ambient NO levels of 225 pptv (median) ranging as high as
$600 \mathrm{pptv}$, provided a strong secondary source of $\mathrm{OH}$ (Chen et al., 2001), via the reaction $\mathrm{HO}_{2}+\mathrm{NO} \rightarrow \mathrm{OH}+\mathrm{NO}_{2}$.

Elevated $\mathrm{OH}$ and $\mathrm{NO}$ were again observed during the ISCAT 2000 and ANTCI 2003 campaigns, which also occurred in November and December. Measurements from these three field campaigns yield an overall average $\mathrm{OH}$ of $2.0( \pm 0.9) \times 10^{6}$ molecule $\mathrm{cm}^{-3}$ and a median of $1.9 \times 10^{6}$ molecule $\mathrm{cm}^{-3}$ (Mauldin et al., 2001, 2004) (Table 2). The average NO mixing ratio is $187( \pm 175)$ pptv and the median value is 122 pptv. While NO values have varied considerably between years (Table 2, Fig. 5), periods with NO levels of several hundred pptv were observed in all years. Average $\mathrm{HO}_{2}+\mathrm{RO}_{2}$ concentrations measured during more limited periods in 2000 were $8.3( \pm 2.4) \times 10^{7}$ molecule $\mathrm{cm}^{-3}$, with a median of $8.1 \times 10^{7}$ molecule $\mathrm{cm}^{-3}$.

Figure 9 displays the relationship between observed $\mathrm{OH}$ and NO for all South Pole observations. Peaks in observed $\mathrm{OH}$ occur between 70 and $300 \mathrm{pptv}$ of NO. These peak $\mathrm{OH}$ values, however, vary by a factor of 3 . A similar $\mathrm{OH}$ dependence on NO was also seen in the first modeling study of ISCAT 1998 data by Chen et al. (2001). The rapid increase in $\mathrm{OH}$ with increasing $\mathrm{NO}$ levels on the left of the peak is due to increasing $\mathrm{HO}_{2}$ to $\mathrm{OH}$ conversion by $\mathrm{NO}$, shifting the $\mathrm{HO}_{\mathrm{x}}$ partitioning in favor of $\mathrm{OH}$. Some contribution also comes from enhanced $\mathrm{HO}_{\mathrm{x}}$ production from $\mathrm{CH}_{4}$ oxidation. The reduction in $\mathrm{OH}$ concentration with increasingly high NO levels beyond the peak can mainly be attributed to $\mathrm{HO}_{\mathrm{x}}$ loss via formation of $\mathrm{HNO}_{3}$ and $\mathrm{HO}_{2} \mathrm{NO}_{2}$ followed by deposition onto the snow surface. While models including only gas phase chemistry underpredict observed $\mathrm{OH}$, inclusion of $\mathrm{HO}_{\mathrm{x}}$ precursors emitted from the snow during ISCAT 2000 improved model predictions and confirmed that snow 
emissions of $\mathrm{H}_{2} \mathrm{O}_{2}$ and $\mathrm{CH}_{2} \mathrm{O}$ are the dominant $\mathrm{HO}_{\mathrm{x}}$ source at South Pole (Chen et al., 2004; Hutterli et al., 2004). Mist chamber measurements of HONO ( $\sim 30$ pptv average) (Dibb et al., 2004), another important $\mathrm{HO}_{\mathrm{x}}$ precursor emitted from the snow, were less encouraging. When these HONO measurements were used in model calculations, predicted values of boundary layer $\mathrm{OH}$ were 2-5 times greater than observations. These HONO results were also incompatible with ambient $\mathrm{NO}_{\mathrm{x}}$ concentrations given the abundance and very short lifetime of HONO (Chen et al., 2004). As for other polar sites, measurements of $\mathrm{HONO}$ are difficult to reconcile with photochemical observations of $\mathrm{HO}_{\mathrm{x}}$ and $\mathrm{NO}_{\mathrm{x}}$, raising questions about the specificity of the mist chamber measurements (Sjostedt et al., 2005).

Two important and observable consequences result from the intense photochemistry at South Pole. One is the potential for large $\mathrm{O}_{3}$ production rates. Modeling studies of ISCAT 1998 and 2000 showed a net production of $\sim 3-4$ ppbv/day. These prompted a reevaluation of historical ozone observations both at the surface and from ozonesondes at South Pole which revealed strong evidence for a surface source of ozone during Austral spring/summer (Crawford et al., 2001; Oltmans et al., 2007). Tethered balloon observations during ANTCI 2003 provided the strongest evidence yet for nearsurface ozone production with frequent observations of enhanced ozone (20-25 ppbv) over depths of 200+ m (Helmig et al., 2007a). $\mathrm{O}_{3}$ measurements during the US ITASE traverse between Byrd and South Pole in summer 2002/03 showed up to 2-fold increases of near-surface mixing ratios at sampling locations above $2000 \mathrm{~m}$ elevation and indicated that enhanced $\mathrm{O}_{3}$ production is spatially limited to the Antarctic plateau region (Frey et al., 2005). However, ozone can be transported long distances and analysis of surface ozone data from six Antarctic stations gave indications that sites on the exterior of the Antarctic continent are, at least occasionally, influenced by transport of ozone-enriched air from the interior of Antarctica (Helmig et al., 2007b). A consequence is the hypothesized presence of an oxidizing canopy of $\mathrm{OH}$ enshrouding the Antarctic plateau (Davis et al., 2004). Observations of $\mathrm{NO}$ and $\mathrm{NO}_{\mathrm{y}}$ from a Twin Otter aircraft during ANTCI 2003 revealed elevated NO over depths of $500 \mathrm{~m}$ and distances of $400 \mathrm{~km}$ from South Pole, thus, similar to the conclusions derived from the ozone observations by Frey et al. (2005) demonstrating that the photochemical conditions at South Pole may extend across a large portion of the Antarctic plateau.
4.2.3 Recent findings at snow-covered sites: Halley, Antarctica

The Chemistry of the Antarctic Boundary Layer and the Interaction with Snow (CHABLIS) field campaign took place on the floating Brunt Ice Shelf at Halley and consisted of a year-round study (January 2004-February 2005) and a summer intensive (January-February 2005) (Jones et al., 2005). CHABLIS was the first intensive chemistry field campaign above the snowpack in coastal Antarctica. At the time of writing the work is very recent, with final analysis and modeling still in progress, hence our discussion is brief and qualitative, with most references from published conference proceedings. Peak (daily maxima) $\mathrm{OH}$ and $\mathrm{HO}_{2}$ concentrations (measured using laser-induced fluorescence, Heard and Pilling, 2003) varied between $0.9-3.0 \times 10^{6}$ and 2.5-9.3 $\times 10^{7}$ molecule $\mathrm{cm}^{-3}$ (1-4 ppt), respectively (Bloss et al., 2007). The concentrations of both species declined as the campaign progressed. Despite being at higher latitude, the peak $\mathrm{OH}$ concentrations for Halley are considerably higher $(\sim 3-$ 4 times) than observed during SCATE at the Palmer station at a similar time (February) (Jefferson et al., 1998), but are lower than observed at South Pole (in November/December). Airmass back trajectories indicated flow mainly from the Antarctic continent, although on occasion the origin was the Southern Ocean. The site experienced $24 \mathrm{~h}$ daylight during the intensive period, however $\mathrm{J}\left(\mathrm{O}^{1} \mathrm{D}\right)$ was a factor of $40-$ 50 lower during the "night" compared with the maximum at solar noon. The diurnal profiles for both $\mathrm{OH}$ and $\mathrm{HO}_{2}$ are highly distinct, following closely, but not exactly, that of $\mathrm{J}\left(\mathrm{O}^{1} \mathrm{D}\right)$. "Night-time" $\mathrm{OH}$ was observed above the detection limit $\left(1.5 \times 10^{5}\right.$ molecule $\left.\mathrm{cm}^{-3}\right)$ on several occasions, in the range $<1.5-2 \times 10^{5}$ molecule $\mathrm{cm}^{-3}$, and $\mathrm{HO}_{2}$ was always seen "at night" in the range $0.2-1.3 \times 10^{7}$ molecule $\mathrm{cm}^{-3}$. For the period $2 \mathrm{~h}$ either side of local noon, the ratio $\left[\mathrm{HO}_{2}\right] /[\mathrm{OH}]$ was in the range $32-138$, and for the entire campaign the average $24 \mathrm{~h} \mathrm{OH}$ and $\mathrm{HO}_{2}$ concentrations were $3.9 \times 10^{5}$ and $2.0 \times 10^{7}$ molecule $\mathrm{cm}^{-3}$, respectively.

The modeling phase of CHABLIS is at an early stage, and thus we will only discuss here the general factors that control $\mathrm{HO}_{\mathrm{x}}$ at Halley to contrast with other Antarctic regions such as South Pole. Typical noon-time concentrations of some of the sources and sinks of $\mathrm{HO}_{\mathrm{x}}$ observed during the summer CHABLIS intensive are $\mathrm{O}_{3}(10-15 \mathrm{ppbv}), \mathrm{NO}_{\mathrm{x}}(5-25 \mathrm{pptv})$, $\mathrm{CO}$ (35-40 ppbv), and $\mathrm{CH}_{2} \mathrm{O}$ (130 pptv). The $\mathrm{NO}_{\mathrm{x}}$ levels are considerably higher than at Palmer station (Jefferson et al.,1998) because of snowpack emissions initiated via nitrate ion photolysis (Sect. 4.1), but considerably lower than observed at South Pole due in part to the much deeper boundary layer at Halley. Assuming photolysis of ozone was the only $\mathrm{OH}$ source, and reaction with $\mathrm{CO}$ and $\mathrm{CH}_{4}$ its only sinks, calculated $\mathrm{OH}$ was significantly less than the measured value, even when the upwelling component of actinic flux (with a snow albedo of 0.85 ) was added to $\mathrm{J}\left(\mathrm{O}^{1} \mathrm{D}\right)$. This discrepancy suggests other sources of $\mathrm{OH}$ are required, which 
Table 3. Median noontime (10:00-15:00 Western Greenland Standard Time) boundary layer values from Summit 2003 and 2004 campaigns.

\begin{tabular}{|c|c|c|c|}
\hline Species & $\begin{array}{l}\text { Early Spring } 2004 \\
1-10 \text { April } 2004\end{array}$ & $\begin{array}{l}\text { Late Spring } 2004 \\
20-30 \text { April } 2004\end{array}$ & $\begin{array}{l}\text { Summer } 2003 \\
10-30 \text { July } 2003\end{array}$ \\
\hline meas. $\mathrm{HO}_{2}+\mathrm{RO}_{2}$ molecule $\mathrm{cm}^{-3}$ & $6.0 \times 10^{7}$ & $1.9 \times 10^{8}$ & $4.1 \times 10^{8}$ \\
\hline pred. $\mathrm{HO}_{2}+\mathrm{RO}_{2}^{\mathrm{a}}$ molecule $\mathrm{cm}^{-3}$ & $6.3 \times 10^{7}$ & $2.0 \times 10^{8}$ & $4.4 \times 10^{8}$ \\
\hline measured $\mathrm{OH}$ molecule $\mathrm{cm}^{-3}$ & $4.1 \times 10^{5}$ & $1.9 \times 10^{6}$ & $8.4 \times 10^{6}$ \\
\hline predicted $\mathrm{OH}^{\mathrm{a}}$ molecule $\mathrm{cm}^{-3}$ & $4.0 \times 10^{5}$ & $1.5 \times 10^{6}$ & $3.8 \times 10^{6}$ \\
\hline NO (pptv) & 18 & 19 & 18 \\
\hline $\mathrm{NO}_{2}^{b}(\mathrm{pptv})$ & 14 & 18 & 23 \\
\hline $\mathrm{H}_{2} \mathrm{O}_{2}$ (pptv) & 191 & 622 & 1800 \\
\hline $\mathrm{CH}_{2} \mathrm{O}$ (pptv) & 45 & 111 & 181 \\
\hline HONO (pptv) & 6 & 13 & 13 \\
\hline
\end{tabular}

${ }^{a}$ Denotes predictions from a photochemical model constrained to measured parameters $\left(\mathrm{NO}, \mathrm{O}_{3}, \mathrm{H}_{2} \mathrm{O}_{2}\right.$, $\mathrm{CH}_{2} \mathrm{O}$, j values, etc.) except for nitrous acid.

${ }^{\mathrm{b}} \mathrm{NO}_{2}$ levels were calculated assuming steady state constrained to measured values of $\mathrm{NO}, \mathrm{O}_{3}$, photolysis frequencies, and peroxy radicals.

may include photolysis of snowpack emissions (e.g. HONO, $\mathrm{H}_{2} \mathrm{O}_{2}$ and $\mathrm{CH}_{2} \mathrm{O}$ ), $\mathrm{HO}_{2}+\mathrm{NO}$ reaction, or halogen processes (see Sect. 4.3).

\subsubsection{Recent findings at snow-covered sites: Summit, Greenland}

Snowpack emissions of $\mathrm{CH}_{2} \mathrm{O}, \mathrm{H}_{2} \mathrm{O}_{2}$, and $\mathrm{HONO}$ (Dibb et al., 1998, 2002; Honrath et al., 1999; 2002; Hutterli et al., 1999, 2001; Jacobi et al., 2002; Yang et al., 2002) at Summit, Greenland are expected to enhance $\mathrm{HO}_{x}$ levels at this site. In order to directly test the impact of snow emissions on photochemistry at Summit, campaigns were carried out in summer 2003 (July) and spring 2004 (April). Median noontime values of selected parameters are reported for summer, and early and late spring in Table 3 along with predicted values of $\mathrm{OH}$ and $\mathrm{HO}_{2}+\mathrm{RO}_{2}$ obtained from highly constrained photochemical models (Sjostedt et al., 2007).

During the summer 2003 campaign, high levels of $\mathrm{OH}$ were routinely observed $\left(\sim 1 \times 10^{7}\right.$ molecule $\left.\mathrm{cm}^{-3}\right)$. These levels were more than a factor of two higher than model predictions constrained to a full set of photochemical precursors. Typical $\mathrm{HO}_{\mathrm{x}}$ measurement uncertainties of $40 \%$ are reported, so it is unlikely that the disparity is due to measurement error. Conversely, levels of $\mathrm{HO}_{2}+\mathrm{RO}_{2}$ were found to be in excellent agreement with predictions, indicating that peroxy radical sources and sinks were well understood but that the ratio of $\left(\mathrm{RO}_{2}+\mathrm{HO}_{2}\right)$ to $\mathrm{OH}$ was perturbed. The $\mathrm{HO}_{\mathrm{x}}$ source for this campaign was found to be dominated by photolysis of $\mathrm{O}_{3}$ and snow-emitted $\mathrm{H}_{2} \mathrm{O}_{2}$ with smaller contributions from $\mathrm{HONO}$ and $\mathrm{CH}_{2} \mathrm{O}$ (Chen et al., 2007). The perturbation to the ratio of $\left(\mathrm{RO}_{2}+\mathrm{HO}_{2}\right)$ to $\mathrm{OH}$ was particularly enhanced during an extended period of high winds and blowing snow. Large increases in $\mathrm{OH}$ and smaller relative decreases in $\left(\mathrm{RO}_{2}\right.$ $+\mathrm{HO}_{2}$ ) characterized these windy periods. Retroplume anal- ysis for this period indicated that marine boundary layer air was rapidly transported (1-2 days) to Summit, suggesting that halogen chemistry can influence observed chemical conditions (Sjostedt et al., 2007). This point is further discussed in Sect. 4.3 below.

The spring 2004 campaign offered an opportunity to observe $\mathrm{HO}_{\mathrm{x}}$ chemistry during a period of rapidly increasing temperatures and photolysis frequencies (Sjostedt et al., 2005). $\mathrm{OH}$ and $\mathrm{HO}_{2}+\mathrm{RO}_{2}$ levels were observed to increase by approximately a factor of five during the month of April. The observations of $\mathrm{OH}$ and $\mathrm{HO}_{2}+\mathrm{RO}_{2}$ were both found to be in poor agreement with model predictions constrained to all relevant observations (i.e. $\mathrm{NO}, \mathrm{CO}$, J values, dewpoint, $\mathrm{O}_{3}, \mathrm{H}_{2} \mathrm{O}_{2}, \mathrm{CH}_{2} \mathrm{O}, \mathrm{HONO}$, etc.). This disagreement was largest early in the campaign when temperatures were the lowest. Conversely, $\mathrm{HO}_{2}+\mathrm{RO}_{2}$ was in excellent agreement with model predictions constrained to all relevant observations except for HONO. These results strongly suggest that the measured levels of soluble nitrite $\left(\mathrm{NO}_{2}^{-}\right)$can not be simply interpreted as gas phase HONO, a conclusion already drawn during ISCAT/ANTCI South Pole campaigns (Chen et al., 2004). For this reason, the spring $\mathrm{HO}_{\mathrm{x}}$ budget was analyzed assuming $\mathrm{HONO}$ was not a significant radical source. This analysis showed that photolysis of $\mathrm{H}_{2} \mathrm{O}_{2}$ and $\mathrm{CH}_{2} \mathrm{O}$ emitted from the snow dominated the radical source early in the spring with $\mathrm{O}_{3}$ photolysis becoming dominant by the end of the campaign. Low ratios of $\mathrm{HO}_{2}+\mathrm{RO}_{2}$ to $\mathrm{OH}$ were also observed in the spring during periods of high winds and blowing snow. Similar to summer 2003 these periods coincided with transport of marine boundary layer air to Summit.

\subsubsection{Model estimates not validated by $\mathrm{HO}_{\mathrm{x}}$ measurements}

As noted above, the high levels of $\mathrm{HO}_{\mathrm{x}}$ observed at Summit in summer 2003 were expected, based on earlier 
measurements of major precursors. Yang et al. (2002) used a photostationary state point model to estimate $\mathrm{HO}_{\mathrm{x}}$ for the conditions of the 1999 and 2000 Summit campaigns. Interestingly, estimated $\mathrm{OH}$ for summer 1999 was very similar to that observed in 2003. However, estimated $\left(\mathrm{HO}_{2}+\mathrm{RO}_{2}\right)$ values for 1999 were more than 2-fold higher than the $2003 \mathrm{ob}$ servations. Yang et al. (2002) suggested that the $\mathrm{HO}_{\mathrm{x}}$ source from the photolysis of $\mathrm{HONO}, \mathrm{CH}_{2} \mathrm{O}$ and $\mathrm{H}_{2} \mathrm{O}_{2}$ combined was 2-3 times stronger than that from $\mathrm{O}_{3}$ photolysis, in contrast to 2003 where $\mathrm{O}_{3}$ was found to be the dominant precursor followed closely by $\mathrm{H}_{2} \mathrm{O}_{2}$ with only minor production from $\mathrm{CH}_{2} \mathrm{O}$ and HONO (Chen et al., 2007).

At Alert, significant concentrations of $\mathrm{HONO}$ and $\mathrm{CH}_{2} \mathrm{O}$ have been measured, with emissions of both compounds occurring from sunlit snowpack (Zhou et al., 2001; Sumner et al., 2002). Using both snow manipulation experiments and ambient air measurements, Zhou et al. (2001) found that a significant photochemical snowpack source exists for $\mathrm{HONO}$, at times making it the dominant $\mathrm{OH}$ source in the boundary layer, implying a much greater role for $\mathrm{OH}$ in Arctic springtime chemistry than previously believed. Modeling results of Grannas et al. (2002) simulate upwards of $1 \times 10^{6}$ molecule $\mathrm{cm}^{-3} \mathrm{OH}$ at Alert at springtime solar noon under typical atmospheric conditions and $7 \times 10^{5}$ molecule $\mathrm{cm}^{-3}$ during ozone depletion events when halogen chemistry is active. In both cases, HONO was hypothesized to be the dominant $\mathrm{OH}$ source, followed by $\mathrm{CH}_{2} \mathrm{O}$ photolysis. $\mathrm{HO}_{\mathrm{x}}$ removal was dominated by formation of $\mathrm{HO}_{2} \mathrm{NO}_{2}$ and $\mathrm{HNO}_{3}$ (81\% and $8 \%$ ) during typical ambient conditions and by $\mathrm{HO}_{2} \mathrm{NO}_{2}$ and $\mathrm{HOBr}$ formation (40\% and $45 \%$ ) during ozone depletion events. $\mathrm{Li}$ (1994) also found that calculated $\mathrm{OH}$ production rates from $\mathrm{HONO}$ dominated both $\mathrm{O}_{3}$ and $\mathrm{CH}_{2} \mathrm{O}$, with a calculated $\mathrm{OH}$ concentration of $3 \times 10^{5}$ molecule $\mathrm{cm}^{-3}$ at noon on 5 April 1992. However, the authors would like to note that these Alert model predictions were not verified by actual HOx observations.

Summer observations during the US ITASE ground traverse confirmed snowpack emissions of $\mathrm{H}_{2} \mathrm{O}_{2}$ and $\mathrm{CH}_{2} \mathrm{O}$ across the Antarctic Ice Sheet between $76^{\circ} \mathrm{S}$ and $90^{\circ} \mathrm{S}$ (Frey et al., 2005). Model calculations constrained by observed atmospheric hydroperoxides $(\mathrm{ROOH}), \mathrm{CH}_{2} \mathrm{O}$ and $\mathrm{O}_{3}$ suggest enhanced $\mathrm{NO}$ and $\mathrm{OH}$ levels on the East Antarctic plateau, similar to what is seen at South Pole (Frey et al., 2005). However, as the Summit example illustrates, modeling results need to be validated by in situ measurements, particularly of $\mathrm{HO}_{\mathrm{x}}$.

\subsubsection{Oxidant production and chemistry in/on snow and ice grains}

Much of the past research on snow photochemistry has focused on how these reactions affect the oxidizing capacity of the atmosphere, primarily by emitting $\mathrm{NO}_{\mathrm{x}}$ and precursors of $\mathrm{HO}_{\mathrm{x}}$ from the snowpack into the overlying boundary layer. The chemistry that leads to the release of reactive gases from the snowpack is largely uncharacterized. This condensed phase chemistry includes two general types of reactions: direct photolysis (such as for nitrate) and indirect photoreactions involving a photochemically formed oxidant reacting with a trace contaminant such as an organic compound. In this section we discuss the various oxidants that are present on snow grains and their potential contributions to snowpack chemistry. Of the major oxidants involved in snow photochemistry, the most is probably known about hydrogen peroxide $\left(\mathrm{H}_{2} \mathrm{O}_{2}\right) . \mathrm{H}_{2} \mathrm{O}_{2}$ is thermally cycled between the atmosphere and snowpack, with emission occurring during daytime when temperatures increase, and deposition occurring during the cooler night (Sigg et al., 1992; Hutterli et al., 2001). This reversible deposition of $\mathrm{H}_{2} \mathrm{O}_{2}$ has been described with a physically based atmosphere-to-snow transfer model (McConnell et al., 1997a, b, 1998; Hutterli et al., 2003). Concentrations in fresh snow reflect water-to- $\mathrm{H}_{2} \mathrm{O}_{2}$ ratios in the cloud, whereas snow exposed sufficiently long to the atmosphere will approach a temperature-dependent partitioning equilibrium analogous to Henry's Law (Conklin et al., 1993; Bales et al., 1995). Levels of $\mathrm{H}_{2} \mathrm{O}_{2}$ in fresh snow are altered by subsequent temperature-driven recycling between the snow and the air until the snow is buried below several $10 \mathrm{~s}$ of $\mathrm{cm}$. In addition to sorption processes, snow metamorphism and wind enhanced ventilation of the top layers of the snowpack can modulate the air-snow exchange, and a net $\mathrm{H}_{2} \mathrm{O}_{2}$ loss from the snow is expected in the course of a year (Sigg and Neftel, 1988; McConnell et al., 1997a; Hutterli et al., 2001, 2003, Frey et al., 2006). Most measurements on the polar ice sheets suggest net $\mathrm{H}_{2} \mathrm{O}_{2}$ emission from the snowpack into the boundary layer in summer (Table 4). In one summer study at Summit, Greenland there was a net deposition of $\mathrm{H}_{2} \mathrm{O}_{2}$ (Jacobi et al., 2002), but this was likely a result of frequent fog events causing significant night-time deposition (Table 4). Estimates of average emission fluxes from the Arctic and Antarctic snowpack in summer vary between $10^{11}$ and $10^{13}$ molecule $\mathrm{m}^{-2} \mathrm{~s}^{-1}$ (Table 4) or $10^{7}$ and $10^{9}$ molecule $\mathrm{cm}^{-3} \mathrm{~s}^{-1}$ for an assumed BL height of $100 \mathrm{~m}$. For comparison, based on one measurement from an illuminated solution of extracted particles, in situ photoformation in airborne particles provides a volumetric $\mathrm{H}_{2} \mathrm{O}_{2}$ flux of $\sim 10^{4}$ molecule $\mathrm{cm}^{-3} \mathrm{~s}^{-1}$ to the boundary layer at Alert, Canada in April (Anastasio and Jordan, 2004). Although the rate is relatively small, this photoformation of $\mathrm{H}_{2} \mathrm{O}_{2}$ in aerosol particles suggests that deposition of these particles to the snowpack will lead to $\mathrm{H}_{2} \mathrm{O}_{2}$ photoformation on snow grains as well (Anastasio and Jordan, 2004), which may slow down the loss rate of $\mathrm{H}_{2} \mathrm{O}_{2}$ from the snow while slightly increasing the emission fluxes. However, this idea of the photochemical formation of $\mathrm{H}_{2} \mathrm{O}_{2}$ on snow grains is in its infancy (Chu and Anastasio, 2005). Indeed, Jacobi et al. (2006) have identified the photochemical decomposition of $\mathrm{H}_{2} \mathrm{O}_{2}$ in snow. More work is needed to quantify the snow grain budget of $\mathrm{H}_{2} \mathrm{O}_{2}$.

Because it is reactive, $\mathrm{H}_{2} \mathrm{O}_{2}$ likely plays an active role in 
Table 4. Average gas phase levels (range in parentheses) of atmospheric radical precursors in air above the snowpack (ambient air) and in the interstitial pore space right below the snow surface (firn air). Positive area flux values indicate net emission, while negative values are equivalent to deposition to the snowpack. ${ }^{\mathrm{a}}$

\begin{tabular}{|c|c|c|c|c|}
\hline Site & Ambient Air ${ }^{\mathrm{b}}$ pptv & $\begin{array}{l}\text { Firn Air }{ }^{c} \\
\text { pptv }\end{array}$ & $\begin{array}{l}\text { Area Flux } \\
\text { molecule } \mathbf{m}^{-2} \mathbf{s}^{-1}\end{array}$ & Reference \\
\hline \multicolumn{5}{|l|}{$\mathbf{H}_{2} \mathbf{O}_{2}$} \\
\hline South Pole & $278(23-773)$ & $884(375-1515)$ & $9.5 \times 10^{12}$ (up to $\left.2.0 \times 10^{14}\right)^{\mathrm{d}}$ & Hutterli et al., 2004 \\
\hline $90^{\circ} \mathrm{S}$ & 5-23 Dec 2000 & $18-23$ Dec $2000,24 \mathrm{~h}$ total & $\begin{array}{l}5-23 \text { Dec } 2000 \\
1.4 \times 10^{12}\left(3.6 \times 10^{11}-4.3 \times 10^{12}\right)^{\mathrm{e}} \\
18-23 \text { Dec } 2000,24 \mathrm{~h} \text { total } \\
7.6 \times 10^{13}(-)^{\mathrm{f}} \\
18-22 \operatorname{Dec} 2000\end{array}$ & \\
\hline Antarctic Plateau & $274(59-643)$ & $564(70-3209)$ & $6.9 \times 10^{11}\left(1.8 \times 10^{10}-1.9 \times 10^{12}\right)^{\mathrm{e}}$ & Frey et al., 2005 \\
\hline $84-90^{\circ} \mathrm{S}$ & 20 Dec 2002-4 Jan 2003 & 21-29 Dec 2002 & $21-29$ Dec 2002 & \\
\hline West Antarctica & $370(<30-918)$ & $388(111-692)$ & $3.4 \times 10^{11}\left(-2.0 \times 10^{11}-8.7 \times 10^{11}\right)^{\mathrm{e}}$ & Frey et al., 2005 \\
\hline $82-84^{\circ} \mathrm{S}$ & 27 Nov-16 Dec 2002 & $11-16$ Dec 2002 & $11-15$ Dec 2002 & \\
\hline Summit, Greenland & $1400(90-4600)$ & $1630(1000-2100)$ & $4.9 \times 10^{13}\left(4.0 \times 10^{13}-5.8 \times 10^{13}\right)^{\mathrm{d}}$ & Hutterli et al., 2001 \\
\hline \multirow[t]{2}{*}{$73^{\circ} \mathrm{N}, 39^{\circ} \mathrm{W}$} & 4-20 June 1996 & 20 June 1996 & 20 June 1996 & \\
\hline & $\begin{array}{l}650(-) \\
5 \text { June- } 8 \text { July } 2000\end{array}$ & - & $\begin{array}{l}-\left(-1.3 \times 10^{13}-1.6 \times 10^{13}\right)^{\mathrm{d}} \\
16 \text { June-7 July } 2000\end{array}$ & Jacobi et al., 2002 \\
\hline \multicolumn{5}{|c|}{ e } \\
\hline South Pole & $103(27-184)$ & $747(425-1238)$ & $1.7 \times 10^{12}\left(9.0 \times 10^{11}-2.9 \times 10^{12}\right)^{\mathrm{d}}$ & Hutterli et al., 2004 \\
\hline $90^{\circ} \mathrm{S}$ & $\begin{array}{l}5-23 \text { Dec } 2000 \\
-\end{array}$ & $\begin{array}{l}18-23 \text { Dec } 2000,24 \mathrm{~h} \text { total } \\
-\end{array}$ & $\begin{array}{l}5-23 \operatorname{Dec} 2000 \\
1.5 \times 10^{12}\left(7.5 \times 10^{11}-3.0 \times 10^{12}\right)^{\mathrm{e}} \\
18-23 \operatorname{Dec} 2000,24 \text { h total } \\
3.5 \times 10^{12}(-)^{\mathrm{f}} \\
7-18 \operatorname{Dec}^{2} 2000 \\
2.9 \times 10^{12}\left(1.3 \times 10^{12}-4.3 \times 10^{12}\right) \\
7-23 \operatorname{Dec} 2000 \\
-\left(0-2 \times 10^{12}\right) \\
\text { Jan-Dec } 1999\end{array}$ & Hutterli et al., 2002 \\
\hline \multicolumn{5}{|l|}{$\mathrm{CH}_{2} \mathbf{O}$} \\
\hline Antarctic Plateau & $155(-)$ & $142(-)$ & $-3.0 \times 10^{10}(-)^{\mathrm{e}}$ & Frey et al., 2005 \\
\hline $88^{\circ} \mathrm{S}, 108^{\circ} \mathrm{W}$ & $30-31$ Dec $2002,13 \mathrm{~h}$ total & $30-31$ Dec $2002,13 \mathrm{~h}$ total & 30-31 Dec 2002 & \\
\hline $\begin{array}{l}\text { Dome C } \\
75^{\circ} \mathrm{S}, 123^{\circ} \mathrm{E}\end{array}$ & - & - & $\begin{array}{l}-\left(-0.1 \times 10^{11}-2.1 \times 10^{11}\right) \\
\text { Jan-Dec } 1998\end{array}$ & Hutterli et al., 2002 \\
\hline Byrd & $121(52-169)$ & $171(130-209)$ & $1.0 \times 10^{11}\left(-8.1 \times 10^{10}-3.3 \times 10^{11}\right)^{\mathrm{e}}$ & Frey et al., 2005 \\
\hline $80^{\circ} \mathrm{S}, 120^{\circ} \mathrm{W}$ & 3-7 Dec 2002 & 3-7 Dec 2002 & $3-7$ Dec 2002 & \\
\hline Neumayer & $-(<30-700)$ & - & $-\left(1.5 \times 10^{13}-2.5 \times 10^{13}\right)^{\mathrm{j}}$ & Riedel et al., 1999; Riedel et \\
\hline $70^{\circ} \mathrm{S}, 8^{\circ} \mathrm{W}$ & March 1997-Jan 1998, Feb 1999 & & March 1997-Jan 1998, Feb 1999 & al., 2005 \\
\hline Summit, Greenland & $230(100-450)$ & $->1500$ & $-\left(1.4 \times 10^{12}-8.8 \times 10^{12}\right)^{\mathrm{e}}$ & Hutterli et al., 1999 \\
\hline $73^{\circ} \mathrm{N}, 39^{\circ} \mathrm{W}$ & $\begin{array}{l}\text { 4-20 June } 1996 \\
120(-) \\
5 \text { June-8 July } 2000\end{array}$ & $\begin{array}{l}\text { 20 June } 1996 \\
-\end{array}$ & $\begin{array}{l}\text { 20 June } 1996 \\
-\left(-1.1 \times 10^{12}-4.2 \times 10^{12}\right)^{\mathrm{d}} \\
\text { 16 June-7 July } 2000\end{array}$ & Jacobi et al., 2002 \\
\hline Alert, Canada & $-(52-690)$ & $-(120-150)$ & $4.9 \times 10^{13}(-)^{\mathrm{h}}$ & Sumner and Shepson, 1999 \\
\hline $83^{\circ} \mathrm{N}, 62^{\circ} \mathrm{W}$ & 15 Feb-26 April 1998 & $\begin{array}{l}\text { 9 March } 1998 \\
-(280-610) \\
7 \text { April } 1998 \\
-(650-750) \\
16 \text { April } 1998\end{array}$ & & \\
\hline Ahmeek, MI & $-(190-310)$ & $-(450-680)$ & - & Couch et al., 2000 \\
\hline $47^{\circ} \mathrm{N}, 88^{\circ} \mathrm{W}$ & Jan 1999,1 profile & Jan 1999,1 profile & & \\
\hline
\end{tabular}

snowpack chemistry. Correlations between $\mathrm{H}_{2} \mathrm{O}_{2}$ and $\mathrm{CO}_{2}$ trapped in air bubbles in Greenland ice cores suggest that $\mathrm{H}_{2} \mathrm{O}_{2}$ may oxidize organic compounds such as formaldehyde $\left(\mathrm{CH}_{2} \mathrm{O}\right)$ to produce $\mathrm{CO}_{2}$ at depth and possibly in the upper snowpack as well (Tschumi and Stauffer, 2000). The thermal reaction of $\mathrm{H}_{2} \mathrm{O}_{2}$ with bromide (or chloride) to form $\mathrm{HOBr}$ (or $\mathrm{HOCl}$ ) might also be significant on snow grains as a source of volatile, reactive halogens. While the rates of these reactions are slow (Mohammad and Liebhafsky, 1934), they might be significant in the quasi-liquid layers of snow if the reactants are sufficiently concentrated.

One of the most significant roles of hydrogen peroxide in snow grain chemistry is as a photochemical source of hydroxyl radical (Chu and Anastasio, 2005; Jacobi et al., 2006; France et al., 2007):

$\mathrm{H}_{2} \mathrm{O}_{2}$ (snow) + light $\rightarrow 2 \mathrm{OH}$ 
Table 4. Continued.

\begin{tabular}{|c|c|c|c|c|}
\hline Site & Ambient Air ${ }^{\mathrm{b}}$ pptv & $\begin{array}{l}\text { Firn Air } \\
\text { pptv }\end{array}$ & $\begin{array}{l}\text { Area Flux } \\
\text { molecule } \mathbf{m}^{-2} \mathbf{s}^{-1}\end{array}$ & Reference \\
\hline \multicolumn{5}{|l|}{$\mathrm{CH}_{3} \mathrm{CHO}$} \\
\hline Alert, Canada & $90(70-110)$ & $-(220-270)$ & $4.2( \pm 2.1) \times 10^{12}(-)^{d}$ & Guimbaud et al., 2002 \\
\hline \multirow[t]{3}{*}{$83^{\circ} \mathrm{N}, 62^{\circ} \mathrm{W}$} & 22 Apr. $2000,5 \mathrm{~h}$ total & 22 Apr. $2000,5 \mathrm{~h}$ total & 22 April $2000,5 \mathrm{~h}$ total & Boudries et al., 2002 \\
\hline & $166(26-459)$ & - & $2.6( \pm 0.1) \times 10^{13}(-)^{i}$ & \\
\hline & 1 Apr-4 May 2000 & & 16 and 19 April 2000 & \\
\hline Ahmeek, MI & $1800(-)$ & -(6000-7200) & - & Couch et al., 2000 \\
\hline $47^{\circ} \mathrm{N}, 88^{\circ} \mathrm{W}$ & Jan 1999,1 profile & Jan 1999, 1 profile- & & \\
\hline \multicolumn{5}{|l|}{$\mathrm{CH}_{3} \mathrm{C}(\mathrm{O}) \mathrm{CH}_{3}$} \\
\hline Alert, Canada & $-(380-420)$ & $-(410-580)$ & $-6.2( \pm 4.2) \times 10^{12}(-)^{\mathrm{d}}$ & Guimbaud et al., 2002 \\
\hline \multirow[t]{3}{*}{$83^{\circ} \mathrm{N}, 62^{\circ} \mathrm{W}$} & 22 April $2000,5 \mathrm{~h}$ total & 22 April $2000,5 \mathrm{~h}$ total & $22 \mathrm{Apr} .2000,5 \mathrm{~h}$ total & Boudries et al., 2002 \\
\hline & $871(183-1470)$ & - & $-7.5( \pm 1.8) \times 10^{12}(-)^{\mathrm{i}}$ & \\
\hline & 1 April-4 May 2000 & & 16 and 19 April 2000 & \\
\hline Ahmeek, MI & $600(-)$ & $-(2000-4000)$ & - & Couch et al., 2000 \\
\hline $47^{\circ} \mathrm{N}, 88^{\circ} \mathrm{W}$ & Jan 1999,1 profile & Jan 1999, 1 profile & & \\
\hline \multicolumn{5}{|l|}{ Alkenes } \\
\hline Summit, Greenland & Ethene & - (up to 163$)$ & - & Swanson et al., 2002 \\
\hline \multirow{8}{*}{$73^{\circ} \mathrm{N}, 39^{\circ} \mathrm{W}$} & $9(-)$ & June-Aug 1999 & - & Swanson et al., 2002 \\
\hline & June-Aug 1999 & - (up to 89 ) & - & Swanson et al., 2002 \\
\hline & Propene & June-Aug 1999 & - & \\
\hline & $6.2(-)$ & - (up to 42$)$ & & \\
\hline & June-Aug 1999 & June-Aug 1999 & & \\
\hline & 1-Butene & & & \\
\hline & 3.3 & & & \\
\hline & June-Aug 1999 & & & \\
\hline
\end{tabular}

\footnotetext{
a Studies were included, which report fluxes and/or mixing ratios in ambient and firn air; for a comprehensive compilation of all available atmospheric observations see Sander et al. (available as an electronic supplement to Simpson et al., 2007)

b Ambient air levels typically at $\sim 1 \mathrm{~m}$ above the snow surface

${ }^{\mathrm{c}}$ Firn air levels within $\sim 0.5 \mathrm{~m}$ below the snow surface

$\mathrm{d}$ derived with the gradient method (Monin-Obukhov similarity theory)

e based on firn-ambient air gradients and effective molecular diffusivities in air

${ }^{\mathrm{f}}$ derived from concentration changes in the top layer of snow

$\mathrm{g}$ based on simulations with a physical atmosphere-to-snow transfer model

${ }^{\mathrm{h}}$ Steady-state estimate assuming a BL height of $600 \mathrm{~m}$

i determined with a quartz chamber

$\mathrm{j}$ inferred from the difference between modeled and observed ambient mixing ratios
}

Calculations based on laboratory measurements of 12 indicate that $\mathrm{H}_{2} \mathrm{O}_{2}$ photolysis is the dominant source of $\mathrm{OH}$ on Antarctic and Arctic snow grains (Chu and Anastasio, 2005). However, in snow or ice where nitrate concentrations are much greater than those of hydrogen peroxide (i.e., by at least an order of magnitude), nitrate photolysis will be the dominant source of $\mathrm{OH}$, as has been suggested for the photic zone of Antarctic sea ice (King et al., 2005). Measurements at Summit indicate that the rate of $\mathrm{OH}$ formation on surface snow grains at midday during summer is typically $300 \mathrm{nmol}$ $\mathrm{L}^{-1} \mathrm{~h}^{-1}$ and that $\mathrm{H}_{2} \mathrm{O}_{2}$ photolysis accounts for nearly all of this production (Anastasio et al., 2007). Based on peak measured concentrations of $\mathrm{OH}$ in the interstitial air of surface snow at Summit $\left(\sim 3 \times 10^{6}\right.$ molecule $\mathrm{cm}^{-3}$; Beyersdorf et al., 2007), the rate of partitioning of gaseous $\mathrm{OH}$ to snow grains will be approximately equal to the rate of formation from photolysis of $\mathrm{H}_{2} \mathrm{O}_{2}$ on the grains. However, the photolysis of $\mathrm{H}_{2} \mathrm{O}_{2}$ on snow grains is not a source of hydroxyl radical to the gas phase, as preliminary results indicate that the $\mathrm{OH}$ lifetime on snow grains at Summit during summer is short enough that $\mathrm{OH}$ will react before it can evaporate (Anastasio et al., 2007).

Like $\mathrm{H}_{2} \mathrm{O}_{2}$, formaldehyde $\left(\mathrm{CH}_{2} \mathrm{O}\right)$ is an important radical precursor (Hutterli et al., 2001; Yang et al., 2002; Chen et al., 2004; Riedel et al., 2005) that is recycled between nearsurface snow and the atmosphere (Hutterli et al., 1999, 2002, 2003). Distribution coefficient $\left(\mathrm{K}_{d}\right)$ values for $\mathrm{CH}_{2} \mathrm{O}$, determined between -5 and $-35^{\circ} \mathrm{C}$, are about $1 \%$ of those reported for $\mathrm{H}_{2} \mathrm{O}_{2}$ (Burkhart et al., 2002). Air-snow exchange of $\mathrm{CH}_{2} \mathrm{O}$ accumulated at or near the ice-air interface of snow grains leads to fast equilibration, and to significant fluxes into the boundary layer (Table 4). Total emission fluxes 
of $\mathrm{CH}_{2} \mathrm{O}$ (Table 4) originate from both physical and photochemical sources, with the former being dominant. For example, South Pole data suggest that net production of $\mathrm{CH}_{2} \mathrm{O}$ within the snow by heterogeneous photochemical processes is likely to contribute not more than $20 \%$ to the total measured flux (Hutterli et al., 2004). However, the ratio between these sources will vary at sites with different concentrations of organic precursors in the snow. It will also vary with time as snow temperatures and actinic flux change on diurnal and seasonal time scales. The estimated net fluxes of $\mathrm{CH}_{2} \mathrm{O}$ in the Arctic and Antarctic are generally lower than the corresponding $\mathrm{H}_{2} \mathrm{O}_{2}$ fluxes and range between $10^{10}$ and $10^{12}$ molecule $\mathrm{m}^{-2} \mathrm{~s}^{-1}$, except for the coastal Neumayer, where estimated fluxes of $\sim 2 \times 10^{13} \mathrm{~m}^{-2} \mathrm{~s}^{-1}$ were needed to reconcile measured with modeled $\mathrm{CH}_{2} \mathrm{O}$ mixing ratios (Riedel et al., 2005) (Table 4).

Other radical precursors such as acetaldehyde $\left(\mathrm{CH}_{3} \mathrm{CHO}\right)$ and acetone $\left(\mathrm{CH}_{3} \mathrm{C}(\mathrm{O}) \mathrm{CH}_{3}\right)$, have been detected in surface snow (Houdier et al., 2002). Firn air levels of these species exceed those in the ambient air, suggesting snowpack emissions (Couch et al., 2000; Boudries et al., 2002; Guimbaud et al., 2002) (see also Sect. 4.4), probably with contributions from both physical and photochemical processes. However, a physical description of the air-snow transfer of these chemical species is still lacking, as well as net flux estimates between snow and atmosphere over longer time periods (Table 4). Modeling results of Grannas et al. (2002) indicate that both a daytime snowpack source (possibly photochemistry) and a nighttime snowpack sink (temperature-dependent uptake) of $\mathrm{CH}_{2} \mathrm{O}, \mathrm{CH}_{3} \mathrm{CHO}$, and $\mathrm{CH}_{3} \mathrm{C}(\mathrm{O}) \mathrm{CH}_{3}$ were required to correctly model the observed springtime diurnal variation of mixing ratios observed for these species in 2000 at Alert, Canada.

The snowpack chemistry of $\mathrm{H}_{2} \mathrm{O}_{2}$ and volatile carbonyls (as well as other organic compounds) is likely intimately linked to the hydroxyl radical. Because of its very high reactivity, $\mathrm{OH}$ is probably the major oxidant for organic compounds and other contaminants on sunlit snow grains (Anastasio et al., 2007; France et al., 2007), as it is in the atmosphere. Indeed, away from coastal regions with elevated seasalt levels, the greatest sink for snow grain $\mathrm{OH}$ is possibly organic compounds (Anastasio et al., 2007). In this case, most photoformed $\mathrm{OH}$ will react with organics and these reactions probably account for a significant portion of the carboncontaining products that are emitted from snow (Dominé and Shepson, 2002; Grannas et al., 2004). In addition to $\mathrm{CH}_{2} \mathrm{O}$ and other carbonyls such as those described above (Hutterli et al., 1999; Sumner and Shepson, 1999; Boudries et al., 2002; Guimbaud et al., 2002; Jacobi et al., 2002; Sumner et al., 2002; Hutterli et al., 2004), the products formed from $\mathrm{OH}$ reactions with organics may also include $\mathrm{CO}$ (Haan et al., 2001) and carboxylic acids (Dibb and Arsenault, 2002). It should be noted, however, that other mechanisms - such as direct photoreactions of organic compounds and indirect photoreactions involving other oxidants (Sects. 2.4 and 4.4) are probably also significant in the release of $\mathrm{CO}$ and VOCs.

In regions where snow composition is affected by inputs of sea-salt particles, reactions of $\mathrm{OH}$ with bromide and chloride on snow grains may also be important. While coastal regions certainly fall in this category, recent observations of boundary layer $\mathrm{HO}_{\mathrm{x}}$ chemistry at Summit suggest that halogen chemistry can also be important in regions $100 \mathrm{~s}$ of kilometers from the coast (Sjostedt et al., 2007). Hydroxyl radical oxidizes both bromide and chloride to initially form halogen radical species (such as $\mathrm{Br}, \mathrm{Br}_{2}^{-}$, and the analogous chloride species), which can be further transformed into volatile reactive halogens (such as $\mathrm{Br}_{2}$ and $\mathrm{BrCl}$ ) (Simpson et al., 2007). Based on results in solution, a portion of these reactive halogens on snow grains likely reacts with various organic functional groups to form halogenated organic compounds (Anastasio and Matthew, 2006). Such reactions could be responsible for the measured fluxes of alkyl halides out of the snow at Summit (Swanson et al., 2002). The volatile reactive halogens are also important because they will evaporate into the gas phase - both into the interstitial firn air and into the boundary layer - and photolyze to form halogen radicals, which in turn will destroy ozone and react with hydrocarbons, as described by Simpson et al. (2007).

Based on past studies in mid-latitude cloud and fog drops, illuminated polar snow grains likely manufacture a number of other oxidants in addition to $\mathrm{OH}$. These additional oxidants include singlet molecular oxygen $\left({ }^{1} \mathrm{O}_{2} *\right.$, excited triplet states of organic compounds, and peroxyl radicals (Faust, 1994; Anastasio et al., 1997). Initial work has shown that ${ }^{1} \mathrm{O}_{2} *$ is indeed formed on illuminated Summit snow and that the corresponding steady-state concentrations are high enough to be a significant sink for electron rich species such as polycyclic aromatic hydrocarbons (McKellar et al., 2005). As far as we are aware, no one has yet attempted to measure the presence of excited triplet states or peroxyl radicals on snow grains, but these oxidants probably also affect snowpack chemistry and emissions into the boundary layer.

\subsection{Halogens}

\subsubsection{Introduction}

The chemistry of reactive halogens is most widely known through the impacts on ozone, causing dramatic depletions in both the stratosphere and in the polar boundary layer at sunrise. When the relationship between $\mathrm{O}_{3}$ depletion and bromine was first discovered in the polar boundary layer, gaseous bromocarbons (e.g., $\mathrm{CHBr}_{3}$ ) were suggested to be the source of reactive Br. Further study pointed to bromide in sea salt as the ultimate source, though unaltered airborne sea-salt aerosol is not sufficient. The current understanding is that sea salt expelled from the ice lattice during formation of sea ice and to some extent sea-salt aerosol that are deposited on ice is the halogen source. Modifications through interaction with ice surfaces, including brine and frost flowers 
or perhaps just through exposure after deposition onto sea ice and its snow cover during winter play a key role. Current understanding of halogen chemistry and ozone depletion in the polar boundary layer is the subject of a companion paper (Simpson et al., 2007). There is also increasing speculation that halogen chemistry is important throughout much of the troposphere (e.g., Vogt et al., 1996; Platt and Hönninger, 2003; von Glasow and Crutzen, 2006). Direct evidence for the release of photolyzable bromine compounds from the snowpack was first obtained by Foster et al. (2001) at Alert, Canada. Several recent studies investigating snow photochemistry have found evidence that halogen chemistry may be impacting $\mathrm{HO}_{\mathrm{x}}$ and $\mathrm{NO}_{\mathrm{x}}$ cycling in coastal Antarctica during the summer (outside of the severe ozone depletion season), and, surprisingly, at $3 \mathrm{~km}$ elevation along the crest of the Greenland ice sheet. In this section the evidence that halogen chemistry may be important in unexpected times and places in the polar regions, and the interactions between $\mathrm{HO}_{\mathrm{x}}, \mathrm{NO}_{\mathrm{x}}$ and halogen chemistry that appear to result, are briefly introduced.

\subsubsection{Direct release of halogen compounds from the snow}

Laboratory experiments of Huff and Abbatt (2000, 2002) and Adams et al. (2002) showed that the uptake and reaction of $\mathrm{HOBr}$ on frozen salt surfaces of variable $\mathrm{NaCl} / \mathrm{NaBr}$ composition and temperature led to the release of $\mathrm{Br}_{2} / \mathrm{BrCl}$ to the gas phase. In the case of frozen surfaces no dependence on the $\mathrm{pH}$ of the solution that was used to prepare the frozen salt surfaces was observed, whereas in liquid a $\mathrm{pH}$ dependence was observed. This result points to a different mechanism in the case of frozen surfaces which so far has not been identified. The mass spectrometer measurements of Foster et al. (2001) and Spicer et al. (2002) showed very high mixing ratios of $\mathrm{Br}_{2}$ and $\mathrm{BrCl}$ of up to 27 and $35 \mathrm{pptv}$, respectively at $1.5 \mathrm{~m}$ above the snow surface at Alert, Canada. Enhanced $\mathrm{Br}_{2}$ concentrations within the snowpack (relative to the boundary layer concentrations measured just above the snowpack) were detected at depths down to $20 \mathrm{~cm}$. These measurements provided the first direct evidence of a snowpack source of reactive molecular halogens potentially responsible for the observed tropospheric ozone depletion phenomenon. Comparison of $\mathrm{BrO}$ concentrations measured with an in-situ chemical conversion/resonance fluorescence technique and a DOAS system showed a strong vertical gradient of $\mathrm{BrO}$ at Alert (Avallone et al., 2003) again pointing to a strong influence from the snowpack. Measurements $1 \mathrm{~m}$ and $0.25 \mathrm{~m}$ above the snow showed up to 20 pptv of $\mathrm{BrO}$ hinting at a possible direct impact of the snowpack on $\mathrm{BrO}$ mixing ratios. Modeling results by Piot and von Glasow (pers. comm.) show that the life cycle of an ozone depletion event can only be simulated if re-emission of deposited (mainly particulate) bromine from the snowpack is considered. The exact processes and kinetics behind this remain, however, unknown. For a better understanding of the processes and a more correct inclusion into numerical models it is crucial that the details of halogen cycling in the snow are elucidated.

\subsubsection{Atmospheric impact of halogen chemistry}

As discussed in previous sections, several polar field campaigns observed $\mathrm{OH} / \mathrm{HO}_{2}$ and $\mathrm{NO} / \mathrm{NO}_{2}$ ratios that could not satisfactorily be explained with models. It was suggested that this is due to halogen chemistry. In the case of Summit, Greenland (as noted above), the measured $\mathrm{OH}$ levels were exceptionally high, and could not be accounted for by standard homogeneous chemistry that did not include halogens (Sjostedt et al., 2007). Since measured peroxy radical levels at Summit are well reproduced by model calculations, ozone production rates $\left(\mathrm{P}\left[\mathrm{O}_{3}\right]\right.$ $\left.=\mathrm{k}_{1}\left[\mathrm{RO}_{2}\right][\mathrm{NO}]+\mathrm{k}_{2}\left[\mathrm{HO}_{2}\right][\mathrm{NO}]\right)$ should be accurately predicted. During the 2003 Summit field campaign average production rates of $\sim 0.8 \mathrm{ppbv} \mathrm{O}_{3}$ day $^{-1}$ were calculated for the boundary layer, which is about $2 \%$ of the daily average ozone mixing ratio. However, at Summit photochemical production within the surface layer does not appear to have an important influence on surface ozone levels (Helmig et al., 2002, 2007c), much in contrast to the findings from South Pole. In fact the boundary layer appears to be slightly depleted in ozone as balloon profiles frequently show higher mixing ratios above the boundary layer (Helmig et al., 2002). Firn air measurements of ozone at Summit are lower than ambient, often by a factor of two or more (Peterson and Honrath, 2001). Ozone in the firn air declines with increasing solar irradiance levels, both diurnally and seasonally. While during April, up to $90 \%$ of ambient ozone was preserved to depths of $1 \mathrm{~m}$, during mid-summer, only $20-50 \%$ remained at the same depth. Diurnal cycles in firn air ozone were clearly evident, with maximum ozone levels observed during the night and minima occurring after solar noon (Helmig et al., 2007d). These observations imply that photochemical depletion is the most important removal mechanism of ozone in the interstitial air. The predominantly positive ozone gradients (higher ozone above the surface than in the snowpack) also point towards the snowpack being a sink of boundary layer ozone. This assumption has indeed been confirmed by direct ozone flux measurements at Summit, which show diurnally changing ozone fluxes with maximum deposition rates occurring in the afternoon (Helmig, personal communication).

Sjostedt et al. (2007) speculated that the lack of observed ozone production at Summit and the perturbed $\left(\mathrm{HO}_{2}+\mathrm{RO}_{2}\right) / \mathrm{OH}$ ratio might be explained by a related chemical mechanism. The presence of halogen radicals could help explain both the slight depletion of boundary layer ozone and the enhancement in OH (Stutz et al., 1999; Foster et al., 2001; von Glasow et al., 2004). It is also possible that this chemistry could be altered by heterogeneous processes due to increased particle surface area (primarily blowing snow) in the high wind events. Alternatively, rapid transport of air that contains halogen compounds and/or sea-salt aerosol from the 

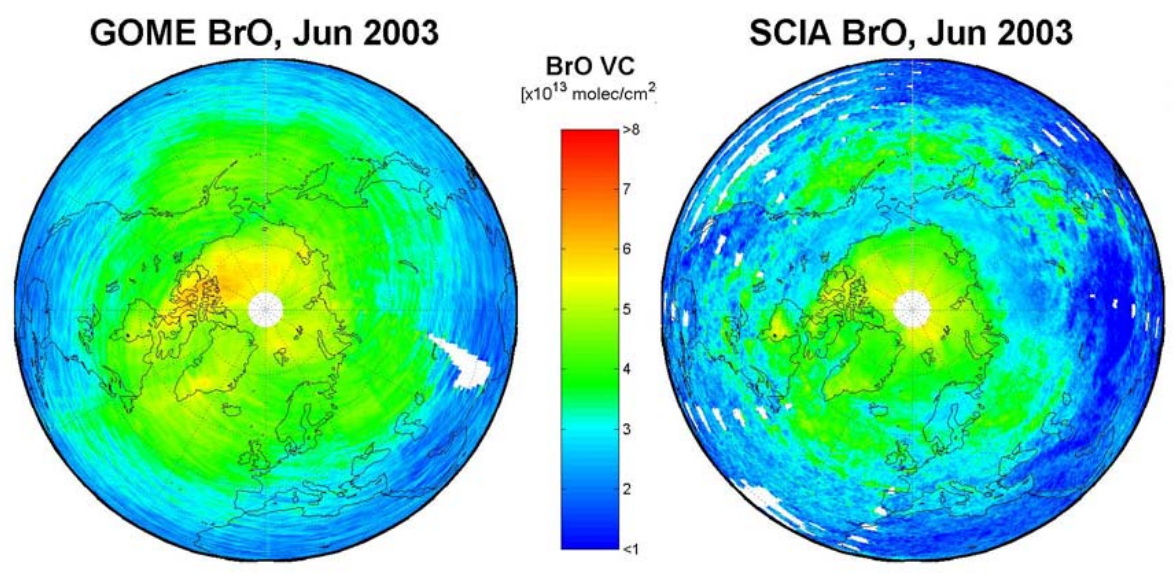

Fig. 10. Total vertical column densities of BrO over the Arctic observed from GOME and SCIAMACHY during summer 2003.

marine boundary layer (as suggested by FLEXPART backwards simulations) to Summit might be another mechanism for activating halogen chemistry.

Although there are no measurements of $\mathrm{BrO}$ or IO at Summit, there exists ancillary evidence that suggests that both species may be present. For example, both the GOME and SCIAMACHY instruments on the ERS-2/ENVISAT satellites show moderate (approx. $3-5 \times 10^{13}$ molecule $\mathrm{cm}^{-2}$ ) atmospheric columns of $\mathrm{BrO}$ during the summertime over the entire Greenland icesheet (see June 2003 composites, Fig. 10) (Richter et al., 1998; Wagner and Platt, 1998). Assuming the satellite $\mathrm{BrO}$ retrievals are correct and that the entire column of $\mathrm{BrO}$ is in a maximum $1 \mathrm{~km}$ boundary layer would result in ambient mixing ratios in the boundary layer of about 20 pptv. Low mixing ratios (1-2 pptv) of soluble gas-phase bromine species (Evans et al., 2003) were consistently detected by the UNH mist chamber during summer 2003. However, on 28 June when $\mathrm{OH}$ reached peak values for the 2003 campaign, soluble gas-phase bromide was above 8 pptv from the onset of measurement (10:00 a.m. local time) until 02:30 p.m. and reached a maximum of $11 \mathrm{pptv}$ during this period. Halocarbons such as methyl bromide, ethyl bromide, methyl iodide and ethyl iodide have been observed in the atmosphere at Summit (Swanson et al., 2002). The observed concentrations of all four are enhanced in the firn column indicating active photochemistry involving halogen radicals within the snowpack. Annual changes of isobutane/propane ratios in the firn column at Summit also suggest a seasonal variance of bromine radicals. Consequently, we believe that further study of photochemistry at Summit should address the potential link between $\mathrm{HO}_{\mathrm{x}}$ and halogen chemistry in this environment by direct measurement of such species as BrO. A MAXDOAS installed at Summit in summer 2006 will provide preliminary testing of the hypothesis that halogens are impacting chemical cycles at this site. Intensive campaigns to be conducted in 2007 and 2008 will de- ploy long-path DOAS and in situ instrumentation to provide indirect evidence of halogen chemistry $\left(\mathrm{OH} /\left(\mathrm{HO}_{2}+\mathrm{RO}_{2}\right)\right.$, $\mathrm{NO} / \mathrm{NO}_{2}, \mathrm{Hg}$ speciation, $\mathrm{NMHC}$ ) to confirm or refute the hypothesis, and should determine whether snowpack emissions or advection of marine air masses are the dominant source of any tropospheric halogens reaching the crest of the Greenland ice sheet.

In the case of Halley, Antarctica, measurements during the CHABLIS field campaign showed the presence of significant mixing ratios ( $\sim 5$ pptv) of both $\mathrm{IO}$ and $\mathrm{BrO}$ radicals at noon during the summer, with IO levels being much higher than observed in the Arctic. The levels for both halogen oxides peaked in spring with mixing ratios near 15 pptv (Saiz-Lopez et al., 2007). Under these conditions halogen oxides control the lifetime of $\mathrm{NO}_{\mathrm{x}}$ through the formation of halogen nitrates $\left(\mathrm{XONO}_{2}\right)$ and their subsequent hydrolysis on aerosols (Sander et al., 1999). In addition, the $\mathrm{NO}_{2} / \mathrm{NO}$ ratio is also affected by the reaction of $\mathrm{IO}$ and $\mathrm{BrO}$ with $\mathrm{NO}$, and the rate of removal of DMS via reaction with $\mathrm{BrO}$, for which the rate coefficient is an order of magnitude greater than for removal by $\mathrm{OH}$. $\mathrm{IO}$ and $\mathrm{BrO}$ also affect the oxidizing capacity of the Antarctic boundary layer by reacting with $\mathrm{HO}_{2}$ and hence reducing the $\mathrm{HO}_{2} / \mathrm{OH}$ ratio.

In order to study the impact of halogens on $\mathrm{HO}_{\mathrm{x}}$ concentrations at Halley, a time-resolved photochemical model using the Master Chemical Mechanism v3.1 (Jenkin et al., 1997), which included an explicit non-methane hydrocarbon scheme (11 NMHC species), and an additional halogen scheme, and constrained using measurements of longer-lived sources and sinks, was used to calculate the diurnal variation of $\mathrm{OH}$ and $\mathrm{HO}_{2}$ (Bloss et al., 2006). The concentration of photolabile halogen precursors (for example $\mathrm{Br}_{2}$ and $\mathrm{I}_{2}$ ) was selected to give agreement with $[\mathrm{BrO}]$ and $[\mathrm{IO}]$ at the DOAS measurement height of $\sim 5 \mathrm{~m}$. When the halogen chemistry was switched off, the model overestimated $\mathrm{HO}_{2}$ by more than a factor of 2 at noon, but when it was included, the agreement 
for $\mathrm{HO}_{2}$ was much better, whereas for $\mathrm{OH}$ there was a significant model overprediction, suggesting that further sinks are required. Apart from $\mathrm{CH}_{2} \mathrm{O}$, there were no measurements during CHABLIS of oxygenated VOCs, a class of compound which may represent a significant unmeasured sink for $\mathrm{OH}$. This was observed, for example, during the North Atlantic Marine Boundary Layer Experiment (NAMBLEX), held at the remote Mace Head station in Ireland, where acetone, methanol and acetaldehyde were significant sinks for $\mathrm{OH}$ (Heard et al., 2006). HONO concentrations and J(HONO) were also determined during CHABLIS, but including photolysis of measured $\mathrm{HONO}$ as an $\mathrm{OH}$ source led to a large overprediction of $\mathrm{OH}$, and this finding requires further investigation. The first and second most important sinks of $\mathrm{HO}_{2}$ were reaction with $\mathrm{IO}$ and $\mathrm{BrO}$, respectively, and HOI photolysis dominated $\mathrm{OH}$ production. The field and modeling results strongly suggest that the snowpack is a source for the measured halogens (Saiz-Lopez et al., 2007).

\subsection{Organics}

\subsubsection{Organic materials in snow}

Organic compounds in the atmosphere exist in particulate matter (solid and liquid) and as gases, originating from both natural (e.g. biomass burning, emission from plants) and anthropogenic (e.g. vehicles, industrial emissions, cooking) sources. They can be incorporated into snow by both wet and dry deposition processes (e.g. Sempere and Kawamura, 1994; Franz and Eisenreich, 1998; Wania et al., 1999; Grollert and Puxbaum, 2000; Lei and Wania, 2004; Roth et al., 2004). Section 2 discusses the incorporation of atmospheric constituents into snow. Here we focus on "reactive" organic materials, while we note that other organic compounds (e.g. methane, halogenated organic molecules) are present in snow at significant concentrations, but due to their chemical inertness, their contribution to snow reactivity is considered neglible. Dry deposition is controlled by a number of factors including meteorology, snow surface properties, and, for particulates, the aerosol size distribution. There is a need to improve our understanding of the fundamental processes that deposit specific gas phase and particulate organic compounds to snow.

There are only limited measurements of organic compounds in snow, but these suggest that these compounds are ubiquitous and present at significant concentrations. At remote high latitude sites (Alert, Summit, Greenland, South Pole, see Fig. 2) measurements of total organic carbon, TOC, in snow ranged from $<10$ to $700 \mu \mathrm{g} \mathrm{C} \mathrm{L}^{-1}$ (Twickler et al., 1986; Grannas et al., 2004; Lyons et al., 2007). For comparison, values for sulfate in Greenland snow are in the range 100-300 $\mathrm{g} \mathrm{L}^{-1}$ (e.g., Twickler et al., 1986). By contrast, TOC values at Mount Sonnblick, Austria are higher, ranging from $1000 \mu \mathrm{g} \mathrm{C} \mathrm{L}^{-1}$ to $3000 \mu \mathrm{g} \mathrm{C} \mathrm{L}^{-1}$ (Haan et al., 2001), probably because of closer proximity to urban sources. Ha- gler et al. (2006) separated "dissolved" and "particulate" OC by filtration (nominal pore size $0.7 \mu \mathrm{m}$ ) in a profile of $20 \mathrm{~cm}$ thick samples collected in a $3 \mathrm{~m}$ deep snowpit at Summit. They found levels of dissolved organic carbon, DOC, typically in the range $10-100 \mu \mathrm{g} \mathrm{C} \mathrm{L}^{-1}$, with a mean of $50 \mu \mathrm{g} \mathrm{C} \mathrm{L}^{-1}$ and particulate organic carbon concentrations in the range $2.5-12 \mu \mathrm{g} \mathrm{CL}^{-1}$, with a mean of $5 \mu \mathrm{g} \mathrm{CL}^{-1}$. The TOC derived from these data (mean of $55 \mu \mathrm{g} \mathrm{C} \mathrm{L}^{-1}$ ) are significantly lower than the Summit measurements by Grannas et al. (2004), possibly because of differences in collection and measurement techniques.

A number of natural and anthropogenic organic compounds have been measured in snow including: polycyclic aromatic hydrocarbons (PAHs) (e.g., Jaffrezo et al., 1994; Masclet et al., 2000); phthalates, alkanes and phenols (Grollert and Puxbaum, 2000); low molecular weight carbonyls (e.g., Perrier et al., 2002; Houdier et al., 2002); persistent organic pollutants (e.g., Jaffrezo et al., 1994; Lode et al., 1995; Blais et al., 2001a, b; Garbarino et al., 2002; Villa et al., 2003; Halsall, 2004); and low molecular weight organic acids (e.g., Dibb and Arsenault, 2002; Legrand and De Angelis, 1995; Narukawa et al., 2003). Humic-like substances, the relatively high-molecular weight material consisting of multifunctional oxygenated organic compounds, have also been found in snow and polar ice (Calace et al., 2001; Kawamura et al., 2001, 2003, 2005; Grannas et al., 2004, 2006). It has been hypothesized that the observed production of VOCs from snow and ice results from photooxidation of these humic-like substances (Sumner and Shepson, 1999; Grannas et al., 2004). Fulvic acids were quantified in snow collected in Antarctica (Calace et al., 2005), while lignin and fatty acids have been quantified in Arctic snow (Grannas et al., 2004). Compared to the few TOC measurements available, it appears that biogenic organic matter represents a significant fraction of the total organic carbon measured in high latitude snow and ice, and could indeed be a relatively abundant substrate available for photochemical processing. Grannas et al. (2006) reported molecular-level characterization of the dissolved organic material in an ice core collected from Franz Josef Land, Russia. Several thousand unique molecular species were identified over a mass range of 300-800 Daltons (molecular weight). Molecular formulae of the identified species indicate potentially important biogenic organic sources. However, due to current analytical limitations, there is little information on specific chemical functionalities and structures of the complex mixture of organic materials found in this core. Indeed, much work remains to characterize the complex organic material contained in both remote and urban snow.

There have also been several studies reporting a variety of biological organisms in snow including bacteria (Felip et al., 1995, 1999; Carpenter et al., 2000; Takeuchi et al., 2001). Snow algae have been identified globally at a variety of sites, including the Arctic, Antarctic, Greenland, U.S., Canada, Europe and Japan (Gerrath and Nicholls, 1974; 
Cota, 1985; Felip et al., 1995; Duval et al., 1999; Painter et al., 2001; Yamamoto et al., 2004; Edwards et al., 2004). Organic carbon from biological sources may react with radical compounds in snow (e.g. $\mathrm{OH}$ ) thus serving as radical sinks. By-products of these reactions can result in the generation of additional organic compounds in snow (Grannas et al., 2004). Living organisms can also use existing organic compounds as an energy source, and hence organisms can potentially modify snow chemistry. The extent to which living organisms are involved in snow chemistry is not well understood, in particular due to a general lack of information on the specific organism concentrations in snow, and their ability to thrive under the existing chemical and physical conditions in snow-covered regions of the world. More attention has been given to this topic recently, however. Through concurrent experimental and field studies of (semi)volatile organic compounds (VOC), snow-embedded microbes and bioaerosols at several urban, suburban/remote mountainous, and Arctic sites, Hudson and Ariya (2007) show that a wide range of VOC and bioaerosols can be emitted from snow to the atmosphere. They also show that snow-borne taxa can increase snow surface area, and thus modify the snowatmosphere partitioning of chemicals adsorbed on the snow surface (P. Ariya, personal communication). These results suggest that snow photo-biochemical reactions, in addition to physico-chemical reactions, should be considered in describing air-snow exchange.

\subsubsection{The role of organic compounds in snow photochem-} istry

Organic compounds can be involved in snow photochemistry in a number of ways. They can directly absorb photons, thereby changing the radiation balance within the snowpack, and also create radicals that can react with other compounds (including organics) in snow (Hoffmann, 1996). Measurements on filtered, melted snow samples from Summit and Dome Concordia suggest that these direct photoreactions of organics are significant: unknown, presumably organic, species typically account for approximately half of the sunlight absorbed by these samples, while $\mathrm{H}_{2} \mathrm{O}_{2}$ and $\mathrm{NO}_{3}^{-}$account for the other half (Robles and Anastasio, 2007 ${ }^{1}$ ). In addition to direct photoreactions, organic compounds can also react with other radicals generated within the snowpack, such as $\mathrm{OH}$, which has a variety of sources including photodissociation of $\mathrm{H}_{2} \mathrm{O}_{2}$ (Chu and Anastasio, 2005) and, to a smaller extent, photolysis of nitrate in snow (Zhou et al., 2001; Dibb et al., 2002) (see Sect. 4.2). Finally, organic compounds can react directly with reactive species such as $\mathrm{H}_{2} \mathrm{O}_{2}$ and $\mathrm{O}_{3}$ that may also be found within snowpack interstitial air.

\footnotetext{
${ }^{1}$ Robles, T. and Anastasio, C.: Light absorption by soluble chromophores in Arctic and Antarctic snow, J. Geophys. Res., submitted, 2007.
}

There have been several reports demonstrating that some organic molecules are subject to post-depositional processing. Jaffrezo et al. (1994) found that the PAH benzopyrene decreased by nearly $90 \%$ from the surface to the bottom of a $3 \mathrm{~m}$ snow pit in Greenland. The results are consistent with measurements by Hagler et al. (2006) which show much higher concentrations of POC in Greenland surface snow than in shallow snowpits. At this time it is not clear whether the observed degradation of particulate organic compounds in snow is dominated by photochemical or physical processes.

A number of studies have observed ambient and/or firn air concentrations of gas phase organic compounds hinting at organic compound-related photochemistry in snow. Dibb and Aresenault (2002) found that the concentrations of formic and acetic acid in firn air were more than ten-fold higher than ambient concentrations. They hypothesize that snow photochemistry, in particular the production of carbonyls such as formaldehyde through oxidation of organics in snow (Sumner and Shepson, 1999), are linked with the observed production of organic acids in firn air. Haan et al. (2001) conducted chamber experiments on freshly fallen snow from Mount Sonnblick in Austria and found evidence for light-dependent $\mathrm{CO}$ generation. It is worthwhile to note that $\mathrm{CO}$ generation was a function of snow TOC concentration, suggesting that it is related to the oxidation of organic compounds. Haan et al. (2001) also suggest that carbonyls in snow are linked with photochemical CO production. Similarly, Grannas et al. (2004) found that ice pellets made from melted Arctic and Antarctic snow produced $\mathrm{CH}_{2} \mathrm{O}$ and $\mathrm{CH}_{3} \mathrm{CHO}$ when irradiated in the laboratory. Production rates were enhanced by addition of nitrate to the melted snow, perhaps due to enhanced $\mathrm{OH}$ production. Of particular interest is the finding that a variety of organic compounds characterized in this work, in particular plant vascular material, were hypothesized to be involved in the photochemical production of $\mathrm{CH}_{2} \mathrm{O}$ and $\mathrm{CH}_{3} \mathrm{CHO}$ (Grannas et al., 2004).

Radical organic compounds generated through snow photochemistry may also play a more general role through subsequent reactions with compounds of environmental importance. Recently Lahoutifard et al. (2003) suggested that organic radicals in snow are responsible for scavenging gas phase mercury. This finding is supported by experiments where the addition of $\mathrm{H}_{2} \mathrm{O}_{2}$ (an $\mathrm{OH}$ radical source) to snow samples caused a dramatic increase in snow mercury concentrations during solar irradiation.

\subsubsection{Production rates and snow as a source of boundary- layer gas-phase organics}

A number of field and modeling studies indicate that a source of gas-phase organic compounds exists in polar snowpacks, and that the evolution and emission of these species may significantly impact the overlying boundary layer. For example, fluxes of organic compounds such as carbonyls, alkyl halides, 
alkenes, and organic nitrates out of the snowpack have been measured during various field campaigns (Sumner and Shepson, 1999; Hutterli et al., 1999, 2004; Couch et al., 2000; Grannas et al., 2002, 2004; Guimbaud et al., 2002; Dassau et al., 2002; Perrier et al., 2002; Swanson et al., 2002; Dibb et al., 2002; Klán and Holoubek, 2002). Oxygenated hydrocarbons in the atmosphere were measured at Alert from February to May 2000 (Boudries et al., 2002). During sunlight hours, concentrations measured in the snowpack interstitial air were higher than those measured in the overlying boundary layer, implying a positive flux from the snowpack to the Arctic boundary layer, proposed to be related to photochemical production in the snowpack. Guimbaud et al. (2002) found similar behavior for $\mathrm{CH}_{3} \mathrm{CHO}$ and $\mathrm{CH}_{3} \mathrm{C}(\mathrm{O}) \mathrm{CH}_{3}$ and calculated fluxes from the snowpack of $4.2 \times 10^{8}$ and $6.2 \times$ $10^{8}$ molecule $\mathrm{cm}^{-2} \mathrm{~s}^{-1}$, respectively. Hutterli et al. (1999) report fluxes of $\mathrm{CH}_{2} \mathrm{O}$ from sunlit Summit, Greenland snow between 1.4-8.8 $\times 10^{8}$ molecule $\mathrm{cm}^{-2} \mathrm{~s}^{-1}$, and Jacobi et al. (2002) report $8 \times 10^{7}$ molecule $\mathrm{cm}^{-2} \mathrm{~s}^{-1} \cdot \mathrm{CH}_{2} \mathrm{O}$ fluxes from sunlit South Pole snow were on the order of $2 \times 10^{8}$ molecule $\mathrm{cm}^{-2} \mathrm{~s}^{-1}$ (Hutterli, 1999; Hutterli et al., 2004). Bottenheim et al. (2002) report a flux of ethene from Alert, Canada snowpack of the order of $1 \times 10^{7}$ molecule $\mathrm{cm}^{-2} \mathrm{~s}^{-1}$. Swanson et al. (2002) report production rates of several alkyl halides on the order of $10^{3}-10^{5}$ molecule $\mathrm{cm}^{-3} \mathrm{~s}^{-1}$ in irradiated Summit, Greenland snowpack.

Although the aforementioned studies point toward photochemical pathways the emissions of organics are also influenced by physical processing within the snowpack, which in some instances can dominate over photochemical production. In the case of $\mathrm{CH}_{2} \mathrm{O}$, air-snow exchange of $\mathrm{CH}_{2} \mathrm{O}$ accumulated at or near the ice-air interface of snow grains leads to fast equilibration, and to significant fluxes into the boundary layer (see refs in Table 4). In this case, emission is dominated by physical partitioning processes. For example, South Pole data suggest that net photochemical production of $\mathrm{CH}_{2} \mathrm{O}$ within the snow accounts for no more than $20 \%$ of the total measured flux (Hutterli et al., 2004). The partitioning of other low molecular weight carbonyls is less well understood. As mentioned above, $\mathrm{CH}_{3} \mathrm{CHO}$ and $\mathrm{CH}_{3} \mathrm{C}(\mathrm{O}) \mathrm{CH}_{3}$ fluxes were approximated by Guimbaud et al. (2002) and the condensed phase analyses of Houdier et al. (2002) shows seasonal concentration trends in opposition to thermodynamic expectations - implicating photochemical production as a possible explanation for the observations. The modeling work of Grannas et al. (2002) indicates that both snowpack photochemical production and temperature-dependent adsorption/desorption processes play a role in the observed diurnal variations of gas-phase low molecular weight carbonyl compounds in the Arctic boundary layer. To understand the extent to which physical or photochemical processes dominate the measured fluxes of particular organic species will require further fundamental studies of air/snow partitioning and a mechanistic understanding of the processes that may produce these compounds in sunlit snow or ice. It should be noted that fluxes and gradients are related by an exchange velocity and measured concentration gradients may not directly relate to the magnitude of the flux. To quantitatively determine the surface-air flux, and the magnitude of the vertical impact of snowpack emissions/sinks, it is necessary to understand the dynamics above the snow surface, as discussed in Sect. 5.1 and in greater detail in the accompanying boundary layer physics review (Anderson and Neff, 2007).

\subsubsection{Processing of anthropogenic organics in snow/ice}

Although much focus has been on the natural organic matter present in snow and ice, several laboratory studies have focused on the processing of anthropogenic organic materials in sunlit snow and ice. Laboratory experiments are necessary to elucidate snowpack photochemistry, however, at present the substrates generally used are significantly different from natural snow. Experiments use frozen solutions with high reactant concentrations, and it is possible that reactants are located in highly concentrated pockets of liquid solutions. In natural snow, concentrations are much lower, thus reactants could simply be adsorbed or contained in organic aerosols, and reaction pathways could be different.

Klán and coworkers have reported the unusual photobehavior of halobenzenes (such as chlorobenzene, 2- or 4dichlorobenzene, bromobenzene, and 1,4-dibromobenzene) in ice (Klán et al., 2000; Klán et al., 2001). Photolysis of relatively concentrated $\left(>10^{-4} \mathrm{~mol} \mathrm{~L}^{-1}\right)$ frozen solutions of chlorobenzene, for example, produced chlorinated biphenyls (PCBs) or terphenyls as the major products because of the reactant concentrations. Similarly, Klánová et al. (2003 a,b) reported that chlorobiphenyldiols were the major products obtained by UV-irradiation of 2- and 4-chlorophenol $\left(>10^{-7}\right.$ mol L ${ }^{-1}$ ) in ice during laboratory studies at $253 \mathrm{~K}$. Photosolvolysis products (i.e. those resulting from reactions between organic and water molecules) were obtained at temperatures above $263 \mathrm{~K}$ and it was suggested that such transformations must occur in a quasi-liquid layer. Subsequent fieldwork confirmed that the same phototransformations as observed in the laboratory can occur in natural sunlight in polar regions, such as Svalbard (Klán et al., 2003). The toxic effect of these photoproducts was determined by Blaha et al. (2004) and found to be greater than for the parent molecules, suggesting that such chemistry occurring in snow and ice could be highly deleterious to the biosphere. Recent work by Sprenkle and Grannas (2006) indicates that certain persistent organic pollutants are also subject to photochemical degradation in snow/ice. Dubowski and Hoffman (2000) investigated the photochemical degradation of 4-nitrophenol in ice pellets and found products similar to what is produced in liquid water. Guzmán et al. (2006b) reported that frozen aqueous solutions of pyruvic acid, irradiated at $\lambda>300 \mathrm{~nm}$ exibit paramagnetic signals corresponding to distant triplet radical pairs. The photodecarboxylation reaction was shown 
to proceed by the same mechanism with similar quantum efficiencies in water and ice (Guzmán et al., 2006c, 2007).

Oxidation of aromatic and saturated aliphatic hydrocarbons and their derivatives (concentration $=10^{-3}-10^{-5} \mathrm{~mol}$ $\mathrm{L}^{-1}$ ) by $\mathrm{OH}$, photochemically produced from hydrogen peroxide (concentration $=10^{-1}-10^{-5} \mathrm{~mol} \mathrm{~L}^{-1}$ ), in frozen aqueous solutions was recently investigated by Klán and coworkers (Klánová et al., 2003a, b; Dolinova et al., 2007). While aromatic molecules (benzene, phenol, or naphthalene) reacted to form the corresponding hydroxy compounds, saturated hydrocarbons (methane, butane, cyclohexane) were oxidized to alcohols or carbonyl compounds. When frozen solutions containing nitrite or nitrate as well as aromatic compounds (such as phenol or 4-methoxyphenol) were photolyzed, the principal chemical processes included nitration, hydroxylation and coupling reactions (Matykiewiczova et al., 2007). However, the probability of any bimolecular reaction occurring in the natural environment will ultimately depend on organic contaminant local concentrations and oxidant availability at specific locations of the ice/snow matrix, as well as temperature, wavelength, and photon flux.

Although only a few studies report specific speciation, and we are far from understanding the organic carbon mass balance in snow, it is clear that there are a wide range of compounds existing both as particulates and in the QLL. Evidence suggests that these organic compounds play an important role in the chemistry of snow and the overlying atmosphere. There are still many unknowns including the chemical composition of organic compounds, the processes that deposit them to snow surfaces, their ability to partition between the air and snow, and the fundamental chemical processes that transform them within snow. Currently we are able to predict the course of photoreactions of organic compounds in ice/snow qualitatively but have insufficient data to extrapolate the experimental photolysis rate values to those occurring in the natural environment. Similarly, experiments that duplicate more closely the microphysical characteristics of natural snow are required.

\section{Wider impacts of snow photochemistry}

From the data presented above, both direct measurements of fluxes, and also the highly unusual and unexpected chemical composition measured in some regions of the polar boundary layer, it is clear that emissions from polar snowpacks influence the overlying boundary layer. Whether trace gas emissions from the snow have influences beyond the local or regional boundary layer is explored in this section.

5.1 The vertical extent of the influence of snowpack photochemistry

To have an atmospheric influence beyond the local boundary layer, trace gas emissions from snow need to reach the higher troposphere. However, extensive snowcover and reduced diurnal radiation cycles at high latitudes result in greatly reduced convective mixing and frequent conditions of shallow boundary layer depths and high atmospheric stability (see Anderson and Neff, 2007). Consequently, snowpack emissions are likely to be "trapped" in a thin air layer above the snow surface. Even differing boundary layer dynamics at various sites can have significant impacts on the vertical extent of snowpack influence. For example, ozone gradients measured during the summer from a tethered balloon at Summit were small and variable, and positive gradients in the lowest few hundred meters (on the order of a few ppbv) were observed more frequently than negative gradients. These data pointed towards a small uptake of ozone to the snow (Helmig et al., 2002). In contrast, much more pronounced, negative ozone gradients were the predominant, summertime condition at South Pole. Ozone near the surface frequently exceeded two times the levels that were observed in the lower free troposphere (Helmig et al., 2007a). Investigations of balloon sonde records further reveal that enhanced ozone concentrations near the surface are a predominant summertime phenomenon at South Pole (Crawford et al., 2001; Oltmans et al., 2007). Due to the lack of diurnal radiation cycles, stable boundary layer conditions with suppressed vertical mixing were noted to be more pronounced and longer-lasting at South Pole than at other polar locations (Cohen et al., 2007; Helmig et al., 2007a). This causes snowpack emissions at South Pole to accumulate to higher mixing ratios than at other sites. For example, mixing ratios of NO in the first few meters above the surface were significantly elevated and dropped to much lower levels at $100 \mathrm{~m}$ height above the surface (Fig. 11) (Helmig et al., 2007e).

Under these enhanced NO levels, ozone production occurs at rates reaching $\sim 3-6$ ppbv day $^{-1}$ (Crawford et al., 2001; Chen et al., 2004). Concentration gradients are directly related to the atmospheric lifetime of the chemical species. Ozone in the polar boundary layer has an estimated lifetime that is about 2 orders of magnitude longer than for NO. This causes ozone concentrations to decrease more slowly with height, with surface enhancements extending to several hundred meters above the surface (Fig. 11). Increased levels of NO in air nearest the surface were also observed during several aircraft flights made over the Antarctic Plateau (Davis et al., 2006). Various flights were made between South Pole and McMurdo station, including a sortie to Vostok and flights to midway (Dome C). These flights showed that over much (and possibly all) of the Plateau, NO levels were substantially higher than those observed along coastal areas. Mixing ratios of $\mathrm{HO}_{\mathrm{x}}$ and ozone production rates are expected to be highest not right above the surface, but within a distinct, several $10 \mathrm{~s}$ of meters high layer above the surface (Oltmans et al., 2007). Given the non-linearity of $\mathrm{HO}_{\mathrm{x}}-\mathrm{NO}_{\mathrm{x}}$ chemistry and the resulting sharp changes of oxidation rates with height, other chemical reactions are similarly expected to have strong height dependencies. 

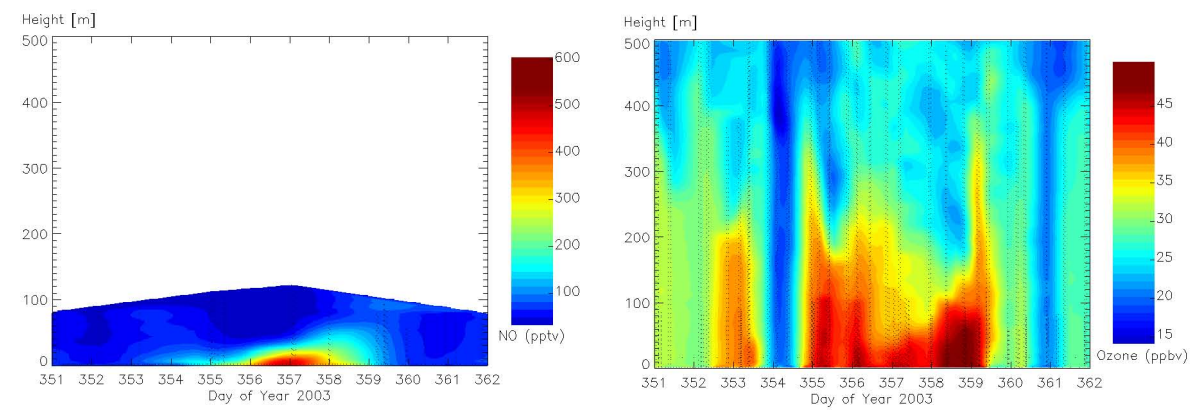

Fig. 11. Comparison of the vertical distribution of NO (left) and ozone (right) during December 2003 at South Pole. These data are from concurrent vertical profile measurements of $\mathrm{NO}$ and ozone using a tethered balloon. (figures adapted from Helmig et al., 2007a, 2007e).

An earlier set of aircraft profile measurements aimed at investigating tropospheric ozone destruction events (ODEs) were carried out during the 2000 TOPSE campaign, flying from Colorado, through the Hudson Bay area, to north of Alert (Ridley et al., 2003). Several vertical profiles were conducted to as low as $30 \mathrm{~m}$ over the surface, including over the Arctic Ocean. At $30 \mathrm{~m}$ no evidence was found of an impact of a surface source of $\mathrm{NO}_{\mathrm{x}}$, while the $\mathrm{CH}_{2} \mathrm{O}$ data were consistent with a significant impact of surface emissions of $\mathrm{CH}_{2} \mathrm{O}$. The authors also concluded that surface sources of HONO had no impact by $30 \mathrm{~m}$, based on the quite low levels of $\mathrm{OH}$.

On the other hand, the halogens responsible for ODEs can have quite significant mixing ratios up to heights of several kilometers (eg. Hönninger and Platt, 2002; Friess et al., 2004; Hönninger et al., 2004), and associated $\mathrm{O}_{3}$ loss has also been observed to 1 to $2 \mathrm{~km}$ (Leaitch et al., 1994; Solberg et al., 1996; Bottenheim et al., 2002; Ridley et al., 2003; Tackett et al., 2007). Please see more discussion on halogen chemistry and ozone in Sect. 4.3 and Simpson et al. (2007).

5.2 Global/regional impacts: modeling assessment and observations

A first study to assess the global impact of the release of $\mathrm{NO}_{\mathrm{x}}$ from the snowpack was carried out by Carver et al. (2004). They used the chemical transport model p-TOMCAT (Savage et al., 2004) which includes a detailed inventory of $\mathrm{NO}_{\mathrm{x}}$ emissions, including for example, lightning and ship emissions. A number of multiannual integrations were carried out with the model to assess the impact of the release of snowpack $\mathrm{NO}_{\mathrm{x}}$. Different scenarios were used in which the $\mathrm{NO}_{\mathrm{x}}$ emission rate was varied to look at the sensitivity of model results to the emission rate. The $\mathrm{NO}_{\mathrm{x}}$ emission was taken to occur over all snow covered regions around the globe during sunlit hours (solar zenith angle $<90$ ). Results from the model runs show that the estimated global $\mathrm{NO}_{\mathrm{x}}$ emission from snow is less than $1 \%$ of the global total. The polar regions accounted for most of the emissions due to the longer day compared to lower latitudes. Model results for a realistic emission scenario showed very large differences in surface $\mathrm{NO}_{\mathrm{x}}$ for Antarctica, with 10-fold increases in places, whereas in the northern polar regions the impact of snow emissions on surface $\mathrm{NO}_{\mathrm{x}}$ was considerably less. This is due to the much lower background concentration of $\mathrm{NO}_{\mathrm{x}}$ in the southern hemisphere. The study concluded that release of $\mathrm{NO}_{\mathrm{x}}$ from the snowpack makes a significant impact locally over Antarctica, consistent with observations.

Another question is whether the chemistry driving emissions from snow is occurring at other altitudes in the atmosphere. Cirrus clouds, for example, are radiatively important in the atmosphere and also provide surfaces for heterogeneous reactions. Laboratory studies have shown that $\mathrm{HNO}_{3}$ can be taken up by ice surfaces at tropospheric temperatures (e.g., Hudson et al., 2002) and observations of uptake of $\mathrm{HNO}_{3}$ by cirrus are accumulating (e.g., Weinheimer et al., 1998; Popp et al., 2004; Ziereis et al., 2004). A long-standing issue within atmospheric chemistry is that numerical models generally overestimate $\mathrm{HNO}_{3} / \mathrm{NO}_{\mathrm{x}}$ ratios in the upper troposphere (e.g., Chatfield, 1994; Brunner et al., 2005). Various model studies have considered different variables that might affect this ratio, such as lightning and convective transport from the polluted boundary layer (Brunner et al., 2003; Staudt et al., 2003), and heterogeneous reactions on sulfate aerosol (Tie et al., 2003). Calculations indicate that the photolysis of $\mathrm{NO}_{3}^{-}$on cirrus ice particles is too slow to improve model overestimations of the $\mathrm{HNO}_{3} / \mathrm{NO}_{\mathrm{x}}$ ratio (Chu and Anastasio, 2003), but there might be other ice chemical processes that are significant in this conversion.

\subsection{Implications of snow photochemistry for the ice core community}

Ice cores are powerful archives detailing how the Earth's atmospheric composition and climate have changed over time (e.g. Legrand and Mayewski, 1997; EPICA community members, 2004). Provided there are no significant production or loss processes in the firn column and/or air bubbles, then the composition of air trapped in ice is representative of the overlying air, which, in the case of trace gases with long lifetimes, may also represent an "average" hemispheric 
or global concentration. For Antarctic ice, this condition is more or less met, so that ice cores have provided us with detailed records of $\mathrm{CH}_{4}, \mathrm{CO}_{2}$, and $\mathrm{N}_{2} \mathrm{O}$ over timescales up to 800 kyr (Siegenthaler et al., 2005; Spahni et al., 2005) . The question, then, is whether photochemistry occurring in the snowpack influences the preserved concentrations of minor impurities, with a consequent effect on our ability to interpret them.

Ice cores hold the potential to tell us about other aspects of atmospheric chemistry, e.g. changes in the oxidative capacity or in $\mathrm{NO}_{\mathrm{x}}$ chemistry. The primary molecules and radicals involved, however, are short-lived, so the emphasis has been on studying more stable reaction products, such as $\mathrm{CH}_{2} \mathrm{O}$ (Staffelbach et al., 1991) and $\mathrm{H}_{2} \mathrm{O}_{2}$ (Sigg and Neftel, 1988) for the oxidative capacity, and $\mathrm{NO}_{3}^{-}$for $\mathrm{NO}_{\mathrm{x}}$ chemistry (Wolff, 1995). Unfortunately there are two issues: (a) the ice record is derived from the polar boundary layer and may be disconnected from the relevant global or regional picture; (b) many of the important chemicals are found in the snow phase and are poorly preserved as the snow is compacted into firn and then ice. Snow photochemistry is relevant to both these issues. For the latter issue, the importance of snow photochemistry depends on the residence time in the photic zone and how this compares with the photolytic lifetime of the impurity. With an e-folding depth of actinic flux on the order of $5-25 \mathrm{~cm}$, snow layers at low accumulation rate sites, such as in central Antarctica, remain under the influence of light for as much as several years and can undergo particularly intense photolytic loss.

For both $\mathrm{CH}_{2} \mathrm{O}$ and $\mathrm{H}_{2} \mathrm{O}_{2}$, it seems now to be wellestablished that both physical (Hutterli et al., 2002, 2003) and photochemical (Sumner and Shepson, 1999) processes alter the concentrations preserved in polar ice. $\mathrm{H}_{2} \mathrm{O}_{2}$ in either the gas or aqueous phase would have a photochemical lifetime of several days in the upper layers of snow; therefore if it can reach the surface of snow grains it can be photolyzed to $\mathrm{OH}$ (which itself may then influence the concentrations of other molecules). However, physical exchange of $\mathrm{H}_{2} \mathrm{O}_{2}$ between the gas and snow phase is not limited to the photic zone, making it likely that physical processes determine the $\mathrm{H}_{2} \mathrm{O}_{2}$ ice core record and no measurable influence from photolysis is expected, since surface snow is buried by subsequent snowfall and moved rapidly below the photic zone. Decadal averages of $\mathrm{H}_{2} \mathrm{O}_{2}$ preserved in the West Antarctic Ice Sheet show indeed a strong correlation to local accumulation rate (Frey at al., 2006). For $\mathrm{CH}_{2} \mathrm{O}$, production from organic material in the ice (Sumner and Shepson, 1999, Grannas et al., 2004) and photolysis to CO (as one possible product) (Haan et al., 2001) may both occur, but again it seems likely that physical uptake and loss dominates the final preservation of the molecule in the ice sheet (Hutterli et al., 2003, 2004). The implication is that, for these compounds, to understand the relationship between concentrations in the overlying air and those preserved in firn beneath the photic zone, we need to concentrate on models that de- scribe the physical air-firn equilibria, but that we may be able to finesse the photochemical processes in the upper layers. More difficult is the relationship between the chemistry of these compounds in the polar boundary layer and any globally relevant properties. This is certainly heavily influenced both by the confined nature of the boundary layer and by photochemical production and physical emission from snow and ice: for example, at South Pole, concentrations of both molecules are several times higher in the lowest levels of the atmosphere compared to those calculated from models that ignore emissions from the snowpack (Hutterli et al., 2004).

For nitrate in snow, the situation is also complicated. It has been calculated that, for snow accumulation rates and actinic fluxes typical for central Antarctica, as much as $40 \%$ of deposited nitrate might be photolyzed in the snowpack (Wolff et al., 2002). Although 40\% might seem significant (and recent findings of deeper light penetration into polar snow would suggest even larger photolytic losses, Warren et al., 2006), it turns out that central Antarctic sites undergo huge losses of nitrate (in extreme cases by a factor 100) (Röthlisberger et al., 2000), and these losses continue down to $50 \mathrm{~cm}$ or more, where photolytic losses should be small. It therefore seems likely that physical losses of nitric acid dominate over photochemical losses, a suggestion that seems to be confirmed by measurements of $\delta^{15} \mathrm{~N}$ in nitrate in firn (Blunier et al., 2005) (see earlier discussion). In coastal sites with higher snow accumulation rates, smaller losses of nitrate can be expected despite the somewhat higher actinic fluxes. However, we know that snow photochemistry very much dominates the $\mathrm{NO}_{\mathrm{x}}$ chemistry of the boundary layer at some sites (Davis et al., 2001), and so there probably is a close relationship between snow nitrate concentrations and local $\mathrm{NO}_{\mathrm{x}}$ concentrations, but with the large snow reservoir dominating the system. More interesting at the larger scale is to investigate how the input from outside the combined firn-boundary layer box influences the nitrate concentration preserved in snow and ice, and modeling studies are needed to investigate this further.

A secondary effect of the photochemistry might also be to induce an artificial seasonal cycle, because snow deposited just before the winter is buried before it can be significantly photolyzed. Alternatively, redeposition of nitric and pernitric acid formed from $\mathrm{NO}_{\mathrm{x}}$ generated in the top 10-20 cm of the snowpack could create a summertime surface peak in nitrate that actually represented redistribution of nitrate that accumulated over much longer times (nearly a year at South Pole, or several years at very low accumulation rate sites in central east Antarctica).

One further comment is that under conditions of the last glacial maximum (LGM) we expect compounds such as nitric acid to be "fixed" by reaction with alkaline dust material in the air or the snowpack (Röthlisberger et al., 2002). Under these conditions, physical exchange probably becomes negligible, and photochemical loss may also be reduced (if nitrate no longer sits on the outside of snow crystals). Such changes, 
induced ultimately by climate, must also be considered.

In summary, although snow photochemistry is clearly very important for the chemistry of the polar boundary layer, physical exchange seems to be a more important determinant of what is preserved in deeper firn. If, however, we want to learn anything of more than local interest from these concentrations, we need to use modeling to determine which influences from a more regional or global scale can still be discerned in the preserved concentrations, despite the complications of the boundary layer/firn reactor.

\section{Current limitations}

There are currently a number of major constraints limiting progress in our understanding of snow phase photochemistry and its impacts on atmospheric composition. These are issues for field, laboratory and modeling studies, as discussed here.

\subsection{Field studies}

\subsubsection{Infrastructure and access for field studies}

Field studies in polar environments are highly challenging and the difficulties of accessing these regions with appropriate instrumentation are significant limitations in the study of snowpack photochemistry. For example, there are only a limited number of fully supported field laboratories in polar regions, and to allow detailed chemical and physical analysis, they must have access to uncontaminated snow and ice and clean air. Field stations may be carefully located to minimize contamination, but an important area of research is in development of renewable (non-fossil) sources of electric power for research in these extreme environments. This is currently happening at the GeoSummit station Greenland, but similar sites are needed elsewhere in the Arctic and Antarctica. Furthermore, the harsh conditions associated with polar research lead naturally to the majority of research being carried out during the summer months. To really probe the processes at work extended measurement campaigns with year-round duration are necessary.

Assessments of trace gas fluxes out of the snowpack can be used to parameterize numerical model calculations into wider impacts of snow photochemistry. These fluxes are influenced by a number of variables, including atmospheric stability, frequency of fresh snow fall events, snowpack concentrations, and changes in irradiance. More flux measurements carried out during all seasons and addressing a wider range of chemical species are required and these experiments should also aim at differentiating between contributions from physical and photochemical sources. Flux measurements are experimentally very challenging, as they require either a method for the fast and selective measurement of the species of interest for eddy correlation measurement or highly precise and accurate measurements for flux determinations by the tower gradient methods. For many of the gases of interest, such instrumentation is currently not available. Furthermore, micrometeorological flux measurement approaches often fail under the frequently highly stable conditions over snow, therefore improvements in micrometeorological methods for flux measurements under stable conditions are desireable. Finally, much of the previous snow research has been done in polar environments. In order to assess the influence globally, flux measurements are also needed at snow-covered non-polar locations.

To date, few studies have focused on snow photochemistry occurring in mid-latitude regions. It is likely that snowpack photochemistry will be very active at lower latitudes, due to lower solar zenith angle, increased irradiance and higher concentrations of reactive precursors within snow (nitrate, peroxide, organic materials, etc). It could also be expected that the chemistry occurring in the QLL would be more active at mid-latitudes, as the liquid water content of a relatively warm mid-latitude snowpack would be larger than in a much colder, high latitude snowpack. However, the overall impact of snowpack emissions to the overlying boundary layer may be less due to the proximity to anthropogenic influences of e.g. $\mathrm{NO}_{\mathrm{x}}$. To assess the influence of mid-latitude snow on atmospheric chemistry will require further field studies in these regions.

\subsubsection{Instrumentation for field studies}

A crucial question concerns the impact of snowpack photochemistry on the overlying atmosphere, as outlined in Sect. 5 . To address this question in the field it is currently necessary to use instrument platforms such as tall towers, tethered balloons, released balloons, blimps, and/or aircraft. For several of these platforms, associated instrumentation must be light weight and low-power, and such instrumentation currently only exists for a very limited suite of molecules. Instrumentation must also be developed for remotely sensing the vertical structure of the atmosphere, including variations in composition, over the snowpack.

Making gas phase measurements within the snowpack interstitial air is difficult, particularly for some molecules at very low mixing ratios. Gas phase sampling rates can be on the order of many liters of air per minute, which leads to efficient artificial ventilation of the snowpack from ambient air above (or interstitial air below) the point of sampling (Albert et al., 2002). This will lead to a potentially mixed signal of both interstitial and boundary layer air and may mask real concentration differences that exist between these two locations. Passive sampling methods could be developed (such as those currently used for persistent organic pollutants, e.g. Farrar et al., 2006), however these often require long exposure times, so high resolution measurements would be prohibited. Additionally, incorporation of such samplers into the snowpack is difficult to achieve without disturbing the very medium they are intended to study. 


\subsection{Laboratory studies}

\subsubsection{Laboratory studies on snow surfaces}

Laboratory studies of snow surfaces are severely limited by the techniques used to generate the frozen samples studied. Often the analytical detection limits of instrumentation used to monitor processes are well above the typical ambient level of a reactive species present in a natural snowpack. Thus, investigators may find it necessary to use high solute concentrations (relative to what is present in a natural snow sample). If solute concentrations are very high, it is possible that complete freezing will not be achieved and the experimental surface being studied is actually a liquid and not a true disordered QLL. Additionally, samples frozen under laboratory conditions certainly do not represent the true nature of a natural snow formed by e.g., condensation of water vapor onto IFN or riming. Regardless, laboratory studies provide important information about the nature of the surface, reactivity of species in frozen matrices and mechanistic considerations that prove invaluable to field and modeling studies and efforts to improve laboratory techniques are continuing.

\subsubsection{Chemical analysis of snow}

There is substantial uncertainty about the chemical nature of important snowpack reactants and chromophores, particularly for organic constituents. The chemical analysis of snow for organics is complicated by the fact that much of the organic matter in snow derives both from biota and from bacteria (Sattler et al., 2001; Grannas et al., 2004) and may be in both dissolved and particulate phases. Analysis of meltwater samples will not be representative of the original distribution of organics between the dissolved and particulate phases, thus it is imperative that techniques be developed that can probe the snow chemical environment in situ. This will probably take the form of advanced microscopic or spectroscopic techniques, such as scanning electron microscopy (SEM), nuclear magnetic resonance (NMR) or non-linear spectroscopic methods such as sum frequency generation (SFG) or second harmonic generation (SHG). Similar issues exist for measurement of $\mathrm{pH}$ on the surfaces of snow crystals/grains; $\mathrm{pH}$ of the intact QLL, for example, is likely to be significantly different to that of the melted crystal. We note also that stable isotope studies on trace species in snow and air is a fast growing field with interesting potentials on key processes taking place in the firn/snow interface. Isotope fractionation factors are a good indicator of kinetic processes, with the possibility of differentiating between physical and chemical processes. Sensitivity is constantly improving and new techniques based on spectroscopy methods (e.g. cavity ring down spectroscopy) are emerging with the advantage of in situ, passive and non-disturbing analysis coupled with light weight and low energy consumption equipment capable of producing high-time resolution records of concentration and isotopic composition.

\subsubsection{Nano/micro-scale physical and chemical analysis}

A major set of issues for snowpack photochemistry lies within the physical realm of the reactants and photochemistry in the snowpack. As discussed earlier, reactants can be located on snow crystal surfaces and can also be dissolved within the ice crystal lattice, trapped in aerosol particles, at grain boundaries or in pockets of concentrated solutions that could for example be formed during riming. Knowing where reactants reside is fundamental to theoretical studies of snow photochemistry. The issue of the physical environment is a difficult one and has been the subject of only a few studies. Scanning electron microscopy/energy dispersive spectrometry (SEM-EDS) work (Obbard et al., 2003; Barnes and Wolff, 2004) suggests that the location of reactants cannot be explained by considering only the nature of the reactant. Most likely, interactions between different species come into play, as well as the mechanism of formation of the ice. More studies of natural snow using a variety of advanced microscopic and spectroscopic techniques (e.g., SEM-EDS, extended x-ray absorption fine structure (EXAFS), atomic force microscopy (AFM), SFG, SHG, NMR) are in order if we wish to progress on these aspects. The relevance of reactions on deposited aerosol that is incorporated into the snowpack as reactive sites cannot be addressed with current methods. The relative importance of reactions in the snowpack interstitial air, on aerosol particles, in the QLL or other sites is unknown at this point but crucial for our quantitative understanding of the processes and for our ability to eventually include these processes in detail in numerical models.

Furthermore, we currently have a very limited understanding of the kinetics of reactions occurring on/in snow. Indeed, there are numerous unknowns that must be tackled before we can routinely predict the rates of these reactions. For example, the concentrations of $\mathrm{OH}$ and other oxidants on snow grains must be measured in order to estimate the reaction rates between oxidants and snow grain contaminants. In addition, the rate constants for these snow grain reactions must be determined. It is currently unclear whether rate constants can be estimated from solution data or whether they are specific for ice at a given temperature and composition. While quantum yields for the direct photolysis of chromophores such as nitrate and hydrogen peroxide behave similarly in solution and ice (e.g., Chu and Anastasio, 2003, 2005), secondorder thermal reactions that require collisions between the two reactants are likely to be not as well behaved. Direct photochemical reactions of organic compounds probably also play a significant role in chemistry occurring on snow surfaces, but understanding these processes will require determining the identities of the organics, their light absorption properties and quantum yields for reaction, and the products formed. 


\subsection{Modeling studies}

The real test of our understanding of snowpack photochemistry is whether the first principle based numerical models can simulate observations. The challenges currently presented to us involve not only incomplete, or lack of, understanding of the polar physical and chemical processes (e.g., snow chemistry and air-snow exchanges) but also scarce meteorological observations necessary for model simulations in polar regions. One critical need is for specific, lower dimensional models, based on first principles and including all relevant chemical species, to describe the chemistry of the atmosphere-snow system. Development of modules describing chemistry occurring in the QLL and ice grains is at early stages. These modules will need to be coupled to models of the transport processes that exchange reactants and products between the several condensed phases and the firn air within the snowpack, and between the snowpack and the overlying lowermost part of the atmospheric boundary layer. Heterogeneous processing within this lowermost boundary layer also needs to be simulated because uptake by aerosol, fog and snowflakes contributes to recycling of reactive species emitted from snow; reactions in these atmospheric condensed phases may also transform the emitted species to different chemical forms. Such a unified 1-D model could then link the snowpack and boundary layer to the free troposphere above sunlit snow. A long-term goal is to couple such snowpack models to 3-D atmospheric chemistry transport models to allow calculations of snowpack photochemistry and investigate its impacts over large geographical areas as well as the impact of transport from lower latitudes on snowpack chemical compositions.

\section{Conclusions}

The capacity for snow on the Earth's surface to photochemically-generate reactive trace gases and release them into the overlying atmosphere is an important phenomenon that has only recently come to light. Measurements in both polar regions have shown that emissions from snow are fundamental to driving local and regional boundary layer chemistry; early modeling studies are exploring the global effect. The scientific community has made significant progress in understanding snow photochemistry since its initial discovery. Field measurements investigating gasphase, aerosol-phase and snow-phase chemistry have been undertaken in a variety of locations. Laboratory studies have investigated, both qualitatively and quantitatively, a variety of important factors such as reaction rates and mechanisms, quantum yields, fundamental behavior of molecules at the snow/ice surface, and partitioning of chemicals within snow/ice. There remains a lot to investigate and to learn, but obstacles limiting the progress of our understanding (e.g. the analytical techniques available to study processes at the microscopic and molecular level) are not insignificant.

The Earth's cryosphere is undergoing significant change. Reductions in sea ice extent in both the Arctic and parts of the Antarctic are already reported, and further reductions as well as decreases in global land snowcover are anticipated. These changes will affect the influence of snowpack photochemistry, adding urgency to our current task of understanding and quantifying relevant processes. For example, a reduction in global snowcover (both over land and ocean) will reduce the net emission of trace gases from snow into the atmosphere while increasing processes that occur on the underlying surfaces. In addition, changes in precipitation rates will affect scavenging processes. The modeling studies carried out to date, as well as field observations, suggest that reductions in snowpack emissions are likely to be regionally important, but the direct effect globally has not yet been addressed. Secondary effects might also be anticipated from a reduced albedo, which will reduce photolysis rates and hence the fate of snowpack products. Similarly, changes in atmospheric stability and mixing, resulting from increased heat inputs will tend to dilute the concentrations of species emitted from the surface, again slowing photochemistry. Further, trace gases emitted from snow or influenced by these emissions (e.g., $\mathrm{OH}, \mathrm{NO}$ and halogens) are involved in production of CCN from DMS. Reduced snowpack photochemistry would decrease DMS oxidation rates and hence CCN production. Finally, as discussed earlier (and see also Simpson et al., 2007), concentrations of polar boundary layer ozone are also affected by snowpack photochemistry. In polar regions, the radiative impacts of ozone are more important than at lower latitudes due to lower concentrations of water vapor. Hansen et al. (2005) have concluded that tropospheric ozone is an important contributor to warming and sea ice loss in the Arctic. However, in particular through the reactions involving halogens, there is an intriguing positive feedback between sea ice loss, and the contribution of tropospheric ozone to radiative forcing, as loss of sea ice may cause reduced ozone depletion events and higher ozone levels, with increased radiative forcing and warming from tropospheric ozone.

It is thus clear that a warming climate will affect trace gas emissions from snow and all the subsequent processes that these emissions influence. It is essential that we build on our current knowledge in order to develop comprehensive numerical models that can address issues of snow photochemistry and its influence on the regional and global atmosphere both now and in a future warmer world.

Acknowledgements. This paper arose from a meeting held at LGGE, Grenoble, in May 2006. It was sponsored by the International Global Atmospheric Chemistry program (IGAC), the British Antarctic Survey, LGGE, Rgion Rhone-Alpes, Universit Jopseph Fourier and the city of Grenoble. This paper is a contribution to the IGAC task on Air-Ice Chemical Interactions (AICI). Each of the three first authors on this work contributed equally to this review 
article, and the subsequent alphabetic list of co-authors includes contributors of major material and review of the manuscript. We would like to thank IGAC, the British Antarctic Survey, the National Science Foundation Office of Polar Programs and the National Science Foundation Atmospheric Sciences Division (NSF-ATM \#0547435)) for financial support of this effort. We would like to thank P. Ariya for making unpublished material available to us and D. Davis for helpful discussion. We thank an anonymous reviewer for helpful comments which improved the quality of the final manuscript.

Edited by: W. T. Sturges

\section{References}

Abbatt, J. P. D.: Interactions of atmospheric trace gases with ice surfaces: Adsorption and reaction, Chem. Rev., 103, 4783-4800, 2003.

Adams, J .W., Holmes, N. S., and Crowley, J. N.: Uptake and reaction of $\mathrm{HOBr}$ on frozen and dry salt surfaces, Atmos. Chem. Phys., 2, 79-91, 2002,

http://www.atmos-chem-phys.net/2/79/2002/.

Albert, M. R., Grannas, A. M., Bottenheim, J. W., Shepson, P. B., and Perron, F. E.: Processes and properties of snow-air transfer in the high Arctic with application to interstitial ozone at Alert, Canada, Atmos. Environ., 36, 2779-2787, 2002.

Alexander, B., Savarino, J., Kreutz, K., and Thiemens, M. H.: Impact of preindustrial biomass-burning emissions on the oxidative pathways of tropospheric sulfur and nitrogen, J. Geophys. Res., 109, D08303, doi:10.1029/2003JD004218, 2004.

Amoroso, A., Beine, H. J., Sparapani, R., and Nardino, M.: Observation of coinciding Arctic boundary layer ozone depletion and snow surface emissions of nitrous acid, Atmos. Environ., 40, 1949-1956, 2005.

Anastasio, C., Faust, B. C., and Rao, C. J.: Aromatic carbonyl compounds as aqueous-phase photochemical sources of hydrogen peroxide in acidic sulfate aerosols, fogs, and clouds. 1. Non-phenolic methoxybenzaldehydes and methoxyacetophenones with reductants (phenols), Environ. Sci. Technol., 31(1), 218-232, 1997.

Anastasio, C. and Jordan, A. L.: Photoformation of hydroxyl radical and hydrogen peroxide in aerosol particles from Alert, Nunavut: implications for aerosol and snowpack chemistry in the Arctic, Atmos. Environ., 38, 1153-1166, 2004.

Anastasio, C. and Matthew, B. M.: A chemical probe technique for the determination of reactive halogen species in aqueous solution: Part 2 - Chloride solutions and mixed bromide/chloride solutions, Atmos. Chem. Phys., 6, 2439-2451, 2006, http://www.atmos-chem-phys.net/6/2439/2006/.

Anastasio, C., Galbavy, E. S., Hutterli, M. A., Burkhart, J. F., and Friel, D. K.: Photoformation of hydroxyl radical on snow grains at Summit, Greenland, Atmos. Environ., 41(24), 51105121, doi:10.1016/j.atmosenv.2006.12.011, 2007.

Anderson, P. S. and Neff, W. D.: Boundary Layer Physics over Snow and Ice, Atmos. Chem. Phys. Discuss., 7, 7625-7677, 2007

Aoki, T., Fukabori, M., Hachikubo, A., Tachibana, Y., and Nishio, F.: Effects of snow physical parameters on spectral albedo and bidirectional reflectance of snow surface, J. Geophys. Res., 105(D), 10219-10236, 2000.

Arimoto, R., Nottingham, A. S., Webb, J., Schloesslin, C. A., and Davis, D. D.: Non-sea salt sulfate and other aerosol constituents at the South Pole during ISCAT, Geophys. Res. Lett., 28(19), 3645-3648, 2001.

Arimoto, R., Hogan, A., Grube, P., Davis, D., Webb, J., Schloesslin, C., Sage, S., and Raccah, F.: Major ions and radionuclides in aerosol particles from the South Pole during ISCAT-2000, Atmos. Environ., 38(32), 5473-5484, 2004.

Avallone, L. M., Toohey, D. W., Fortin, T. J., McKinney, K. A., and Fuentes, J. D.: In situ measurements of bromine oxide at two high-latitude boundary layer sites: Implications of variability, J. Geophys. Res., 108, 4089, doi:10.1029/2002JD002843, 2003.

Bales, R. C., Losleben, M., McConnell, J., Fuhrer, K., and Neftel, A.: $\mathrm{H}_{2} \mathrm{O}_{2}$ in snow, air and open pore space in firn at Summit, Greenland, Geophys. Res. Lett., 22(10), 1261-1264, 1995.

Banham, S. F., Horn, A. B., Koch, T. G., and Sodeau, J. R.: Ionisation and solvation of stratospherically relevant molecules on ice films, Faraday. Disc., 100, 321-332, 1995.

Barnes, P. R. F. and Wolff, E. W.: Distribution of soluble impurities in cold glacial ice, J. Glaciol., 50, 311-324, 2004.

Bartels-Rausch, T., Eichler, B., Zimmermann, P., Gäggeler, H. W., and Ammann, M.: The adsorption enthalpy of nitrogen oxides on crystalline ice, Atmos. Chem. Phys., 2, 235-247, 2002, http://www.atmos-chem-phys.net/2/235/2002/.

Bartels-Rausch, T., Guimbaud, C., Gäggeler, H. W., and Ammann, M.: The partitioning of acetone to different types of ice and snow between 198 and 223 K, Geophys. Res. Lett., 31, L16110, doi:10.1029/2004GL020070, 2004.

Bausch, A. R., Grannas, A. M., and Mahanna, K. M.: Photochemistry in the quasi-liquid layer of ice, Abstracts, 35th Northeast Regional Meeting of the American Chemical Society, Binghamton, NY, United States, 5-7 October, NRM-399, 2006.

Beine, H. J., Jaffe, D. A., Herring, J. A., Kelley, J. A., Krognes, T., and Stordal, F.: High latitude springtime photochemistry part I: $\mathrm{NO}_{\mathrm{x}}$, PAN and Ozone relationships, J. Atmos. Chem., 27, 127153, 1997.

Beine, H. J., Allegrini, I., Sparapani, R., Ianniello. A., and Valentini, F.: Three years of springtime trace gas and particle measurement at Ny-Ålesund, Svalbard, Atmos. Environ., 35(21), 3645-3658, 2001.

Beine, H. J., Dominé, F., Simpson, W. R., Honrath, R. E., Sparapani, R., Zhou, X., and King, M.: Snow-pile and chamber experiments during the Polar Sunrise Experiment 'Alert 2000': Exploration of nitrogen chemistry, Atmos. Environ., 36(15-16), 27072719, 2002a.

Beine, H. J., Honrath, R. E., Dominé, F., Simpson, W. R., and Fuentes, J. D.: $\mathrm{NO}_{\mathrm{x}}$ during background and ozone depletion periods at Alert: Fluxes above the snow surface, J. Geophys. Res., 107(D21), 4584, doi:10.1029/2002JD002082, 2002 b.

Beine, H. J., Dominé, F., Ianniello, A., Nardino, M., Allegrini, I., Teinila, K., and Hillamo, R.: Fluxes of nitrates between snow surfaces and the atmosphere in the European high Arctic, Atmos. Chem. Phys., 3, 335-346, 2003, http://www.atmos-chem-phys.net/3/335/2003/.

Beine, H. J., Amoroso, A., Esposito, G., Sparapani, R., Ianniello, A., Georgiadis, T., Nardino, M., Bonasoni, P., Cristofanelli, P., and Dominé, F.: Deposition of atmospheric nitrous acid 
on alkaline snow surfaces, Geophys. Res. Lett., 32, L10808, doi:10.1029/2005GL022589, 2005.

Beine, H. J., Amoroso, A., Dominé, F., King, M., Nardino, M., Ianniello, A., and France, J. L.: Surprisingly small HONO emissions from snow surfaces at Browning Pass, Antarctica, Atmos. Chem. Phys., 6, 2569-2580, 2006,

http://www.atmos-chem-phys.net/6/2569/2006/.

Bergin, M. H., Jaffrezo, J.-L., Davidson, C. L., Caldow, R., and Dibb, J.: Fluxes of chemical species to the Greenland ice sheet at Summit by fog and dry deposition, Geochim. Cosmochim. Acta, 58, 3207-3215, 1994

Bergin, M. H., Jaffrezo, J.-L., Davidson, C. I., Dibb, J. E., Pandis, S. N., Hillamo, R., Maenhaut, W., Kuhns, H. D., and Makela, T.: The contribution of snow, fog, and dry deposition to the summer flux of anions and cations at Summit, Greenland, J. Geophys. Res., 100, 16275-16288, 1995.

Bergin, M. H., Pandis, S. N., Davidson, C. I., Jaffrezo, J.-L., Dibb, J. E., Russell, A. G., and Kuhns, H. D.: Modeling of the processing and removal of trace gas and aerosol species by Arctic radiation fogs and comparison with measurements, J. Geophys. Res., 101, 14 465-14 478, 1996.

Berresheim, H. and Eisele, F. L.: Sulfur chemistry in the Antarctic Troposphere Experiment: An overview of project SCATE, J. Geophys. Res., 103, 1619-1628, 1998.

Bertilsson, L., Engquist, I., and Liedberg, B.: Interaction of dimethyl methylphosphonate with alkanethiolate monolayers studied by temperature-programmed desorption and infrared spectroscopy, J. Phys. Chem. B, 101, 6021-6027, 1997.

Bertilsson, L., Potje-Kamloth, K., Liess, H. D., and Liedberg, B.: On the adsorption of dimethyl methylphosphonate on selfassembled alkanethiolate monolayers: Influence of humidity, Langmuir, 15, 1128-1135, 1999.

Betterton, E. A. and Anderson, D. J.: Autoxidation of N(III), S(IV) and other Species in Frozen Solution - a Possible Pathway for Enhanced Chemical Transformation in Freezing Systems, J. Atmos. Chem., 40, 171-189, 2001.

Beyersdorf, A. J., Blake, N. J., Swanson, A. L., Meinardi, S., Dibb, J. E., Sjostedt, S., Huey, G., Lefer, B., Rowland, F. S., and Blake, D. R.: Hydoxyl concentration estimates in the sunlit snowpack at Summit, Greenland, Atmos. Environ., 41(24), 5101-5109, 2007.

Blaha, L., Klánová, J., Klán, P., Janosek, J., Skarek, M., and Ruzicka, R.: Toxicity increases in ice containing monochlorophenols upon photolysis: Environmental consequences, Environ. Sci. Technol., 38, 2873-2878, 2004.

Blais, J. M., Schindler, D. M., Muir, D. C. G., Kimpe, L. E., Donald, D. B., and Rosenberg, B.: Accumulation of persistent organochlorine compounds in mountains of western Canada, Nature, 395, 585-588, 1998.

Blais, J. M., Schindler, D. W., Muir, D. C. G., Sharp, M., Donald, D., Lafreniere, M., Braekevelt, E., and Strachan, W. M. J.: Melting glaciers: A major source of persistent organochlorines to subalpine Bow Lake in Banff National Park, Canada, Ambio. 30(7), 410-415, 2001a.

Blais, J. M., Schindler, D. W., Sharp, M., Braekevelt, E., Lafreniere, M., McDonald, K., Muir, D. C. G., and Strachan, W. M. J.: Fluxes of semivolatile organochlorine compounds in Bow Lake, a high-altitude, glacier-fed, subalpine lake in the Canadian rocky mountains, Limnol. Oceanog., 46(8), 2019-2031, 2001 b.

Bloss, W., Lee, J., Heard, D., Salmon, R., Bauguitte, S., and
Jones, A.: Box model studies of $\mathrm{OH}$ and $\mathrm{HO}_{2}$ levels during the CHABLIS campaign at Halley Base, Antarctica, EGU General Assembly, Vienna, April 2006, Geophys. Res. Abstracts, Volume 8, 03328, 2006.

Bloss, W., Lee, J., Heard, D., Salmon, R., Bauguitte, S., and Jones, A.: Observations of $\mathrm{OH}$ and $\mathrm{HO}_{2}$ radicals in coastal Antarctica, Atmos. Chem. Phys. Discuss., 7, 2893-2935, 2007, http://www.atmos-chem-phys-discuss.net/7/2893/2007/.

Blunier, T., Floch, G. L., Jacobi, H.-W, and Quansah, E.: Isotopic view on nitrate loss in Antarctica surface snow, Geophys. Res. Lett., 32, L13501, doi:10.1029/2005GL023011, 2005.

Bohren, C. F. and Barkstrom, B.-R.: Theory of the optical properties of snow, J. Geophys. Res., 79, 4527-4535, 1974.

Borodin, A., Hofft, O., Kahnert, U., Kempter, V., Krischok, S., and Abou-Helal, M. O.: The interface between benzenes $\left(\mathrm{C}_{6} \mathrm{H}_{6}\right.$; $\mathrm{C}_{6} \mathrm{H}_{5} \mathrm{Cl} ; 2-\mathrm{C}_{6} \mathrm{H}_{4} \mathrm{OHCl}$ ) and amorphous solid water studied with metastable impact electron spectroscopy and ultraviolet photoelectron spectroscopy (HeI and II), J. Chem. Phys., 120, 54075413, 2004.

Bottenheim, J. W., Fuentes, J. D., Tarasick, D. W., and Anlauf, K. G.: Ozone in the Arctic lower troposphere during winter and spring 2000 (ALERT2000), Atmos. Environ., 36, 2535-2544, 2002.

Boudries, H., Bottenheim, J. W., Guimbaud, C., Grannas, A. M., Shepson, P. B., Houdier, S., Perrier, S., and Dominé, F.: Distribution and trends of oxygenated hydrocarbons in the high Arctic derived from measurements in the atmospheric boundary layer and interstitial snow air during the ALERT2000 field campaign, Atmos. Environ., 36(15-16), 2573-2583, 2002.

Bourgeois, C. S., Calanca, P., and Ohmura, A.: A field study of the hemispherical directional reflectance factor and spectral albedo of dry snow, J. Geophys. Res., 111, D20108, doi:10.1029/2006JD007296, 2006.

Boxe, C. S., Colussi, A. J., Hoffmann, M. R., Murphy, J. G., Wooldridge, P. J., Bertram, T. H., and Cohen, R. C.: Photochemical production and release of gaseous $\mathrm{NO}_{2}$ from nitrate-doped water ice, J. Phys. Chem. A, 109(38), 8520-8525, 2005.

Bruice, T. C. and Butler, A. R.: Catalysis in water and ice. II. The reaction of thiolactones with morpholine in frozen systems, J. Amer. Chem. Soc., 86, 4104-4108, 1964.

Brunner, D., Staehelin, J., Rogers, H. L., Koehler, M. O., Pyle, J. A., Hauglustaine, D., Jourdain, L., Berntsen, T. K., Gauss, M., Isaksen, I. S. A., Meijer, E., Van Velthoven, P., Pitari, G., Mancini, E., Grewe, V., and Sausen, R.: An evaluation of the performance of chemistry transport models by comparison with research aircraft observations. Part 1: concepts and overall model performance, Atmos. Chem. Phys., 3, 1609-1631, 2003, http://www.atmos-chem-phys.net/3/1609/2003/.

Brunner, D., Staehelin, J., Rogers, H. L., Koehler, M. O., Pyle, J. A., Hauglustaine, D. A., Jourdain, L., Berntsen, T. K., Gauss, M., Isaksen, I. S. A., Meijer, E., van Velthoven, P., Pitari, G., Mancini, E., Grewe, V., and Sausen, R.: An evaluation of the performance of chemistry transport models - Part 2: Detailed comparison with two selected campaigns, Atmos. Chem. Phys., 5, 107-129, 2005, http://www.atmos-chem-phys.net/5/107/2005/.

Burkhart, J. F., Hutterli, M. A., and Bales, R. C.: Partitioning of formaldehyde between air and ice at $-35^{\circ} \mathrm{C}$ to $-5^{\circ} \mathrm{C}$, Atmos. Environ., 36(13), 2157-2163, 2002. 
Butler, A. R. and Bruice, T. C.: Catalysis in water and ice. A comparison of the kinetics of hydrolysis of acetic anhydride, betapropiolactone, J. Amer. Chem. Soc., 86, 313-319, 1964.

Cabanes, A., Legagneux, L., and Dominé, F.: Evolution of the specific surface area and of crystal morphology of Arctic fresh snow during the ALERT 2000 campaign, Atmos. Environ., 36, 27672777, 2002.

Cabanes, A., Legagneux, L., and Dominé, F.: Rate of evolution of the specific surface area of surface snow layers, Environ. Sci. Technol., 37, 661-666, 2003.

Calace, N., Petronio, B. M., Cini, R., Stortini, A. M., Pampaloni, B., and Udisti, R.: Humic marine matter and insoluble materials in Antarctic snow, Internat. J. Environ. Anal. Chem., 79(4), 331348, 2001.

Calace, N., Cantafora, E., Mirante, S., Petronio, B. M., and Pietroletti, M.: Transport and modification of humic substances present in Antarctic snow and ancient ice, J. Environ. Monit., 7, 1320$1325,2005$.

Carignano, M. A., Baskaran, E., Shepson, P. B., and Szleifer, I.: Molecular dynamics simulation of ice growth from supercooled pure water and from salt solution, Annals Glaciol., 44, 113-117, 2006.

Carpenter, E. J., Lin, S. J., and Capone, D. G.: Bacterial activity in South Pole snow, Appl. Environ. Microbiol., 66 (10), 45144517, 2000.

Carver, G. D., Jones, A. E., and Wolff, E. W.: Global Modelling of $\mathrm{NO}_{\mathrm{x}}$ emissions from snow, EOS. Trans. AGU, 85(47), 2004.

Chatfield, R. B.: Anomalous $\mathrm{HNO}_{3} / \mathrm{NO}_{\mathrm{x}}$ ratio of remote tropospheric air: Conversion of nitric acid to formic acid and $\mathrm{NO}_{\mathrm{x}}$ ?, Geophys. Res. Lett., 21(24), 2705-8, doi:10.1029/94GL02659, 1994.

Chen, G., Davis, D., Crawford, J., Nowak, J.B., Eisele, F., Mauldin, R.L.., Tanner, D., Buhr, M., Shetter, R., Lefer, B., Arimoto, R., Hogan, A., and Blake, D.: An investigation of South Pole HOx chemistry: Comparison of model results with ISCAT observations, Geophys. Res. Lett., 28, 3633-3636, 2001.

Chen, G., Davis, D., Crawford, J., Mauldin, L., Eisele, F., Huey, G., Slusher, D., Tanner, D.J., Dibb, J., Buhr, M., Hutterli, M.A., McConnell, J., Lefer, B., Shetter, R., Blake, D., Lombardi, K., and Arnoldy, J.: A reassessment of $\mathrm{HO}_{\mathrm{x}}$ chemistry based on observations recorded during ISCAT 2000, Atmos. Environ., 38, 5451-5462, 2004.

Chen, G., Crawford, J. H., Olson, J. R., Huey, L. G., Hutterli, M. A., Sjostedt, S., Tanner, D., Dibb, J., Blake, N., Lefer, B., and Honrath, R.: An assessment of the polar HOx photochemical budget based on 2003 Summit Greenland field observation, Atmos. Environ., doi:10.1016/j.atmosenv.2007.06.014, 2007.

Cheung, J. L., Li, Y. Q., Boniface, J., Shi, Q., Davidovits, P., Worsnop, D. R., Jayne, J. T., and Kolb, C. E.: Heterogeneous interactions of $\mathrm{NO}_{2}$ with aqueous surfaces, J. Phys. Chem. A, 104, 2655-2662, 2000.

Cho, H., Shepson, P. B., Barrie, L. A., Cowin, J. P., and Zaveri, R.: NMR investigation of the quasi-brine layer in ice/brine mixtures, J. Phys. Chem. B, 106, 11 226-11 232, 2002.

Chu, L. T., Leu, M. T., and Keyser, L. F.: Uptake of $\mathrm{HCl}$ in water ice and nitric acid films, J. Phys. Chem., 97, 7779-7785, 1993.

Chu, L. and Anastasio, C.: Quantum yields of hydroxyl radical and nitrogen dioxide from the photolysis of nitrate on ice, J. Phys. Chem. A, 107, 9594-9602, 2003.
Chu, L. and Anastasio, C.: Formation of hydroxyl radical from the photolysis of frozen hydrogen peroxide, J. Phys. Chem. A, 109(28), 6264-6271, 2005.

Chu. L. and Anastasio, C.: Temperature and wavelength dependence of nitrite photolysis in frozen and aqueous solutions, Environ. Sci Technol., 41(10), 3626-3632, 2007.

Cohen, S. R., Weissbuch, I., Popovitz Biro, R., Majewski, J., Mauder, H. P., Lavi, R., Leiserowitz, L., and Lahav, M.: Spontaneous assembly in organic thin films spread on aqueous subphase: A scanning force microscope (SFM) study, Israel J. Chem., 36, 97-110, 1996.

Cohen, L., Helmig, D., Neff, W., Grachev, A., and Fairall, C.: Boundary-layer dynamics and its influence on atmospheric chemistry at Summit, Greenland, Atmos. Environ., 41(24), 5044-5060, 2007.

Colussi, A. J. and Hoffmann, M. R.: In situ photolysis of deep ice core contaminants by Cerenkov radiation of cosmic origin, Geophys. Res. Lett., 30(4), 1195, doi:10.1029/2002GL016112, 2003.

Compoint, M., Toubin, C., Picaud, S., Hoang, P. N. M., and Girardet, C.: Geometry and dynamics of formic and acetic acids adsorbed on ice, Chem. Phys. Lett., 365, 1-7, 2002.

Conklin, M. H. and Bales, R. C.: $\mathrm{SO}_{2}$ uptake on ice spheres - liquid nature of the ice-air interface, J. Geophys. Res., 98(D9), 16851$16855,1993$.

Conklin, M. H., Sigg, A., Neftel, A., and Bales, R.: Atmospheresnow transfer function for $\mathrm{H}_{2} \mathrm{O}_{2}$ : microphysical considerations, J. Geophys. Res., 98(D10), 18 367-18 376, 1993.

Cotter, E. S. N., Jones, A. E., Wolff, E. W., and Bauguitte, S. J.B.: What controls photochemical $\mathrm{NO}$ and $\mathrm{NO}_{2}$ production from Antarctic snow? Laboratory investigation assessing the wavelength and temperature dependence, J. Geophys. Res., 108(D4), 4147, doi:10.1029/2002JD002602, 2003.

Couch, T. L., Sumner, A. L., Dassau, T. M., Shepson, P. B., and Honrath, R. E.: An investigation of the interaction of carbonyl compounds with the snowpack, Geophys. Res. Lett., 27, 22412244, 2000.

Crawford, J. H., Davis, D. D., Chen, G., Buhr, M., Oltmans, S., Weller, R., Mauldin, L., Eisele, F., Shetter, R., Lefer, B., Arimoto, R., and Hogan, A.: Evidence for photochemical production of ozone at the South Pole surface, Geophys. Res. Lett., 28, 3641-3644, 2001

Daly, G. L. and Wania, F.: Simulating the influence of snow on the fate of organic compounds, Environ. Sci. Technol., 38, 41764186, 2004.

Dash, J. G., Fu, H. Y., and Wettlaufer, J. S.: The premelting of ice and its environmental consequences, Reports on Progress in Physics, 58, 115-167, 1995.

Dassau, T. M., Sumner, A. L., Koeniger, S. L., Shepson, P. B., Yang, J., Honrath, R. E., Cullen, N. J., Steffen, K., Jacobi, H. W., Frey, M., and Bales, R.C.: Investigation of the role of the snowpack on atmospheric formaldehyde chemistry at Summit, Greenland, J. Geophys. Res., 107(D19), 4394, doi:10.1029/2004JD002182, 2002.

Davis, D., Nowak, J.B., Chen, G., Buhr, M., Arimoto, R., Hogan, A., Eisele, F., Mauldin, L., Tanner, D., Shetter, R., Lefer, B., and McMurry, P.: Unexpected high levels of NO observed at South Pole, Geophys. Res Lett., 28(19), 3625-3628, 2001.

Davis, D., Chen, G., Buhr, M., Crawford, J., Lenschow, D., Lefer, 
B., Shetter, R., Eisele, F., Mauldin, L., and Hogan, A.: South Pole $\mathrm{NO}_{\mathrm{x}}$ chemistry: an assessment of factors controlling variability and absolute levels, Atmos. Environ., 38, 5375-5388, 2004.

Davis, D., Eisele, F., Mauldin, L., Buhr, M., Crawford, J., Chen, G., Tanner, D., and Huey, G.: An assessment of the oxidizing canopy surrounding the Antarctic plateau, EGU General Assembly, Vienna, April 2006, Geophys. Res. Abstracts, Volume 8, 07921, 2006.

Devlin, J. P.: Molecular-interactions with icy surfaces - Infraredspectra of $\mathrm{CO}$ absorbed in microporous amorphous ice, J. Phys. Chem., 96, 6185-6188, 1992.

Devlin, J. P. and Buch, V.: Surface of ice as viewed from combined spectroscopic and computer modeling studies, J. Phys. Chem., 99, 16 534-16548, 1995.

Dibb, J. E. and Jaffrezo, J.-L.: Air-snow exchange investigations at Summit, Greenland: An overview, J. Geophys. Res., C102, 26795-26 807, 1997.

Dibb, J. E., Talbot, R. W., Munger, J. W., Jacob, D. J., and Fan, S.M.: Air-snow exchange of $\mathrm{HNO}_{3}$ and $\mathrm{NO}_{\mathrm{y}}$ at Summit, Greenland, J. Geophys. Res., 103, 3475-3486, 1998.

Dibb, J. E. and Arsenault, M.: Shouldn't snowpacks be sources of monocarboxylic acids?, Atmos. Environ., 36(15-16), 25132522, 2002.

Dibb, J. E., Arsenault, M., Peterson, M. C., and Honrath, R. E.: Fast nitrogen oxide photochemistry in Summit, Greenland snow, Atmos. Environ., 26, 2501-2511, 2002.

Dibb, J. E., Huey, L. G., Slusher, D. L., and Tanner, D. J.: Soluble reactive nitrogen oxides at South Pole during ISCAT 2000, Atmos. Environ., 38, 5399-5409, 2004.

Dolinova, J., Ruzicka, R., Kurkova, R., Klánová, J., and Klán, P.: Oxidation of aromatic and aliphatic hydrocarbons by $\mathrm{OH}$ radicals photochemically generated from $\mathrm{H}_{2} \mathrm{O}_{2}$ in ice, Environ. Sci. Technol., 40(24), 7668-7674, doi:10.1021/es0605974, 2006.

Dominé, F. and Rey-Hanot, L.: Adsorption isotherms of acetone on ice between 193 and 213 K, Geophys. Res. Lett., 29(18), 1873, doi:10.1029/2002GL015078, 2002.

Dominé, F. and Shepson, P.B.: Air-snow interactions and atmospheric chemistry, Science, 297, 1506-1510, 2002.

Dominé, F. and Rauzy, C.: Influence of the ice growth rate on the incorporation of gaseous $\mathrm{HCl}$, Atm. Chem. Phys. 4, 2513-2519, 2004.

Dominé, F., Sparapani, R., Ianniello, A., and Beine, H. J.: The origin of sea salt in snow on Arctic sea ice and in coastal regions, Atmos. Chem. Phys., 4, 2259-2271, 2004, http://www.atmos-chem-phys.net/4/2259/2004/.

Dominé, F., Salvatori, R., Legagneux, L., Salzano, R., Fily M., and Casacchia R.: Correlation between the specific surface area and the short wave infrared (SWIR) reflectance of snow, Cold Regions Sci. Technol., 46, 60-68, doi:10.1016/j.coldregions.2006.06.002, 2006.

Dominé, F., Albert, M., Huthwelker, T., Jacobi, H. -W., Kokhanovsky, A. A., Lehning, M., Picard, G., Simpson, W.R.: Snow physics as relevant to snow photochemistry, Atmos. Chem. Phys. Discuss., 7, 5941-6036, 2007, http://www.atmos-chem-phys-discuss.net/7/5941/2007/.

Döppenschmidt, A. and Butt, H. J.: Measuring the thickness of the liquid-like layer on ice surfaces with atomic force microscopy, Langmuir, 16, 6709-6714, 2000.
Dubowski, Y. and Hoffmann, M. R.: Photochemical transformations in ice: Implications for the fate of chemical species, Geophys. Res. Lett., 27, 3321-3324, 2000.

Dubowski, Y., Colussi, A. J., and Hoffmann, M. R.: Nitrogen dioxide release in the $302 \mathrm{~nm}$ band photolysis of spray-frozen aqueous nitrate solutions: Atmospheric Implications, J. Phys. Chem. A, 105, 4928-4932, 2001.

Dubowski, Y., Colussi, A. J., Boxe, C., and Hoffmann, M. R.: Monotonic increase of nitrite yields in the photolysis of nitrate in ice and water between 238 and 294 K, J. Phys. Chem. A, 106, 6967-6971, 2002.

Eichler, A., Schwikowski, M., and Gäggeler, H. W.: Meltwaterinduced relocation of chemical species in Alpine firn, Tellus Ser B: Chem. Phys. Meteor., 53(2), 192-203, 2001.

Eicken, H.: Salinity profiles of Antarctic sea ice: field data and model results, J. Geophys. Res., 97, 15 545-15 557, 1992.

Engquist, I., Lestelius, M., and Liedberg, B.: Hydrogen-bond interaction between self-assembled monolayers and adsorbed watermolecules and its implications for cluster formation, J. Phys. Chem., 99, 14 198-14 200, 1995a.

Engquist, I., Lundstrom, I., and Liedberg, B.: Temperatureprogrammed desorption and infrared studies of $\mathrm{D}_{2} \mathrm{O}$ ice on selfassembled alkanethiolate monolayers - Influence of substrate wettability, J. Phys. Chem., 99, 12 257-12 267, 1995 b.

EPICA community members: Eight glacial cycles from an Antarctic ice core, Nature, 429, 623-628, 2004.

Evans, M. J., Jacob, D. J., Atlas, E., Cantrell, C. A., Eisele, F., Flocke, F., Fried, A., Mauldin, R. L., Ridley, B. J., Wert, B., Talbot, R., Blake, D., Heikes, B., Snow, J., Walega, J., Weinheimer, A. J., and Dibb, J.: Coupled evolution of $\mathrm{BrO}_{\mathrm{x}}-\mathrm{ClO}_{\mathrm{x}}-$ $\mathrm{HO}_{\mathrm{x}}-\mathrm{NO}_{\mathrm{x}}$ chemistry during bromine-catalyzed ozone depletion events in the arctic boundary layer, J. Geophys. Res., 108(D4), 8368, doi:10.1029/2002JD002732, 2003.

Eyal, Y., Maydan, D., and Treinin, A.: The autoxidation of $\mathrm{I}^{-}$in ice, Israel J. Chem., 2, 133-138, 1964.

Farrar, N. J., Prevedouros, K., Harner, T., Sweetman, A. J., Jones, K. C.: Continental scale passive air sampling of persistent organic pollutants using rapidly equilibrating thin films (POGs), Environ. Pollut., 144(2), 423-433, 2006.

Faust, B. C.: Photochemistry of clouds, fogs and aerosols, Environ. Sci. Technol., 28(5), 217A-222A, 1994.

Felip, M., Sattler, B., Psenner, R., and Catalan, J.: Highly-active microbial communities in the ice and snow cover of high-mountain lakes, App. Environ. Microbiol., 61(6), 2394-2401, 1995.

Felip, M., Camarero, L., and Catalan, J.: Temporal changes of microbial assemblages in the ice and snow cover of a high mountain lake, Limnol. Oceanog., 44(4), 973-987, 1999.

Fennema, O.: Reaction kinetics in partially frozen aqueous systems, in water relations of foods, edited by R.G. Duckworth, pp. 539556, Academic Press, London, 1975.

Finnegan, W. G., Pitter, R. L., and Young, L. G.: Preliminary study of coupled oxidation-reduction reactions of included ions in growing ice crystals, Atmos. Environ., 25A, 2531-2534, 1991.

Finnegan, W. G. and Pitter, R. L.: Ion-induced charge separations in growing single ice crystals: Effects on growth and interaction processes, J. Colloid Interface Sci., 189, 322-327, 1997.

Ford, K. M., Campbell, B. M., Shepson, P. B., Bertman, S. B., Honrath R. E., Peterson, M., and Dibb, J. E.: Studies of Peroxyacetyl nitrate (PAN) and its interaction with the 
snowpack at Summit, Greenland, J. Geophys. Res., 107(D10), doi:10.1029/2001JD000547, 2002.

Foster, K. L., Plastridge, R. A., Bottenheim, J. W., Shepson, P. B., Finlayson-Pitts, B. J., and Spicer, C. W.: The role of $\mathrm{Br}_{2}$ and $\mathrm{BrCl}$ in surface ozone destruction at polar sunrise, Science, 291(5503), 471-474, 2001.

France, J. L., King, M. D., and Lee-Taylor, J.: Hydroxyl (OH) radical production rates in snowpacks from photolysis of hydrogen peroxide (H2O2) and nitrate (NO3-), Atmos. Environ., 41, 55025509, 2007.

Franz, T. P. and Eisenreich, S. J.: Snow scavenging of polychlorinated biphenyls and polycyclic aromatic hydrocarbons in Minnesota, Environ. Sci. Technol., 32, 1771-1778, 1998.

Frey, M. M., Stewart, R. W., McConnell, J. R., and Bales, R. C.: Atmospheric hydroperoxides in West Antarctica: links to stratospheric ozone and atmospheric oxidation capacity, J. Geophys. Res., 110, D23301, doi:10.1029/2005JD006110, 2005.

Frey, M. M., Bales, R. C., and McConnell, J. R.: Climate sensitivity of the century-scale hydrogen peroxide $\left(\mathrm{H}_{2} \mathrm{O}_{2}\right)$ record preserved in 23 ice cores from West Antarctica, J. Geophys. Res., 111, D21301, doi:10.1029/2005JD006816, 2006.

Freyer, H. D., Kobel, K., Delmas, R. J., Kley, D., and Legrand, M. R.: First results of N-15/N-14 ratios in nitrate from alpine and polar ice cores, Tellus Ser. B-Chem. Phys. Meteor., 48(1), 93105, 1996.

Friess, U., Hollwedel, J., Konig-Langlo, G., Wagner, T., and Platt, U.: Dynamics and chemistry of tropospheric bromine explosion events in the Antarctic coastal region, J. Geophys. Res., 109(D6), D06305, doi:10.1029/2003JD004133, 2004.

Fuhrer, K., Hutterli, M., and McConnell, J. R.: Overview of recent field experiments for the study of the air-snow transfer of $\mathrm{H}_{2} \mathrm{O}_{2}$ and HCHO, NATO ASI Ser. Vol I, 43, Chemical Exchange Between the Atmosphere and Polar Snow, edited by: Wolff, E. W. and Bales, R. C., Springer-Verlag, Berlin Heidelberg, 1996.

Galbavy, E. S., Anastasio, C., Lefer, B. L., and Hall, S. R.: Light penetration in the snowpack at Summit, Greenland: Part 1. Nitrite and hydrogen peroxide photolysis, Atmos. Environ., 41(24), 5077-5090, doi:10.1016/j.atmosenv.2006.04.072, 2007a.

Galbavy, E. S., Anastasio, C., Lefer, B. L., and Hall, S. R.: Light penetration in the snowpack at Summit, Greenland: Part 2. Nitrate photolysis, Atmos. Environ., 41(24), 5091-5100, doi:10.1016/j.atmosenv.2006.01.066, 2007b.

Garbarino, J. R., Snyder-Conn, E., Leiker, T. J., and Hoffman, G. L.: Contaminants in Arctic snow collected over northwest Alaskan sea ice, Water Air Soil Pollut., 139, 183-214, 2002.

George, C., Strekowski, R. S., Kleffmann, J., Stemmler, K., and Ammann, M.: Photoenhanced uptake of gaseous $\mathrm{NO}_{2}$ on solid organic compounds: a photochemical source of HONO, Faraday Discuss., 130, 195-211, 2005.

Girardet, C. and Toubin, C.: Molecular atmospheric pollutant adsorption on ice: a theoretical survey, Surf. Sci. Reports, 44, 159238, 2001.

Goss, K.-U.: Predicting the equilibrium partitioning of organic compounds using just one linear solvation energy relationship (LSER), Fluid Phase Equilibria, 233, 19-22, 2005.

Grannas, A. M., Shepson, P. B., Guimbaud, C., Dominé, F., Albert, M., Simpson, W., Bottenheim, J. W., and Boudries, H.: A Study of photochemical and physical processes affecting carbonyl compounds in the Arctic marine boundary layer, Atmos. Environ., 36,
2733-2742, 2002.

Grannas, A. M., Shepson, P. B., and Filley, T. R.: Photochemistry and nature of organic matter in Arctic and Antarctic snow, Global Biogeochem. Cycles, 18(1), GB1006, doi:10.1029/2003GB002133, 2004.

Grannas, A. M., Hockaday, W. C., Hatcher, P. G., Thompson, L. G., and Mosley-Thompson, E.: New revelations on the nature of organic matter in ice cores, J. Geophys. Res., 111, D04304, doi:10.1029/2005JD006251, 2006.

Grant, N. H., Clark, D. E., and Alburn, H. E.: Imidazole- and basecatalyzed hydrolysis of penicilin in frozen systems, J. Amer. Chem. Soc., 83, 4476-4477, 1961.

Grenfell, T. C. and Maykut, G. A.: The optical properties of ice and snow in the Arctic basin, J. Glaciol., 18(80), 445-462, 1977.

Grenfell, T. C., Perovich, D. K., and Ogren, J. A.: Spectral albedos of an alpine snowpack, Cold Regions Sci. Technol., 4, 121-127, 1981.

Grenfell, T. C., Warren, S. G., and Mullen, P. C.: Reflection of solar radiation by the Antarctic snow surface at ultraviolet, visible, and near-infrared wavelengths, J. Geophys. Res., 99, 18 669-18 684, 1994.

Grollert, C. and Puxbaum, H.: Lipid organic aerosol and snow composition at a high alpine site in the fall and the spring season and scavenging ratios for single compounds, Water Air Soil Pollut., 117(1-4), 157-173, 2000.

Gudipati, M. S.: Matrix-isolation in cryogenic water-ices: Facile generation, storage, and optical spectroscopy of aromatic radical cations, J. Phys. Chem. A, 108, 4412-4419, 2004.

Guimbaud, C., Grannas, A. M., Shepson, P. B., Fuentes, J. D., Boudries, H., Bottenheim, J. W., Dominé, F., Houdier, S., Perrier, S., Biesenthal, T. B., and Splawn, B. G.: Snowpack processing of acetaldehyde and acetone in the Arctic atmospheric boundary layer, Atmos. Environ., 36, 2743-2752, 2002.

Guzmán, M. I., Colussi, A. J., and Hoffmann, M. R.: Cooperative Hydration of Pyruvic Acid in Ice, J. Am. Chem. Soc., 128, 10621-10 624, 2006a.

Guzmán, M. I., Colussi, A. J., and Hoffmann, M. R.: Photogeneration of distant radical pairs in aqueous pyruvic acid glasses, J. Phys. Chem. A, 110, 931-935, 2006 b.

Guzmán, M. I., Colussi, A. J., and Hoffmann, M. R.: Photoinduced oligomerization of aqueous pyruvic acid, J. Phys. Chem. A, 110, 3619-3626, 2006c.

Guzmán, M. I., Colussi, A. J., and Hoffmann, M. R.: Photolysis of Pyruvic Acid in Ice: Possible Relevance to $\mathrm{CO}$ and $\mathrm{CO}_{2}$ Ice Core Record Anomalies, J. Geophys. Res., 112, D10123, doi:10.1029/2006JD007886, 2007.

Haan, D., Zuo, Y., Gros, V., and Brenninkmeijer, C. A. M.: Photochemical production of carbon monoxide in snow, J. Atmos. Chem., 40(3), 217-230, 2001.

Hagler, G. W., Bergin, M. H., Smith, E., Greenwald, R., Schauer, J. J.: Particulate carbon in the air and snow on the Greenland Ice Sheet, American Association of Aerosol Research (AAAR) Annual Meeting, St. Paul, MN, Sept., 2006

Halsall, C. J.: Investigating the occurrence of persistent organic pollutants (POPs) in the Arctic: their atmospheric behaviour and interaction with the seasonal snow pack, Environ. Pollut., 128, 163-175, 2004.

Hansen, J., Sato, M., Ruedy, R., et al.: Efficacy of climate forcings, J. Geophys. Res., 110, D18104, doi:10.1029/2005JD005776, 
2005.

Harder, S., Warren, S. G., and Charlson, R. J.: Sulfate in air and snow at the South Pole: Implications for transport and deposition at sites with low snow accumulation, J. Geophys. Res., 105D, 22 825-22 832, 2000.

Hastings, M. G., Steig, E. J., and Sigman, D. M.: Seasonal variations in $\mathrm{N}$ and $\mathrm{O}$ isotopes of nitrate in snow at Summit, Greenland: Implications for the study of nitrate in snow and ice cores, J. Geophys. Res., 109(D20), D20306, doi:10.1029/2004JD004991, 2004.

Hastings, M. G., Sigman, D. M., and Steig, E. J.: Glacial/interglacial changes in the isotopes of nitrate from the Greenland Ice Sheet Project 2 (GISP2) ice core, Global Biogeochem. Cycles, 19, GB4024, doi:10.1029/2005GB002502, 2005.

Heard, D. E. and Pilling, M. J.: Measurement of $\mathrm{OH}$ and $\mathrm{HO}_{2}$ in the troposphere, Chem. Rev., 103, 5163-5198, 2003.

Heard, D. E., Read, K. A., Methven, J., et al.: The North Atlantic Marine Boundary Layer Experiment (NAMBLEX). Overview of the campaign held at Mace Head, Ireland, in summer 2002, Atmos. Chem. Phys., 6, 2241-2272, 2006, http://www.atmos-chem-phys.net/6/2241/2006/.

Heaton, T. H. E., Wynn, P., and Tye, A. M.: Low ${ }^{15} \mathrm{~N} /{ }^{14} \mathrm{~N}$ ratios for nitrate in snow in the High Arctic (79N), Atmos. Environ., 38(33), 5611-5621, 2004.

Heger, D., Jirkovsky, J., and Klán, P.: Aggregation of methylene blue in frozen aqueous solutions studied by absorption spectroscopy, J. Phys. Chem. A, 109, 6702-6709, 2005.

Heger, D., Klánová, J., and Klán, P.: Enhanced protonation of cresol red in acidic aqueous solutions caused by freezing, J. Phys. Chem. B, 110, 1277-1287, 2006.

Heger, D. and Klán, P.: Interactions of organic molecules at grain boundaries in ice: A solvatochromic analysis, J. Photochem. Photobiol. A, 187(2-3), 275-284, doi:10.1016/j.photochem.2006.10.012, 2007.

Hellebust, S., Roddis, T., and Sodeau, J.: A potential role of the nitroacidium ion on HONO emissions from the snowpack, J. Phys. Chem. A., 111, 1167-1171, 2007.

Helmig, D., Boulter, J., David, D., Birks, J. W., Cullen, N. J., Steffen, K., Johnson, B. J., and Oltmans, S. J.: Ozone and meteorological boundary-layer conditions at Summit, Greenland, during 3-21 June 2000, Atmos. Environ., 36, 2595-2608, 2002.

Helmig, D., Johnson, B., Oltmans, S. J., Neff, W., Eisele, F., and Davis, D. D.: Elevated Ozone in the Boundary-Layer at South Pole, Atmos. Environ., in press, doi:10.1016/j.atmosenv.2006.12.032, 2007a.

Helmig, D., Oltmans, S. J., Carlson, D., Lamarque, J.-F., Jones, A., Labuschagne, C., Anlauf, K., and Hayden, K.: A Review of surface ozone in the polar regions, Atmos. Environ., 41(24), 5138-5161, 2007b.

Helmig, D., Oltmans, S. J., Morse, T. O., and Dibb, J. E.: What is causing high ozone at Summit, Greenland?, Atmos. Environ., 41(24), 5031-5043, 2007c.

Helmig, D., Bocquet, F., Cohen, L., and Oltmans, S. J.: Ozone uptake to the polar snowpack at Summit, Greenland, Atmos. Environ., 41(24), 5061-5076, 2007d.

Helmig, D., Johnson, B., Warshawsky, M., Morse, T., Neff, W., Eisele, F., and Davis, D. D.: Nitric Oxide in the Boundary-Layer at South Pole during the Antarctic Tropospheric
Chemistry Investigation (ANTCI), Atmos. Environ., in press, doi:10.1016/j.atmosenv.2007.03.061, 2007e.

Hodgkins, R., Tranter, M., and Dowdeswell, J. A.: The hydrochemistry of runoff from a 'cold-based' glacier in the High Arctic (Scott Turnerbreen, Svalbard), Hydrol. Process., 12, 87-103, 1998.

Hoffmann, M. R.: Possible chemical transformations in snow and ice induced by solar (UV photons) and cosmic irradiation (muons), NATO ASI Series, Volume I, 43, 353-377, edited by: Wolff, E. W. and Bales, R. C., Springer-Verlag, Berlin, 1996.

Hofzumahaus, A., Kraus, A., and Muller, M.: Solar actinic flux spectroradiometry: a technique for measuring photolysis frequencies in the atmosphere, Appl. Optics, 38, 4443-4460, 1999.

Holmes, N. S. and Sodeau, J. R.: A study of the interaction between halomethanes and water-ice, J. Phys. Chem. A, 103(24), 46734679, 1999.

Hönninger G., and Platt, U.: Observations of $\mathrm{BrO}$ and its vertical distribution during surface ozone depletion at Alert, Atmos. Environ., 36, 2481-2489, 2002.

Hönninger, G., Leser, H., Sebastian, O., and Platt, U.: Groundbased measurements of halogen oxides at the Hudson Bay by active longpath DOAS and passive MAX-DOAS, Geophys. Res. Lett., 31(4), L04111, doi:10.1029/2003GL018982, 2004.

Honrath, R. E., and Jaffe, D.: The seasonal cycle of nitrogen oxides in the Arctic troposphere at Barrow, Alaska, J. Geophys. Res., 97, 20615-20 630, 1992.

Honrath, R. E., Peterson, M. C., Guo, S., Dibb, J. E., Shepson, P. B., and Campbell, B.: Evidence of $\mathrm{NO}_{\mathrm{x}}$ production within or upon ice particles in the Greenland snowpack, Geophys. Res. Lett., 26, 695-698, 1999.

Honrath, R. E., Guo, S., Peterson, M. C., Dziobak, M. P., Dibb, J. E., and Arsenault, M. A.: Photochemical production of gas phase $\mathrm{NO}_{\mathrm{x}}$ from ice crystal $\mathrm{NO}_{3}^{-}$, J. Geophys., Res., 105, $24183-$ 24 190, 2000a.

Honrath, R. E., Peterson, M. C., Dziobak, M. P., Dibb, J. E., Arsenault, M. A., and Gen, S. A.: Release of $\mathrm{NO}_{\mathrm{x}}$ from sunlightirradiated midlatitude snow, Geophys. Res. Lett., 27, 2237-2240, 2000 b.

Honrath, R. E., Lu, Y., Peterson, M. C., Dibb, J. E., Arsenault, M. A., Cullen, N. J., and Steffen, K.: Vertical fluxes of $\mathrm{NO}_{\mathrm{x}}, \mathrm{HONO}$ and $\mathrm{HNO}_{3}$ above the snowpack at Summit, Greenland, Atmos. Environ., 36, 2629-2640, 2002.

Horn, A. B., Chesters, M. A., McCoustra, M. R. S., and Sodeau J. R.: Adsorption of stratospherically important molecules on thin heavy water ice films using RAIRS, J Chem. Soc., Faraday Transactions, 88, 1077-1018, 1992.

Hou, S. G., Qin, D. H., and Ren, J. W.: Different post-depositional processes of $\mathrm{NO}_{3}^{-}$in snow layers in East Antarctica and on the northern Qinghai-Tibetan Plateau, Ann. Glaciol., 29, 73-76, 1999.

Houdier, S., Perrier, S., Dominé, F., Cabanes, A., Legagneux, L., Grannas, A. M., Guimbaud, C., Shepson, P. B., Boudries, H., and Bottenheim, J. W.: Acetaldehyde and acetone in the Arctic snowpack during the ALERT2000 campaign. Snowpack composition, incorporation processes and atmospheric impact, Atmos. Environ., 36(15-16), 2609-2618, 2002.

Hudson, P. K., Shilling, J. E., Tolbert, M. A., and Toon, O. B.: Uptake of nitric acid on ice at tropospheric temperatures: Implications for cirrus clouds, J. Phys. Chem. A, 106(42), 9874-9882, 
2002.

Hudson, E. and Ariya, P. A.: VOC, DOC and bioaerosol measurements during the POLARSTERN 2004, Chemosphere, in press, 2007.

Huey, L. G., Tanner, D. J., Slusher, D. L., Dibb, J. E., Arimoto, R., Chen, G., Davis, D., Buhr, M.P., Nowak, J. B., Mauldin, R. L., Eisele, F. L., and Kosciuch, E.: CIMS measurements of $\mathrm{HNO}_{3}$ and $\mathrm{SO}_{2}$ at the South Pole during ISCAT 2000, Atmos. Environ., 38, 5411-5421, 2004.

Huff, A. K. and Abbatt, J. P. D.: Gas-phase $\mathrm{Br}_{2}$ production in heterogeneous reactions of $\mathrm{Cl}_{2}, \mathrm{HOCl}$, and $\mathrm{BrCl}$ with halide-ice surfaces, J. Phys. Chem. A, 104, 7284-7293, 2000.

Huff, A. K. and Abbatt, J. P. D.: Kinetics and product yields in the heterogeneous reactions of $\mathrm{HOBr}$ with ice surfaces containing $\mathrm{NaBr}$ and $\mathrm{NaCl}$, J. Phys. Chem. A, 106, 5279-5287, 2002.

Huthwelker, T., Ammann, M., and Peter, T.: The uptake of acidic gases on ice, Chem. Rev., 106, 1375-1444, 2006.

Hutterli, M. A., Roethlisberger, R., and Bales, R. C.: Atmosphereto-snow-to-firn transfer studies of HCHO at Summit, Greenland, Geophys. Res. Lett., 26(12), 1691-1694, 1999.

Hutterli, M. A., McConnell, J. R., Stewart, R. W., Jacobi, H.-W., and Bales, R.C.: Impact of temperature-driven cycling of hydrogen peroxide $\left(\mathrm{H}_{2} \mathrm{O}_{2}\right)$ between air and snow on the planetary boundary layer, J. Geophys. Res., 106(D14), 15 395-15 404, 2001.

Hutterli, M. A., Bales, R. C., McConnell, J. R., and Stewart, R. W.: HCHO in Antarctic snow: Preservation in ice cores and air-snow exchange, Geophys. Res. Lett., 29, 1235, doi:10.1029/2001GL014256, 2002.

Hutterli, M. A., McConnell, J. R., Stewart, R. W., and Bales, R. C.: Sensitivity of hydrogen peroxide $\left(\mathrm{H}_{2} \mathrm{O}_{2}\right)$ and formaldehyde ( $\mathrm{HCHO})$ preservation in snow to changing environmental conditions: Implications for the interpretation of ice core records, J. Geophys. Res., 108, 4023, doi:10.1029/2002JD002528, 2003.

Hutterli, M. A., McConnell, J. R., Chen, G., Bales, R. C., Davis, D. D., and Lenschow, D. H.: Formaldehyde and hydrogen peroxide in air, snow and interstitial air at South Pole, Atmos. Environ., 38(32), 5439-5450, 2004.

Jacobi, H.-W., Weller, R., Jones, A. E., Anderson, P. S., and Schrems, O.: Peroxyacetyl nitrate (PAN) concentrations in the Antarctic troposphere measured during the photochemical experiment at Neumayer (PEAN “99), Atmos. Environ., 34, 52355247, 2000.

Jacobi, H.-W., Frey, M. M., Hutterli, M. A., Bales, R. C., Schrems, O., Cullen, N.J., Steffen, K., and Koehler, C.: Measurements of hydrogen peroxide and formaldehyde exchange between the atmosphere and surface snow at Summit, Greenland, Atmos. Environ., 36(15-16), 2619-2628, 2002.

Jacobi, H.-W., Bales, R. C., Honrath, R. E., Peterson, M. C., Dibb, J. E., Swanson, A. L., and Albert, M. R.: Reactive trace gases measured in the interstitial air of surface snow at Summit, Greenland, Atmos. Environ., 38(12), 1687-1697, 2004.

Jacobi, H.-W., Annor, T., and Quansah, E.: Investigation of the photochemical decomposition of nitrate, hydrogen peroxide, and formaldehyde in artificial snow, J. Photochem. Photobiol. A, 179, 330-338, 2006.

Jacobi, H.-W. and Hilker, B.: A mechanism for the photochemical transformation of nitrate in snow, J. Photochem. Photobiol. A, doi:10.1016/j.jphotochem.2006.06.039, 185(2-3), 371-382,
2007.

Jaffrezo, J. L., Clain, M. P., and Masclet, P.: Polycyclic aromatic hydrocarbons in the polar ice of Greenland - Geochemical use of these atmospheric tracers, Atmos. Environ., 28(6), 1139-1145, 1994.

Jefferson, A., Tanner, D. J., Eisele, F. L., Davis, D. D., Chen, G., Crawford, J., Huey, J. W., Torres, A. L., and Berresheim, H.: $\mathrm{OH}$ photochemistry and methane sulfonic acid formation in the coastal Antarctic boundary layer, J. Geophys. Res., 103, 16471656, 1998.

Jenkin, M. E., Saunders, S. M., and Pilling, M. J.: The tropospheric degradation of volatile organic compounds: A protocol for mechanism development, Atmos. Environ., 31, 81-104, 1997.

Jones, A. E., Weller, R., Minikin, A., Wolff, E. W., Sturges, W. T., McIntyre, H. P., Leonard, S. R., Schrems, O., and Bauguitte, S.: Oxidised nitrogen chemistry and speciation in the Antarctic troposphere, J. Geophys. Res., 104(D17), 21 355-21 366, 1999.

Jones, A. E., Weller, R., Wolff, E. W., and Jacobi, H.-W.: Speciation and rate of photochemical $\mathrm{NO}$ and $\mathrm{NO}_{2}$ production in Antarctic snow, Geophys. Res. Lett., 27(3), 345-348, 2000.

Jones, A. E., Weller, R., Anderson, P. S., Jacobi, H.-W., Wolff, E. W., Schrems, O., and Miller, H.: Measurements of $\mathrm{NO}_{\mathrm{x}}$ emissions from the Antarctic snowpack, Geophys. Res. Lett., 28(8), 1499-1502, 2001.

Jones, A. E., Salmon, R. A., Wolff, E. W., et al.: Challenges projecting polar ozone depletion, Eos Trans. AGU, 86(52), Fall Meet. Suppl., Abstract A24A-05, San Francisco, CA, 2005.

Jones, A. E., Wolff, E. W., Ames, D., Bauguitte, S. J.-B., Clemitshaw, K. C., Fleming, Z., Mills, G. P., Saiz-Lopez, A., Salmon, R. A., Sturges, W. T., and Worton, D. R.: The multi-seasonal NOy budget in coastal Antarctica and its link with surface snow and ice core nitrate: results from the CHABLIS campaign, Atmos. Chem. Phys. Discuss., 7, 4127-4163, 2007,

http://www.atmos-chem-phys-discuss.net/7/4127/2007/.

Kawamura, K., Yokoyama, K., Fujii, Y., and Watanabe, O.: A Greenland ice core record of low molecular weight dicarboxylic acids, ketocarboxylic acids, and alpha-dicarbonyls: A trend from Little Ice Age to the present (1540 to 1989 AD), J. Geophys. Res., 106, 1331-1345, 2001.

Kawamura, K., Nakazawa, T., Aoki, S., Sugawara, S., Fujii, Y., and Watanabe, O.: Atmospheric $\mathrm{CO}_{2}$ variations over the last three glacial-interglacial climatic cycles deduced from the Dome Fuji deep ice core, Antarctica using a wet extraction technique, Tellus, 55B, 126-1372003.

Kawamura, K., Imai, Y., and Barrie, L. A.: Photochemical production and loss of organic acids in high Arctic aerosols during longrange transport and polar sunrise ozone depletion events, Atmos. Environ., 39, 599-614, 2005.

Khvorostyanov, V. I. and Curry, J. A.: A new theory of heterogeneous ice nucleation for application in cloud and climate models, Geophys. Res. Lett., 27, 4081-4084, 2000.

King, M. D. and Simpson, W. R.: Extinction of UV radiation in Arctic snow at Alert, Canada $\left(82^{\circ} \mathrm{N}\right)$, J. Geophys. Res., 106, 12 499-12 507, 2001.

King, M. D., France, J. L., Fisher, F. N., and Beine, H. J.: Measurement and modelling of UV radiation penetration and photolysis rates of nitrate and hydrogen peroxide in Antarctic sea ice: An estimate of the production rate of hydroxyl radicals in first-year sea ice, J. Photochem. Photobiol. A, 176(1-3), 39-49, 2005. 
Klán, P., Ansorgova, A., Del Favero, D., and Holoubek, I.: Photochemistry of chlorobenzene in ice, Tetrahedron Lett., 41, 77857789, 2000.

Klán, P., Del Favero, D., Ansorgova, A., Klánová, J., and Holoubek, I.: Photodegradation of halobenzenes in water ice, Environ. Sci. Pollut. Res., 8, 195-200, 2001.

Klán, P. and Holoubek, I.: Ice (photo)chemistry. Ice as a medium for long-term (photo)chemical transformations - environmental implications, Chemosphere, 46, 1201-1210, 2002.

Klán, P., Klánová, J., Holoubek, I., and Cupr, P.: Photochemical activity of organic compounds in ice induced by sunlight irradiation: The Svalbard project, Geophys. Res. Lett., 30(6), 1313, doi:10.1029/2002GL016385, 2003.

Klánová, J., Klán, P., Nosek, J., and Holoubek, I.: Environmental ice photochemistry: monochlorophenols, Environ. Sci. Technol., 37, 1568-1574, 2003a.

Klánová, J., Klán, P., Heger, D., and Holoubek, I.: Comparison of the effects of $\mathrm{UV}, \mathrm{H}_{2} \mathrm{O}_{2} / \mathrm{UV}$ and gamma- irradiation processes on frozen and liquid water solutions of monochlorophenols, Photochem. Photobiol. Sci., 2, 1023-1031, 2003b.

Kleffman, J., Lorzer, J. C., Wiesen, P., Kern, C., Trick, S., Volkamer, R., Rodenas, M., and Wirtz, K.: Intercomparison of the DOAS and LOPAP techniques for the detection of nitrous acid (HONO), Atmos. Environ., 40, 3640-3652, 2006.

Koerner, R. M., Fisher, D. A., and Goto-Azuma, K.: A 100 year record of ion chemistry from Agassiz ice cap Northern Ellesmere Island NWT, Canada, Atmos. Environ., 33, 347-357, 1999.

Lahoutifard, N., Poissant, L., and Scott, S. L.: Heterogeneous scavenging of atmospheric mercury by snow spiked with hydrogen peroxide, Journal De Physique Iv, 107, 711-714, 2003.

Leaitch, W. R., Barrie, L. A., Bottenheim, J. W., Li, S. M., Shepson, P. B., Muthuramu, K., and Yokouchi, Y.: Airborne observations related to ozone depletion at polar sunrise, J. Geophys. Res., 99, 25 499-25 517, 1994.

Lee-Taylor, J. and Madronich, S.: Calculation of actinic fluxes with a coupled atmosphere-snow radiative transfer model, J. Geophys. Res., 107, 4796, doi:10.1029/2002JD002084, 2002.

Lefer, B. L., Hall, S. R., Cinquini, and Shetter, R. E.: Photolysis frequency measurements at the South Pole during ISCAT-98, Geophys. Res. Lett., 28, 3637-3640, 2001.

Legrand, M. and De Angelis, M.: Origins and variations of light carboxylic acids in polar precipitation, J. Geophys. Res., 100(D1), 1445-1462, 1995.

Legrand, M. and Mayewski, P.: Glaciochemistry of polar ice cores: a review, Rev. Geophys., 35, 219-243, 1997.

Lei, Y. D. and Wania, F.: Is rain or snow a more efficient scavenger of organic chemicals?, Atmos. Environ. 38, 3557-3571, 2004.

Li, S.-M.: Equilibrium of particle nitrite with gas phase HONO: Tropospheric measurements in the high Arctic during polar sunrise, J. Geophys. Res., 99, 469-78, 1994.

Liao, W., Case, A. T., Mastromarino, J., Tan, D., and Dibb, J. E.: Observations of HONO by laser-induced fluorescence at the South Pole during ANTCI 2003, Geophys. Res. Lett., 33, L09810, doi:10.1029/2005GL025470, 2006.

Lode, O., Eklo, O. M., Holen, B., Svensen, A., and Johnsen, A. M.: Pesticides in precipitation in Norway, Sci. Total Environ., 160-161, 421-431, 1995.

Logan, J. A.: Nitrogen oxides in the troposphere: Global and regional budgets, J. Geophys. Res., 88, 10 785-10 807, 1983.
Lyons, W. B., Welch, K. A., Fountain, A. G., Dana, G. L., Vaughn, B. H., and McKnight, D. M.: Surface glaciochemistry of Taylor Valley, southern Victoria Land, Antarctica and its relationship to stream chemistry, Hydrol. Process., 17, 115-130, 2003.

Lyons, W. B., Welch, K. A., and Doggett, J. K.: Organic carbon in Antarctic snow, Geophys. Res. Lett., 34, L02501, doi:10.1029/2006GL028150, 2007.

Mack, J. and Bolton, J. R.: Photochemistry of nitrite and nitrate in aqueous solution: A review, J. Photochem. Photobiol. A, 128, 1-13, 1999.

Madronich, S.: Photodissociation in the atmosphere 1. Actinic flux and the effects of ground reflections and clouds, J. Geophys. Res., 92, 9740-9752, 1987.

Madronich, S. and Weller, G.: Numerical integration errors in calculated tropospheric photodissociation rate coefficients, J. Atmos. Chem., 10(3), 289-300, 1990.

Masclet, P., Hoyau, V., Jaffrezo, J.-L., and Cachier, H.: Polycyclic Aromatic Hydrocarbon deposition on the ice sheet of Greenland. Part I: superficial snow, Atmos. Environ., 34, 3195-3207, 2000.

Matykiewiczova, N., Kurkova, R., Klánová, J., and Klán, P. Photochemically induced nitration and hydroxylation of organic aromatic compounds in the presence of nitrate or nitrite in ice, J. Photochem. Photobiol. A, 187, 24-32, doi:10.1016/j.jphotochem.2006.09.008, 2007.

Mauldin, R. L., Eisele, F. L., Tanner, D. J., Kosciuch, E., Shetter, R., Lefer, B., Hall, S. R., Nowwack, J. B., Buhr, M., Chen, G., Wang, P., and Davis, D.: Measurements of $\mathrm{OH}, \mathrm{H}_{2} \mathrm{SO}_{4}$, and MSA at the South Pole during ISCAT, Geophys. Res. Lett., 28, 3629-3632, 2001.

Mauldin, R. L., Kosciuch, E., Henry, B. Eisele, F. L., Shetter, R., Lefer, B., Chen, G., Davis, D., Huey, G., and Tanner, D.: Measurements of $\mathrm{OH}, \mathrm{HO}_{2}+\mathrm{RO}_{2}, \mathrm{H}_{2} \mathrm{SO}_{4}$, and MSA at the South Pole during ISCAT 2000, Atmos. Environ., 38, 54235437, 2004.

Mayewski, P. A. and Legrand, M. R.: Recent increase in nitrate concentration of Antarctic snow, Nature, 346(6281), 258-260, 1990.

McCabe, J. R., Boxe, C. S., Colussi, A. J., Hoffman, M. R., and Thiemens, M. H.: Oxygen isotopic fractionation in the photochemistry of nitrate in water and ice, J. Geophys. Res., 110, D15310, doi:10.1029/2004JD005484, 2005.

McCabe, J. R., Thiemens, M. H., and Savarino, J.: A record of ozone variability in South Pole Antarctic snow: Role of nitrate oxygen isotopes, J. Geophys. Res., 112, D12303, doi:10.1029/2006JD007822, 2007.

McConnell, J. R., Bales, R. C., Winterle, J. R., Kuhns, H., and Stearns, C. R.: A lumped parameter model for the atmosphereto-snow transfer function for hydrogen peroxide, J. Geophys. Res., 102, 26 809-26 818, 1997a.

McConnell, J. R., Winterle, J. R., Bales, R. C., Thompson, A. M., and Stewart, R. W.: Physically based inversion of surface snow concentrations of $\mathrm{H}_{2} \mathrm{O}_{2}$ to atmospheric concentrations at South Pole, Geophys. Res. Lett., 24(4), 441-444, 1997 b.

McConnell, J. R., Bales, R. C., Stewart, R. W., Thompson, A. M., Albert, M. R., and Ramos, R.: Physically based modeling of atmosphere-to-snow-to-firn transfer of $\mathrm{H}_{2} \mathrm{O}_{2}$ at South Pole, J. Geophys. Res., 103(D9), 10 561-10 570, 1998.

McKellar, S. R., Galbavy, E. S., Ram, K., and Anastasio, C.: Formation of singlet molecular oxygen on illuminated ice and snow, 
Eos Trans. AGU, 86(52), Fall Meet. Suppl., Abstract A21C0868, San Francisco, CA, 2005.

Meier, R. R., Anderson, G. P., Cantrell, C. A., Hall, L. A., Lean, J., Minschwaner, K., Shetter, R. E., Shettle, E. P., and Stamnes, K: Actinic radiation in the terrestrial atmosphere, J. Atmos. SolarTerr. Phys., 59, 2111-2157, 1997.

Meyer, T., Lei, Y. D., and Wania, F.: Measuring the release of organic contaminants from melting snow under controlled conditions, Environ. Sci. Technol., 40, 3320-3326, doi:10.1021/es060049q, 2006.

Mitchell, D. V. and Lamb, D.: Influence of riming on the chemical composition of snow in winter orographic storms, J. Geophys. Res., 94, 14 831-14 840, 1989.

Mohammad, A. and Liebhafsky, H. A.: The kinetics of the reduction of hydrogen peroxide by the halides, J. Am. Chem. Soc., 56, 1680-1685, 1934.

Mulvaney, R. and Wolff, E. W.: Spatial variability of the major chemistry of the Antarctic ice sheet, Ann. Glaciol., 20, 440-447, 1994.

Munger, J. W., Jacob, D. J., Fan, S.-M., Colman, A. S., and Dibb, J. E.: Concentrations and snow-atmosphere fluxes of reactive nitrogen at Summit, Greenland, J. Geophys. Res., 104, 13721$13734,1999$.

Nakamura, K., Nakawo, M., Ageta, Y., Goto-Azuma, K., and Kamiyam, K.: Post-depositional loss of nitrate in surface snow layers of the Antarctic ice sheet, Bull. Glaciol. Res., 17, 11-16, 2000.

Narukawa, M., Kawamura, K., Hatsushika, H., Yamazaki, K., Li, S.-M., Bottenheim J.W., and Anlauf, K.G.: Measurement of halogenated dicarboxylic acids in the Arctic aerosols at polar sunrise, J. Atmos. Chem., 44, 323-335, 2003.

Neff, W., Helmig, D., Garchev, A., and Davis, D.: A Study of Boundary Layer Behavior Associated with High NO Concentrations at the South Pole using a Minisodar, Tethered Balloon, and Sonic Anemometer, Atmos. Environ., in press, doi:10.1016/j.atmosenv.2007.01.033, 2007.

Nelson, J. and Knight, C.: Snow crystal habit change explained by layer nucleation, J. Atmos. Sci., 55, 1452-1465, 1998.

Obbard, R., Iliescu, D., Cullen, D., Chang, J, and Baker, I.: SEM/EDS comparison of polar and seasonal temperate ice, Microsc. Res. Tech., 62, 49-61, 2003.

O’Driscoll, P., Lang, K., Minogue, N., and Sodeau, J.: Freezing halide ion solutions and the release of interhalogens to the atmosphere, J. Phys. Chem. A, 110, 4615-4618, 2006.

Oltmans, S., Johnson, B., and Helmig, D.: Episodes of High Surface Ozone Amounts at South Pole During Summer and Their Impact on the Long-term Surface Ozone Variation, Atmos. Environ., in press, doi:10.1016/j.atmosenv.2007.01.020, 2007.

Oncley, S. P., Buhr, M., Lenschow, D. H., Davis, D., and Semmer, S. R.: Observations of summertime NO fluxes and boundarylayer height at the South Pole during ISCAT 2000 using scalar similarity, Atmos. Environ., 38, 5389-5398, 2004.

Perrier, S., Houdier, S., Dominé, F., Cabanes, A., Legagneux, L., Sumner, A.L. and Shepson, P.B.: Formaldehyde in Arctic snow. Incorporation into ice particles and evolution in the snowpack, Atmos. Environ., 36, 2695-2705, 2002.

Perrier, S., Sassin, P., and Dominé, F.: Diffusion and solubility of HCHO in ice: preliminary results, Can. J. Phys., 81, 319-324, 2003.
Perovich, D. K. and Govoni, J. W.: Absorption coefficients of ice from 250 to $400 \mathrm{~nm}$, Geophys. Res. Lett., 18, 1233-1235, 1991.

Peterson, M. C. and Honrath, R. E.: Observations of rapid photochemical destruction of ozone in snowpack interstitial air, Geophys. Res. Lett., 28, 511-514, 2001.

Petrenko, V. F. and Whitworth, R. W.: Physics of ice, Oxford University Press, Oxford, U.K., 1999.

Phillips, G. J. and Simpson, W. R.: Verification of snowpack radiation transfer models using actinometry, J. Geophys. Res., 110, D08306, doi:10.1029/2004JD005552, 2005.

Picaud, S., Toubin, C., and Girardet, C.: Monolayers of acetone and methanol molecules on ice, Surf. Sci., 454-456, 178-182, 2000.

Platt, U. and Honninger, G.: The role of halogen species in the troposphere, Chemosphere, 52, 325-338, 2003.

Popp, P. J., Gao, R. S., Marcy, T. P., Fahey, D. W., Hudson, P. K., Thompson, T. L., Karcher, B., Ridley, B. A., Weinheimer, A. J., Knapp, D. J., Montzka, D. D., Baumgardner, D., Garrett, T. J., Weinstock, E. M., Smith, J. B., Sayres, D. S., Pittman, J. V., Dhaniyala, S.., Bui, T. P., and Mahoney, M. J.: Nitric acid uptake on subtropical cirrus cloud particles, J. Geophys. Res., 109, D06302, doi:10.1029/2003JD004255, 2004.

Poulida, O., Schwikowski, M., Baltensperger, U., Staehelin, J., and Gaeggeler, H. W.: Scavenging of atmospheric constituents in mixed phase clouds at the high-alpine site Jungfraujoch-part II. Influence of riming on the scavenging of particulate and gaseous chemical species, Atmos. Environ., 32, 3985-4000, 1998.

Preunkert, S., Wagenbach, D., and Legrand, M.: A seasonally resolved alpine ice core record of nitrate: Comparison with anthropogenic inventories and estimation of preindustrial emissions of NO in Europe, J. Geophys. Res., 108(D21), 4681, doi:10.1029/2003JD003475, 2003.

Pruppacher, H. R. and Klett, J. D.: Microphysics of clouds and precipitation, Reidel Pub. Co., Dordrecht, Holland, 1978.

Qiu, R., Green, S. A., Honrath, R. E., Peterson, M. C., Lu, Y., and Dziobak, M.: Measurements of $\mathrm{J}\left(\mathrm{NO}_{3}^{-}\right)$in snow by nitrate-based chemical actinometry, Atmos. Environ., 36, 2751, 2002.

Richter, A., Wittrock, F., Eisinger, M., and Burrows, J. P.: GOME observations of tropospheric $\mathrm{BrO}$ in northern hemispheric spring and summer 1997, Geophys. Res. Lett., 25, 2683-2686, 1998.

Ridley, B., Walega, J., Montzka, D., Grahek, F., Atlas, E., Flocke, F., Stroud, V., Deary, J., Gallant, A., Bottenheim, J., Anlauf, K., Worthy, D., Sumner, A. L., Splawn, B., and Shepson, P. B.: Is the Arctic surface layer a source and sink of $\mathrm{NO}_{\mathrm{X}}$ in winter/spring?, J. Atmos. Chem., 36, 1-22, 2000.

Ridley, Atlas, E. L., Montzka, D. D., et al.: Ozone depletion events observed in the high latitude surface layer during the TOPSE aircraft program, J. Geophys. Res., 8356, doi:10.1029/2001JD001507, 2003.

Riedel, K., Weller, R., and Schrems, O.: Variability of formaldehyde in the Antarctic troposphere, Phys. Chem. Chem. Phys., 1, 5523-5527, 1999.

Riedel, K., Allan, W., Weller, R., and Schrems, O.: Discrepancies between formaldehyde measurements and methane oxidation model predictions in the Antarctic troposphere: An assessment of other possible formaldehyde sources, J. Geophys. Res., 110, D15308, doi:10.1029/2005JD005859, 2005.

Riordan, E., Minogue, N., Healy, D., O’Driscoll, P., and Sodeau, J.: Spectroscopic and optimization modeling study of nitrous acid in aqueous solution, J. Phys. Chem. A, 109, 779-786, 2005. 
Robinson, C., Boxe, C. S., Guzmán, M. I., Colussi, A. J., and Hoffmann, M. R.: Acidity of Frozen Electrolyte Solutions, J. Phys. Chem. B, 110, 7613-7616, 2006.

Roth, C. M., Goss, K., and Schwarzenbach, R. P.: Sorption of diverse organic vapors to snow, Environ. Sci. Technol., 38, 40784084, 2004.

Röthlisberger, R., Hutterli, M. A., Sommer, S., Wolff, E. W., and Mulvaney, R.: Factors controlling nitrate in ice cores: evidence from the Dome C deep ice core, J. Geophys. Res., 105, 20565 20 572, 2000.

Röthlisberger, R., Hutterli, M. A., Wolff, E. W., Mulvaney, R., Fischer, H., Bigler, M., Goto-Azuma, K., Hansson, M. E., Ruth, U., Siggaard-Andersen, M.-L., and Steffensen, J. P.: Nitrate in Greenland and Antarctic ice cores: A detailed description of post-depositional processes, Ann. Glaciol., 35, 209-216, 2002.

Röthlisberger, R., Mulvaney, R., Wolff, E. W., Hutterli, M. A., Bigler, M., de Angelis, M., Hansson, M. E., Steffensen, J. P., and Udisti, R.: Limited dechlorination of sea-salt aerosols during the last glacial period: evidence from the European Project for Ice Coring in Antarctica (EPICA) Dome C ice core, J. Geophys. Res., 108(D16), ACH17/1-ACH17/6, 2003.

Sadtchenko, V. and Ewing, G. E.: Interfacial melting of thin ice films: An infrared study, J. Phys. Chem., 116 (11), 4686-4697, 2002.

Saiz-Lopez, A., Mahajan, A. S., Salmon, R. A., Bauguitte, S. J.-B., Jones, A. E., Roscoe, H.K. and Plane, J.M.C.: Boundary layer halogens in coastal Antarctica, Science, 317, 348-351, 2007.

Sander, R., Rudich, Y., von Glasow, R., and Crutzen, P. J.: The role of $\mathrm{BrNO}_{3}$ in marine tropospheric chemistry: A model study, Geophys. Res. Lett., 26, 2857-2860, 1999.

Sattler, B., Puxbaum, H., and Psenner, R.: Bacterial growth in supercooled cloud droplets, Geophys. Res. Lett., 28, 239-242, 2001.

Savage, N. H., Law, K. S., Pyle, J. A., Richter, A., Nuess, H., and Burrows, J. P.: Using GOME $\mathrm{NO}_{2}$ satellite data to examine regional differences in TOMCAT model performance, Atm. Chem. Phys., 4, 1895-1912, 2004.

Savarino, J., Kaiser, J., Morin, S., and Thiemens, M. H.: Betrayed by its isotopes: Origin of atmospheric nitrate in coastal Antarctica, Atmos. Chem. Phys. Discuss., 6, 8817-8870, 2006, http://www.atmos-chem-phys-discuss.net/6/8817/2006/.

Schaff, J. E. and Roberts, J. T.: The adsorption of acetone on thin films of amorphous and crystalline ice, Langmuir, 14, 14781486, 1998.

Schaff, J. E. and Roberts, J. T.: Adsorbed states of acetonitrile and chloroform on amorphous and crystalline ice studied with Xray photoelectron spectroscopy, Surface Science, 426, 384-394, 1999a.

Schaff, J. E. and Roberts, J. T.: Interaction of acetonitrile with the surfaces of amorphous and crystalline ice, Langmuir, 15, 72327237, 1999b.

Schwikowski, M., Baltensperger, U., Gaggeler, H. W., and Poulida, O.: Scavenging of atmospheric constituents in mixed phase clouds at the high-alpine site Jungfraujoch part III: Quantification of the removal of chemical species by precipitating snow, Atmos. Environ., 32, 4001-4010, 1998.

Sempere, R. and Kawamura, K.: Comparative distributions of dicarboxylic acids and related polar compounds in snow, rain and aerosols from urban atmosphere, Atmos. Environ., 28(3), 449-
459, 1994.

Siegenthaler, U., Stocker, T. F., Monnin, E., Luthi, D., Schwander, J., Stauffer, B., Raynaud, D., Barnola, J. M., Fischer, H., MassonDelmotte, V. and Jouzel, J.: Stable carbon cycle-climate relationship during the late Pleistocene, Science, 310, 1313-1317, 2005.

Sigg, A. and Neftel, A.: Seasonal variations in hydrogen peroxide in polar ice cores, Ann. Glaciol., 10, 157-162, 1988.

Sigg, A., Stafflebach, T., and Neftel, A.: Gas phase measurements of hydrogen peroxide in Greenland and their meaning for the interpretation of $\mathrm{H}_{2} \mathrm{O}_{2}$ in ice cores, J. Atmos. Chem., 14, 223-232, 1992.

Simpson, W. R., King, M. D., Beine, H. J., Honrath, R. E., and Zhou X.: Radiation-transfer modeling of snowpack photochemical processes during ALERT2000, Atmos. Env., 36, 2663-2670, 2002a.

Simpson, W. R., King, M. D., Beine, H. J., Honrath, R. E., and Peterson, M. C.: Corrigendum to Atmospheric photolysis rates during the Polar Sunrise Experiment ALERT2000 (Atmos. Environ. 36 (15-16) 2471-2480 (2002)), Atmos. Environ., 36, 5749, $2002 b$.

Simpson, W. R., von Glasgow, R., Riedel, K., Anderson, P., Ariya, P., Bottenheim, J., Burrows, J., Carpenter, L., Frieß, U., Goodsite, M., Heard, D., Hutterli, M., Jacobi, H.-W., Kaleschke, H., Neff, W., Plane, J., Platt, U., Richter, A., Roscoe, H., Sander, R., Shepson, P., Sodeau, J., Steffen, A., Wagner, T., Wolff, E.: Halogens and their role in polar boundary-layer ozone depletion, Atmos. Chem. Phys., 7, 4375-4418, 2007, http://www.atmos-chem-phys.net/7/4375/2007/.

Sjostedt, S. J., Huey, L. G., Tanner, D. J, Peischl, J., Chen, G., Dibb, J. E., Lefer, B., Hutterli, M. A., Beyersdorf, A. J., Blake, N. J., and Blake, D. R.: Peroxy and Hydroxyl Radical Measurements During the Spring 2004 Summit Field Campaign, Eos Trans. AGU, 86(56), Fall Meet. Suppl., Abstract A24A-02, 2005.

Sjostedt, S. J., Huey, L. G., Tanner, D. J., Pieschl, J., Chen, G., Dibb, J. E., Lefer, B., Hutterli, M. A., Beyersdorf, A. J., Blake, N. J., Blake, D. R., Sueper, D., Ryerson, T., Burkhart, J., and Stohl, A.: Observations of hydroxyl and the sum of peroxy radicals at Summit, Greenland during summer 2003, Atmos. Environ., 41(24), 5122-5137, 2007.

Slusher, D. L., Huey, L. G., Tanner, D. J., Chen, G., Davis, D. D., Buhr, M., Nowak, J. B., Eisele, F., Kosciuch, E., Mauldin, R. L., Lefer, B. L., Shetter, R. E., and Dibb, J. E.: Measurements of pernitric acid at the South Pole during ISCAT 2000, Geophys. Res. Lett., 29, 2011, doi:10.1029/2002GL015703, 2002.

Sokolov, O. and Abbatt, J. P. D.: Adsorption to ice of n-alcohols, acetic acid, and hexanal, J. Phys. Chem. A, 106, 775-782, 2002.

Solberg, S., Schmidbauer, N., Semb, A., Stordal, F., and Hov, Ø.: Boundry-layer ozone depletion as seen in the Norwegian Arctic spring, J. Atmos. Chem., 23, 301-332, 1996.

Spahni, R., Chappellaz, J., Stocker, T. F., Loulergue, L., Hausammann, G., Kawamura, K., Fückiger, J., Schwander, J., Raynaud, D., Masson-Delmotte, V., and Jouzel, J.: Atmospheric Methane and Nitrous Oxide of the Late Pleistocene from Antarctic Ice Cores, Science, 310, 1317-21, 2005.

Spicer, C. W., Plastridge, R. A., Foster, K. L., Finlayson-Pitts, B. J., Bottenheim, J. W., Grannas, A. M., and Shepson, P. B.: Molecular halogens before and during ozone depletion events in the Arctic at polar sunrise: Concentrations and sources, Atmos. Environ., 36, 2721-2731, 2002. 
Sprenkle, A. M. and Grannas, A. M.: Photochemical degradation of organic pollutants in liquid water and ice, EOS Trans. AGU, 87(52), Fall Meet. Suppl., Abstract \#A21F-0919, 2005, San Francisco, December 2005.

Staffelbach, T., Neftel, B., Stauffer, B., and Jacob, D.: A record of the atmospheric methane sink from formaldehyde in polar ice cores, Nature, 349, 603-605, 1991.

Staudt, A. C., Jacob, D. J., Ravetta, F., Logan, J. A., Bachiochi, D., Krishnamurti, T. N., Sandholm, S., Rodley, B., Singh, H. B., and Talbot, B.: Sources and chemistry of nitrogen oxides over the tropical Pacific, J. Geophys. Res., 108(D2), 8239, doi:10.1029/2002JD002139, 2003.

Stemmler, K., Ammann, M., Donders, C., Kleffmann, J., and George, C.: Photosensitized reduction of nitrogen dioxide on humic acid as source of nitrous acid, Nature, 440, 195-198, doi:10.1038/nature04603, 2006.

Stutz, J., Hebestreit, K., Alicke, B., and Platt U.: Chemistry of halogen oxides in the troposphere: Comparison of model calculations with recent field data, J. Atmos. Chem., 34, 65-85, 1999.

Sumner, A. L. and Shepson, P. B.: Snowpack production of formaldehyde and its effect on the Arctic troposphere, Nature, 398, 230-233, 1999.

Sumner, A. L., Shepson, P. B., Grannas, A. M., Bottenheim, J., Anlauf, K. G., Worthy, D., Schroeder, W. H., Steffen, A., Dominé, F., Perrier, S., and Houdier S.: Atmospheric chemistry of formaldehyde in the Arctic troposphere at Polar Sunrise, and the influence of the snowpack, Atmos. Environ., 36, 2553-2562, 2002.

Swanson, A. L., Blake, N. J., Dibb, J. E., Albert, M. R., Blake, D. R. and Rowland, F. S.: Photochemically induced production of $\mathrm{CH}_{3} \mathrm{Br}, \mathrm{CH}_{3} \mathrm{I}, \mathrm{C}_{2} \mathrm{H}_{5} \mathrm{I}$, ethene, and propene within surface snow at Summit, Greenland, Atmos. Environ., 36, 2671-2682, 2002.

Swanson, A. L., Davis, D. D., Arimoto, R., Roberts, P., Atlas, E. L., Flocke, F., Meinardi, S., Rowland, F.S., and Blake, D.R.: Organic trace gases of oceanic origin observed at South Pole during ISCAT, Atmos. Environ., 38, 5463, 2004.

Tackett, P. J., Cavender, A. E., Keil, A.D., Shepson, P. B., Bottenheim, J. W., Morin, S., Deary, J., Steffen, A., and Doerge, C.: A study of the vertical scale of halogen chemistry in the Arctic troposphere during polar sunrise at Barrow, AK, J. Geophys. Res., 112, D07306, doi:10.1029/2006JD007785, 2007.

Takenaka, N., Ueda, A., and Maeda, Y.: Acceleration of the rate of nitrite oxidation by freezing in aqueous-solution, Nature, 358, 736-738, 1992.

Takenaka, N., Ueda, A., Daimon, T., Bandow, H., Dohmaru, T., and Maeda, Y.: Acceleration mechanism of chemical reaction by freezing: The reaction of nitrous acid with dissolved oxygen, J. Phys. Chem., 100, 13 874-13 884, 1996.

Takeuchi, N., Kohshima, S., and Seko, K.: Structure, formation, and darkening process of albedo-reducing material (cryoconite) on a Himalayan glacier: A granular algal mat growing on the glacier, Arct. Antarct. Alp. Res., 33(2), 115-122, 2001.

Targino, A. C., Krejci, R., Noone, K. J., and Glantz, P.: Single particle analysis of ice crystal residuals observed in orographic wave clouds over Scandinavia during INTACC experiment, Atmos. Chem. Phys., 6, 1977-1990, 2006, http://www.atmos-chem-phys.net/6/1977/2006/.

Thibert, E. and Dominé, F.: Thermodynamics and kinetics of the solid solution of $\mathrm{HCl}$ in ice, J. Phys. Chem. B. 101, 3554-3565,
1997.

Thibert, E. and Dominé, F.: Thermodynamics and kinetics of the solid solution of $\mathrm{HNO}_{3}$ in ice, J. Phys. Chem. B, 102, 44324439, 1998.

Tie, X., Emmons, L., Horowitz, L., Brasseur, G., Ridley, B., Atlas, E., Hess, P., Klonecki, A., Madronich, S., Talbot, R., Dibb, J., Marbouty, D., and Hennessy, J.: Effect of sulfate aerosol on tropospheric $\mathrm{NO}_{\mathrm{x}}$ and ozone budgets model simulations and TOPSE evidence, J. Geophys. Res., 108(D4), 8364, doi:10.1029/2001JD001508, 2003.

Tranter, M., Brimbelcombe, P, Davies, T. D., Vincent, C. E., Abrahams, P. W., and Blackwood, I.: The composition of snowfall, snowpack and meltwater in the Scottish highlands - Evidence for preferential elution, Atmos. Environ. 20, 517-525, 1986.

Tschumi, J. and Stauffer, B.: Reconstructing past atmospheric $\mathrm{CO}_{2}$ concentrations based on ice core analyses: Open questions due to in situ production of $\mathrm{CO}_{2}$ in the ice, J. Glaciol., 46, 45-53, 2000.

Twickler, M. S., Spencer, M. J., Lyons, W. B. and Mayewski, P. A.: Measurement of organic carbon in polar snow samples, Nature, 320(6058), 156-158, 1986.

Ullerstam, M. and Abbatt, J. P. D.: Burial of gas-phase $\mathrm{HNO}_{3}$ by growing ice surfaces under tropospheric conditions, Phys. Chem. Chem. Phys., 7(20), 3596-3600, 2005.

Ullerstam, M., Thornberry, T., and Abbatt, J. P. D.: Uptake of gasphase nitric acid to ice at low partial pressures: evidence for unsaturated surface coverage, Faraday Discuss., 130, 211-226, 2005.

Valdez, M. P., Dawson, G. A., and Bales, R. C.: Sulfur dioxide incorporation into ice depositing from the vapour, J. Geophys. Res., 94, 1095-1103, 1989.

Villa, S., Vighi, M., Maggi, V., Finizio, A., and Bolzacchini, E.: Historical trends of organochlorine pesticides in an Alpine glacier, J. Atmos. Chem., 46(3), 295-311, 2003.

Vogt, R., Crutzen, P. J., and Sander, R.: A mechanism for halogen release from sea-salt aerosol in the remote marine boundary layer, Nature, 383, 327-330, 1996.

von Glasow R., von Kuhlmann, R., Lawrence, M. G., Platt, U., and Crutzen, P. J.: Impact of reactive bromine chemistry in the troposphere, Atmos. Chem. Phys., 4, 2481-2497, 2004, http://www.atmos-chem-phys.net/4/2481/2004/.

von Glasow, R. and Crutzen P. J.: Tropospheric halogen chemistry. in: The Atmosphere, edited by: R. F. Keeling, Vol. 4, Chapter 3, in: Treatise on Geochemistry (edited by: Holland, H. D. and Turekian, K. K.), Elsevier-Pergamon, Oxford, 2006.

Waddington, E. D., Cunningham, J., and Harder, S. L.: The effects of snow ventilation on chemical concentrations, NATO ASI Series, Series I: Global Environmental Change, 43(Chemical Exchange Between the Atmosphere and Polar Snow), 403-451, 1996.

Wagenbach, D., Legrand, M., Fischer, H., Pichlmayer, F., and Wolff, E. W.: Atmospheric near-surface nitrate at coastal Antarctic sites, J. Geophys. Res., 103(D9), 11 007-11 020, 1998.

Wagner, T. and Platt, U.: Satellite mapping of enhanced BrO concentrations in the troposphere, Nature, 395, 486-490, 1998.

Wania, F., Hoff, J. T., Jia, C. Q., and Mackay, D.: The effects of snow and ice on the environmental behaviour of hydrophobic organic chemicals, Environ. Pollut., 102, 25-41, 1998.

Wania, F., Mackay, D., and Hoff, J. T.: The importance of snow 
scavenging of polychlorinated biphenyl and polycyclic aromatic hydrocarbon vapors, Environ. Sci. Technol., 33, 195-197, 1999.

Warneck, P. and Wurzinger, C.: Product quantum yields for the 305$\mathrm{nm}$ photodecomposition of $\mathrm{NO}_{3}$ - in aqueous-solution, J. Phys. Chem., 92, 6278-6283, 1988.

Warren, S. G.: Optical properties of snow, Rev. Geophys., 20, 6789, 1982.

Warren, S. G., Brandt, R. E. and Grenfell, T. C.: Visible and nearultraviolet absorption spectrum of ice from transmission of solar radiation into snow, Appl. Optics, 45, 5320-5334, 2006.

Wei, X, Miranda, P. B., and Shen, Y. R.: Surface vibrational spectroscopic study of surface melting of ice, Phys. Rev. Lett., 86(8), 1554-1557, 2001.

Weinheimer, A. J., Campos, T. L., Walega, J. G., Grahek, F. E., Ridley, B. A., Baumgardner, D., Twohy, C., and Gandrud, B.: Uptake of $\mathrm{NO}_{\mathrm{y}}$ on wave-cloud ice particles, Geophys. Res. Lett., 25(10), 1725-1728, 1998.

Weller, R., Minikin, A., Koenig-Langlo, G., Schrems, O., Jones, A.E., Wolff, E.W., and Anderson, P.S.: Investigating possible causes of the observed diurnal variability in Antarctic $\mathrm{NO}_{\mathrm{y}}$, Geophys. Res. Lett., 26, 2853-2856, 1999.

Weller, R., Jones, A. E., Wille, A., Jacobi, H.-W., McIntyre, H. P., Sturges, W.T., Huke, M., and Wagenbach, D.: Seasonality of reactive nitrogen oxides $\left(\mathrm{NO}_{\mathrm{y}}\right)$ at Neymayer stations, Antarctica, J. Geophys. Res., 107(D23), 4673, doi:10.1029/2002JD002495, 2002.
Winkler, A. K., Holmes, N. S., and Crowley, J. N.: Interaction of methanol, acetone and formaldehyde with ice surfaces between 198 and 223 K, Phys. Chem. Chem. Phys., 4, 5270-5275, doi:10.1039/b206258e, 2002.

Wiscombe, W. and Warren, S.: A model for the spectral albedo of snow. 1: pure snow, J. Atmos. Sci., 37, 2712-2733, 1980.

Wolff, E. W.: Nitrate in polar ice, in Ice Core Studies of Global Biogeochemical Cycles, NATO ASI Ser., vol I30, edited by: R. J. Delmas, pp. 195-224, Springer-Verlag, New York, 1995.

Wolff, E. W., Jones, A. E., Martin, T. J., and Grenfell, T. C.: Modelling photochemical $\mathrm{NO}_{\mathrm{x}}$ production and nitrate loss in the upper snowpack of Antarctica, Geophys. Res. Lett., 29, 1944, doi:10.1029/2002GL015823, 2002.

Yang, J., Honrath, R. E., Peterson, M. C., Dibb, J. E., Sumner, A. L., Shepson, P. B., Frey, M., Jacobi, H.-W., Swanson, A., and Blake, N.: Impacts of snowpack emissions on deduced levels of $\mathrm{OH}$ and peroxy radicals at Summit, Greenland, Atmos. Environ., 36, 2523-2534, 2002.

Zhou, X., Beine, H. J., Honrath, R. E., Fuentes, J. D., Simpson, W., Shepson, P.B., and Bottenheim, J.: Snowpack photochemical production as a source for HONO in the Arctic boundary layer in spring time, Geophys. Res. Lett., 28(21), 4087-4090, 2001.

Ziereis, H., Minikin, A., Schlager, H., Gayet, J. F., Auriol, F., Stock, P., Baehr, J., Petzold, A., Schumann, U., Weinheimer, A., Ridley, B., and Strom, J.: Uptake of reactive nitrogen on cirrus cloud particles during INCA, Geophys. Res. Lett., 31, L05115, doi:10.1029/2003GL018794, 2004. 